Reforence $\begin{aligned} & \text { NBS } \\ & \text { Publi- } \\ & \text { cations }\end{aligned}$

NBSIR 81-2289

\title{
Prelımınary Guidelines for Condition Assessment of Buildings Being Considered for Solar Retrofit
}

Frank H. Lerchen James H. Pielert Phillip T. Chen

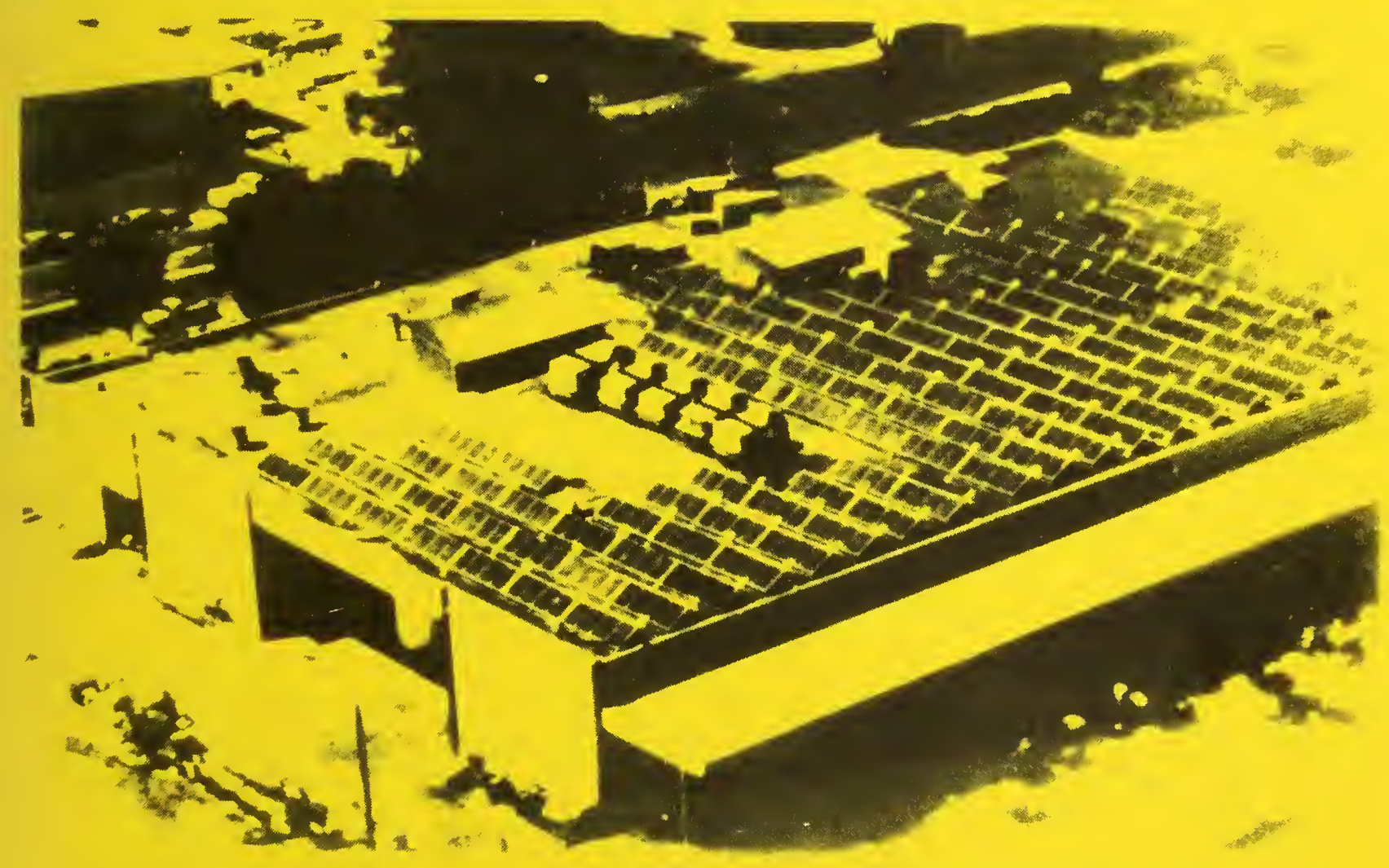

Building Economics and Regulatory Technology Division Center for Building Technology National Engineering Laboratory U.S. Department of Commerce National Bureau of Standards Washington, DC 20234

Prepared for:

\section{U.S. Department of Energy}

ffice of Solar Applications for Buildings

$Q C$ fice of the Assistant Secretary Conservation and Renewable Energy 



\section{PRELIMINARY GUIDELINES FOR CONDITION ASSESSMENT OF BUILDINGS BEING CONSIDERED FOR SOLAR RETROFIT}

Frank $H$. Lerchen James H. Pielert

Phillip T. Chen

Building Economics and Regulatory

Technology Division

Center for Building Technology

National Enginekering Laboratory

U.S. Department of Commerce

National Bureau of Standards

Washington, DC 20234

July 1981

Prepared for:

U.S. Department of Energy

Office of Solar Applications for Buildings

Office of the Assistant Secretary

Conservation and Renewable Energy

Washington, DC 20585

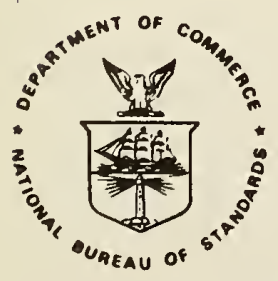

U.S. DEPARTMENT OF COMMERCE, Malcolm Baldrige, Secretary NATIONAL BUREAU OF STANDARDS, Ernest Ambler, Director 



\section{ABSTRACT}

This preliminary report was developed with the intent of assisting government officials, designers, builders, code officials, and others involved with evaluating the condition of the systems (structural, heating, etc.) of existing buildings in order that the impact of solar modifications on them may be assessed.

The report describes evaluation methods specifically for use with the structural materials of concrete, wood, masonry, and steel, as well as for heating/ventilating/air conditioning (HVAC), plumbing, and electrical systems. Engineering information is presented in two stages: (1) preliminary evaluation methods easily used by the building facilities engineer, and (2) secondary evaluation methods which are more detailed and sophisticated, and which may include information obtained away from the building site.

Comparative tables are provided to aid in making a selection of the evaluation method most appropriate for the particular parameter to be tested. Other tables describe the common problems associated with each material or system and their possible causes as well as the impact they may have on the proposed solar retrofit.

Key words: building rehabilitation; concrete; electrical; evaluation; HVAC; masonry; plumbing; solar; solar retrofit; steel; structural systems; test methods; wood. 


\section{ACKNOWLEDGMENTS}

The authors would like to extend appreciation to those individuals who generously provided information on many aspects of the evaluation of existing buildings being considered for solar retrofit. Special appreciation is extended to Mr. James G. Gross, Chief, Building Economics and Regulatory Technology Division, Center for Building Technology (CBT), National Bureau of Standards (NBS), for overall direction of the report; Mr. William J. Meese, General Engineer, NBS, for input in the electrical area; Dr. James R. Clifton, Research Chemist, NBS, for input on evaluation of concrete; and Ulesia B. Gray, Editorial Assistant, Word Processing Center, and Mary M. Chaney, Secretary, Rehabilitation Technology Group, CBT, NBS, for outstanding clerical support.

It is with great appreciation, also, that the authors acknowledge the efforts of individuals outside the National Bureau of Standards for their review of the report concerning technical aspects. In particular, appreciation is extended to Dr. V. M. Malhotra, P.E., Head, Construction Materials Section, Department of Energy, Mines and Resources, Canada, for his review and comments on concrete evaluation; Mr. William L. Galligan, Project Leader, Engineering Properties of Wood, Forest Products Laboratory, Forest Service, U.S. Department of Agriculture; Mr. Alan H. Yorkdale, P.E., Director of Engineering and Research, Brick Institute of America; Mr. Peter Jacobs, Systems Analyst, Solar Environmental Engineering Company; and Mr. Scott Heider, P.E, consultant. 
The study to develop this report was conducted by the Rehabilitation Technology Group, Building Economics and Regulatory Technology Division, National Bureau of Standards. The report contains a general description of methods currently available for condition assessment of the structural; heating, ventilating, and air conditioning (HVAC); electrical; and plumbing systems of an existing building, in order to determine the feasibility of rehabilitation for solar retrofit.

The intended audience for this report includes government officials, designers, builders, code officials, and others involved with making technical decisions on building rehabilitation as related to solar retrofit. It is not intended for use by nontechnical persons who are unfamiliar with the performance of building materials and basic engineering principles.

The report was developed with funding from the Department of Energy (DoE) as part of the Solar Federal Buildings Program (SFBP) which was developed to stimulate the growth and improve the efficiency of the solar industry as applied to Federal buildings.

This report is not presented as an all-inclusive listing of building condition assessment methods. Additionally, neither NBS nor DoE endorses or claims to have evaluated all of the methods described in this report. It is anticipated that this preliminary report will be updated, and the authors would appreciate comments and recommendations for revisions. 
LIST OF TABLES $\ldots \ldots \ldots \ldots \ldots \ldots \ldots \ldots \ldots \ldots \ldots \ldots \ldots \ldots \ldots \ldots \ldots \ldots \ldots \ldots \ldots \ldots \ldots \ldots \ldots \ldots \ldots$

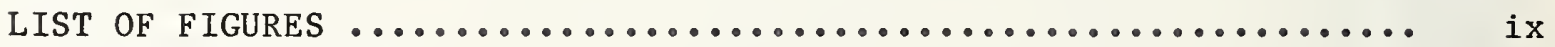

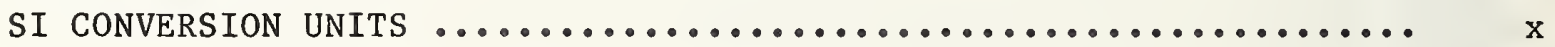

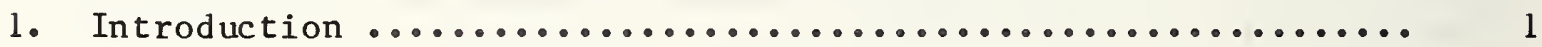

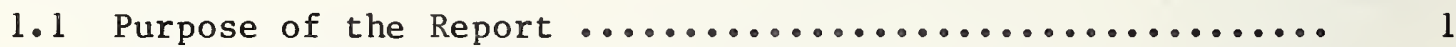

1.2 Authorization .................................. 1

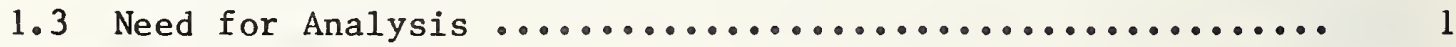

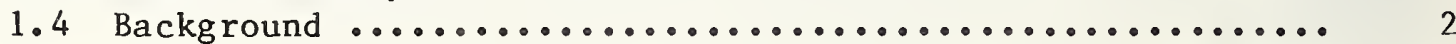

2. Preliminary Evaluation Methods ..................... 5

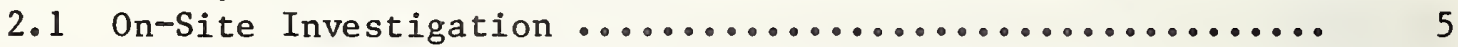

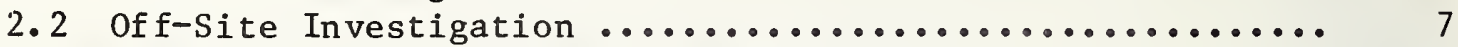

2.3 Destructive vs. Nondestructive Evaluation ............. 7

3. Guidelines for Structural Systems $\ldots \ldots \ldots \ldots \ldots \ldots \ldots \ldots \ldots \ldots \ldots \ldots$

3.1 General Considerations ......................... 10

3. 2 General Inspection Guidelines - Structural Components .... 13

3.3 Concrete Systems ............................. 17

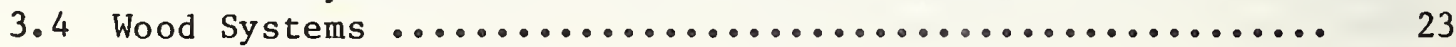

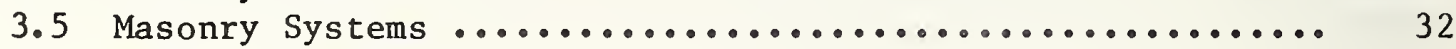

3.6 Metal Systems ............................. 43

4. Guidelines for Heating, Ventilating, and Air Conditioning (HVAC)

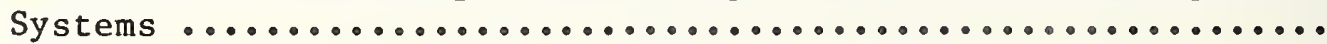

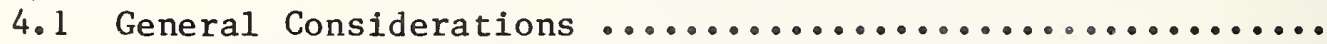

4.2 Preliminary On-Site Investigation Guidelines - HVAC

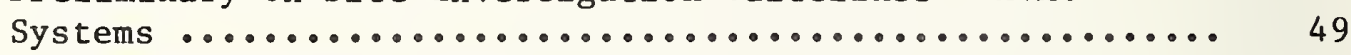

4.3 HVAC Problems and Potential Impact on Solar Retrofit .... . 57

5. Guidelines for Plumbing Systems ......................... 61

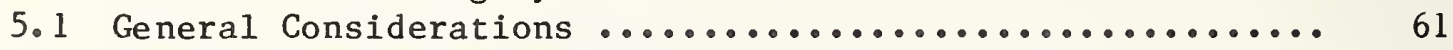

5.2 On-Site Evaluation Guidelines - Plumbing Systems ........ 61

5.3 Plumbing Problems and Potential Impact on Solar Retrofit . 63

6. Guidelines for Electrical Systems .................... 66

6.1 On-Site Evaluation Guidelines - Electrical Systems ...... 66

6.2 Electrical Problems and Potential Impact on Solar

Retrofit .................................. 69

REFERENCES AND SUGGESTED ADDITIONAL READINGS $\ldots \ldots \ldots \ldots \ldots \ldots \ldots \ldots \ldots 71$ 
TABLE OF CONTENTS - (Continued)

$\underline{\text { Page }}$

APPENDIX A - TYPICAL FORMS FOR COLLECTION OF DATA DURING PRELIMINARY ON-SITE INVESTIGATION .............. A-1

APPENDIX B - RECOMMENDED EQUIPMENT FOR FIELD INSPECTION ......... B-1

APPENDIX $C$ - POTENTIAL SOURCES OF INFORMATION ON BUILDINGS BEING CONSIDERED FOR SOLAR RETROFIT ............... C-1

APPENDIX D - METHODS FOR DETAILED EVALUATION OF SYSTEMS ........ D-1

APPENDIX D.1 - Concrete Systems ........................ D-1

APPENDIX D.2 - Wood Systems ............................ D D

APPENDIX D.3 - Masonry Systems .......................... D

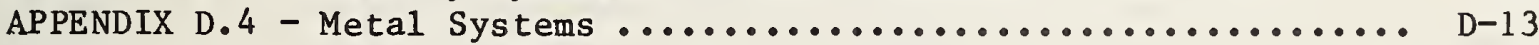

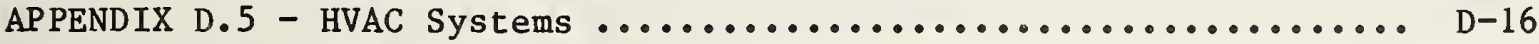

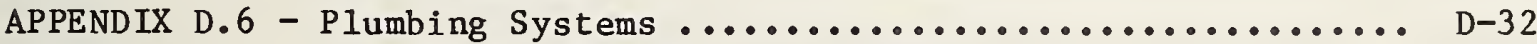

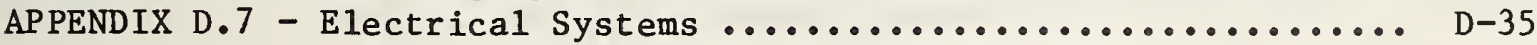


Table 1. Loads from Roof Coverings ...................... 11

Table 2. Size and Weight of Typical Chillers ................ 12

Table 3. Weight of Typical Storage Tanks ................... 12

Table 4. Weight of Typical Storage Tanks ................... 20

Table 5. Preliminary Assessment Checklist (Concrete) ........... 21

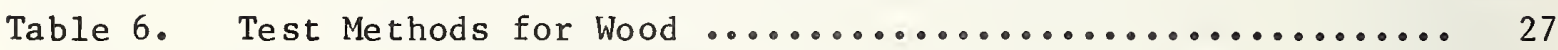

Table 7. Preliminary Assessment Checklist (Wood) .............. 28

Table 8. Test Methods for Masonry ....................... 36

Table 9. Preliminary Assessment Checklist (Masonry) ........... 37

Table 10. Preliminary Assessment Checklist (Metals) ............ 46

Table 11. Preliminary Assessment Checklist (HVAC) ............. 58

Table 12. Preliminary Assessment Checklist (Plumbing) ........... 64

Table 13. Preliminary Assessment Checklist (Electrica1) ......... 70

Table 14. Concrete Evaluation Techniques ................... D-2

Table 15. Wood Evaluation Techniques ...................... D-6

Table 16. Masonry Evaluation Techniques ..................... D-9

Table 17. Metal Evaluation Techniques........................ D-14

Table 18. Residential Duct Air Velocity .................... D-24

Table 19. Capacity Correction Factors for Entering Conditions Other Than $60^{\circ} \mathrm{F}$ EAT and $180^{\circ} \mathrm{F}$ EWT ......................

Table 20. Correction Factors for off Design Performance of Various Natural Convective and Radiant Heat Transfer Equipment ... D-28 


\section{LIST OF FIGURES}

$\underline{\text { Page }}$

Figure 1. Engineering Evaluation Plan ................... 5

Figure 2. Concrete Test Methods and Parameters ............... 19

Figure 3. Historic Energy Consumption Record ............... 50

Figure 4. Existing HVAC Design Identification .............. 52

Figure 5. Pitot Tube Measurement Locations for Rectangular and Large Round Ducts ............................ 56

Figure 6. Blower Static Pressure Tap Locations ................ 60

Figure 7. Simulated Blower Characteristic Curve ............. D-2I

Figure 8. Effects of Water Flow Rate on Coil Heat Transfer for $20^{\circ} \mathrm{F}$ Water Temperature Drop at $200^{\circ}$ Water Supp $1 \mathrm{y}$

Temperature ...................................... D -25

Figure 9. Increase in Air Flow Required to Maintain Constant Heating Coil Output with Decrease in Supply Water

Temperature .............................. D 25

Figure 10. Double Row Baseboard Unit ..................... D-27

Figure 11. Operating Modes of Air Type Solar System with Rock

Bed Storage ............................... D

Figure 12. Water-Based System with Tank Storage .............. D-30

Figure 13. Paralle1 Solar-Heat Pump System ................. D-31

Figure 14. Series Solar-Heat Pump System ................... D-31

Figure 15. Solar Absorption Cooling System ................. D-31 
MOST COMMON SI UNITS AND THEIR

EQUIVALENT VALUES IN

CUSTOMARY UNITS

\begin{tabular}{|c|c|c|c|c|}
\hline \multirow[b]{2}{*}{ LENGTH } & \multirow{2}{*}{$\begin{array}{l}\text { INTERNATIONAL } \\
\frac{(S I) \text { UNIT }}{\text { geter (m) }} \\
\text { millimeter (m) }\end{array}$} & \multirow{2}{*}{$\begin{array}{l}\begin{array}{l}\text { CUSTOMARY } \\
\text { UNIT }\end{array} \\
\text { foot (It) } \\
\text { lach (1n) }\end{array}$} & \multicolumn{2}{|c|}{ APPROXIMATE CONVERSION } \\
\hline & & & $2=$ & $\begin{array}{l}=3.2804 \mathrm{ft} \\
=0.0394 \mathrm{ln}\end{array}$ \\
\hline AREA & $\begin{array}{l}\text { square meter }\left(\mathrm{m}^{2}\right) \\
\text { square mill1meter }\left(\mathrm{mm}^{2}\right)\end{array}$ & $\begin{array}{l}\text { square yard }\left(y d^{2}\right) \\
\text { equare foot }\left(f t^{2}\right) \\
\text { equare lnch }\left(i n^{2}\right)\end{array}$ & $\begin{array}{l}1 \mathrm{~m}^{2} \\
1 \mathrm{~m}^{2} \\
1 \mathrm{~m}^{2}\end{array}$ & $\begin{array}{l}=1.1960 \mathrm{yd}^{2} \\
=10.764 \mathrm{ft}^{2} \\
=1.55 \times 10^{-3} 1 \mathrm{a}^{2}\end{array}$ \\
\hline VOLUME & $\begin{array}{l}\text { cub1c meter }\left(\varpi^{3}\right) \\
\text { cub1c millineter }\left(\min ^{3}\right)\end{array}$ & $\begin{array}{l}\text { cubic yard }\left(\mathrm{gd}^{3}\right) \\
\text { cublc foor }\left(\mathrm{ft}^{3}\right) \\
\text { cubic loch }\left(1 \mathrm{n}^{3}\right)\end{array}$ & $\begin{array}{ll}1 & \mathrm{~m}^{3} \\
1 & \mathrm{~m}^{3} \\
1 & \mathrm{~m}^{3}\end{array}$ & $\begin{array}{l}=1.3080 \mathrm{yd}_{3}^{3} \\
=35.315 \mathrm{ft}^{3} \\
=61.024 \times 10^{-6} \mathrm{ln}^{3}\end{array}$ \\
\hline$\underline{\text { CAPACITY }}$ & 11ter (L) & gallon (gal) & 12 & $=0.2642 \mathrm{gal}$ \\
\hline VELOCITY, SPEED & $\frac{\text { meter per second }(\mathrm{m} / \mathrm{s})}{\text { kllometer per bour }(\mathrm{km} / \mathrm{h})}$ & $\begin{array}{l}\text { foot per second }(\mathrm{ft} / \mathrm{s}) \\
\text { mile per hour (mlle/h or } \mathrm{m} \cdot \mathrm{p} \cdot \mathrm{h})\end{array}$ & $\begin{array}{l}1 \mathrm{~m} / \mathrm{s} \\
1 \mathrm{lom} / \mathrm{h}\end{array}$ & $\begin{array}{l}=3.2808 \mathrm{ft} / \mathrm{s} \\
=0.6214 \mathrm{mlle} / \mathrm{h}\end{array}$ \\
\hline ACCELLERATION & meter per second squared $\left(m / s^{2}\right)$ & foot per second squared $\left(\mathrm{ft} / \mathrm{s}^{2}\right)$ & $1 \mathrm{~m} / \mathrm{s}^{2}$ & $=3.2808 \mathrm{fr} / \mathrm{s}^{2}$ \\
\hline MASS & $\begin{array}{l}\text { metric ton }(t) \\
\frac{k 1 \operatorname{logram}(\mathrm{kg})}{\operatorname{gram}(g)}\end{array}$ & $\begin{array}{l}\text { ton }(20001 b) \\
\text { pound }(1 b) \\
\text { ounce }(02)\end{array}$ & $\begin{array}{ll}1 & \mathrm{t} \\
1 & \mathrm{~kg} \\
1 & 8\end{array}$ & $\begin{array}{l}=1.1023 \mathrm{ton} \\
=2.2046 \mathrm{lb} \\
=0.0353 \mathrm{oz}\end{array}$ \\
\hline DENSITY & $\begin{array}{l}\text { metric ton per cublc meter }\left(\mathrm{t} / \mathrm{m}^{3}\right) \\
\text { k1logram per cublc meter }\left(\mathrm{kg} / \mathrm{m}^{3}\right)\end{array}$ & $\begin{array}{l}\left.\text { ton per cubic yard (ton/yd } \mathrm{d}^{3}\right) \\
\text { pound per cublc foot }\left(1 \mathrm{~b} / \mathrm{ft}^{3}\right)\end{array}$ & $\begin{array}{ll}1 \mathrm{c} / \mathrm{m}^{3} \\
1 \mathrm{~kg} / \mathrm{m}^{3}\end{array}$ & $\begin{array}{l}=0.8428 \mathrm{ron} / \mathrm{yd}^{3} \\
=0.0624 \mathrm{lb} / \mathrm{ft}^{3}\end{array}$ \\
\hline FORCE & $\begin{array}{l}\text { k1lonewton (kN) } \\
\text { newton (N) }\end{array}$ & $\begin{array}{l}\text { ton-force (tonf) } \\
\text { k1p (1000 lbf) } \\
\text { pound-force (1bf) }\end{array}$ & $\begin{array}{ll}1 & \mathrm{kN} \\
1 & \mathrm{kNN} \\
1 \mathrm{~N}\end{array}$ & $\begin{array}{l}=0.1124 \operatorname{tonf} \\
=0.2248 \mathrm{kfp} \\
=0.73761 \mathrm{bf}\end{array}$ \\
\hline $\begin{array}{l}\text { MOMENT OF FORCE, } \\
\text { TORQUE }\end{array}$ & $\begin{array}{l}\text { kllonewton meter }(\mathrm{kN} \cdot \mathrm{m}) \\
\text { Dewton meter }(\mathrm{N} \cdot \mathrm{m})\end{array}$ & $\begin{array}{l}\text { ton-force foot (tonf.ft) } \\
\text { pound-force Inch (lbf.1n) }\end{array}$ & $\begin{array}{ll}1 \mathrm{kN} \cdot \mathrm{m} \\
1 \mathrm{~N} \cdot \mathrm{m}\end{array}$ & $\begin{array}{l}=0.3688 \text { tonf/ft } \\
=8.8508 \mathrm{lbf} \cdot \mathrm{In}\end{array}$ \\
\hline PRESSURE, STRESS & $\begin{array}{l}\text { megapascal }(\mathrm{MPa}) \\
\text { k1lopascal }(\mathrm{kPa}) \\
\text { pascal }(\mathrm{Pa})\end{array}$ & $\begin{array}{l}\left.\text { ton-force per square lach (tonf } / 1 n^{2}\right) \\
\text { ton-force per square foot }\left(\operatorname{tonf} / f t^{2}\right) \\
\text { pound-force per square inch }\left(1 b f / 1 n^{2}\right) \\
\text { pound-force per square foot }\left(1 b f / f t^{2}\right)\end{array}$ & $\begin{array}{ll}1 & \mathrm{MPa} \\
1 & \mathrm{kPa} \\
1 & \mathrm{kPa} \\
1 & \mathrm{~Pa}\end{array}$ & $\begin{array}{l}=0.0725 \operatorname{tonf} / \mathrm{In}^{2} \\
=10.443 \operatorname{tonf} / \mathrm{ft}^{2} \\
=145.04 \mathrm{bf} / 1 \mathrm{n}^{2} \\
=20.885 \mathrm{bf} / \mathrm{ft}^{2}\end{array}$ \\
\hline $\begin{array}{l}\text { WORK, ENERGY, } \\
\text { QIANT ITY OF HEAT }\end{array}$ & $\begin{array}{l}\text { k1lojoule (kJ) } \\
\text { joule }(\mathrm{J})\end{array}$ & $\begin{array}{l}\text { British thermal unit (Btu) } \\
\text { foot pound-force (ft.1bf) }\end{array}$ & $\begin{array}{ll}1 & k J \\
1 & J\end{array}$ & $\begin{array}{l}=0.9478 \mathrm{Btu} \\
=0.7376 \mathrm{ft} \cdot 1 \mathrm{bf}\end{array}$ \\
\hline$\frac{\text { COEFFICIENT OF HEAT }}{\text { TRANSFER (U-Value) }}$ & $\frac{\text { watt per square meter kelv1n }}{\left(\mathrm{W} / \mathrm{m}^{2} \cdot \mathrm{K}\right)}$ & $\begin{array}{l}\text { Btu per square foot hour degree } \\
\left.\text { Fahrenhelt (Btu/ft } / \mathrm{h} \cdot{ }^{\circ} \mathrm{F}\right)\end{array}$ & $\begin{array}{r}1 \mathrm{~W} /\left(\mathrm{m}^{2} \cdot \mathrm{R}\right) \\
0.1\end{array}$ & $=7 \mathrm{Btu} /\left(\mathrm{ft} \mathrm{t}^{2} \cdot \mathrm{h} \cdot{ }^{\circ} \mathrm{F}\right)$ \\
\hline $\begin{array}{l}\text { IHLELLA CONDUC- } \\
\text { IIVITY (k-Value) }\end{array}$ & watt per meter kelvin $(W / m \cdot R)$ & $\begin{array}{l}\text { Btu per foot hour degree Fahrenhelr } \\
\left(\text { Btu/ft.h. }{ }^{\circ} \text { F) }\right.\end{array}$ & $\begin{array}{r}1 \mathrm{w} /(\mathrm{m} \cdot \mathrm{K}) \\
0.5\end{array}$ & $=778 \mathrm{Btu} /\left(\mathrm{ft} \cdot \mathrm{h} \cdot{ }^{\circ} \mathrm{F}\right)$ \\
\hline
\end{tabular}

NOTES: (1) The above conversion factors are shown to four s1gnificant digits, where appropriate.

(2) Unprefixed SI units are underlined. (The k1logram, although prefixed, 1s an SI base un1t.)

REFERENCES:- NBS Metr1c Guidelines, LC1056, August 1977;

NBS Special Publication 330, "The International System of Un1ts (SI);"

NBS Technical Note 938, "Recommended Pract1ce for the Use of Metrie (SI) Un1t8 La Bullding Degign and Construction;"

ASTM Standard E621-78, "Standard Pract1ce for the Use of Metr1c (SI) Onits in Bu1lding Des1gn and Construction;"

ANSI 2210-1976," "American Nat1onal Standard for Metric Pract1ce;" ASTM E380-76, or IEEE Std. 268-1976. 
1. INTRODUC:":ON

\subsection{PURPOSF OF THE REPORT}

This preliminary report was prepared to show Fedecal agencies what evaluation methods are available to determine whether buildings in their inventory are suitable for solar energy retrofit. It describes methods for developing the engineering information needed to determine whether the building and its mechanical/electrical systems can be retrofitted for solar energy under the Solar Federal Buildings Program (SFBP).

The report is intended to be used by the agency's facilities engineer to conduct on-site and/or off-site investigations of the building structure and its systems. Engineering information is developed in two stages: (1) preliminary information derived from reasonably unsophisticated procedures, and (2) secondary information derived from more detailed or sophisticated procedures. The ultimate decision to recommend solar retrofit should be made by the facilities engineer and associated consultants.

\subsection{AUTHORIZATION}

Funding for the report was provided by the Department of Energy (DoE) as part of the Solar Federal Buildings Program (SFBP). This multi-year program is designed to stimulate the growth and improve the efficiency of the solar industry by providing funds to Federal agencies for the design, acquisition, construction, and installation of commercially applicable solar domestic hot water, heating, cooling, and process systems in new and existing Federal buildings. The SFBP was authorized under Title V, Part 2 of the National Energy Conservation Policy Act, enacted on November 2, 1978 (PL 95-619). Program implementation began with the approval of the procedures published in the October 19, 1979, Federal Register (Vol. 44, No. 204), and it became fully operational with the publication of the Federal Energy Management and Planning Programs (FEMP) Final Rule in the January 23, 1980, Federal Register.

If a Federal agency plans to retrofit a building for solar energy under the SFBP, it must submit to the DoE a proposal for each project. Each proposal must contain: (1) general project information; (2) site and building description; (3) building load information; (4) solar system description; and (5) auxiliary (or backup) system information, including the method for selecting the solar design proposed. The guidelines presented in this report will be useful in preparing the required information. The October 19, 1979, Federal Register contains more specific information on the subject.

\subsection{NEED FOR ANALYSIS}

The rapid rise of oil prices and the apparent limit of known sources has resulted in a greater concern for efficient Federal utilization of available energy sources. Since solar energy is a viable supplement to conventional energy sources, Federal agencies are expected to consider its use. However, the cost benefits of solar energy must be considered against other available energy sources. For example, solar energy is generally considered to be 
- Electrical: Additional electrically operated equipment such as blowers, pumps, water chillers or heat pumps will require the modificatioon of the existing power supply system, including possible additional power capacity, wiring and controls.

Figure 1 provides an overview of the sequence recommended for determining whether a particular building and its systems can support a solar retrofit. If solar retrofit is determined to be feasible, further economic evaluation may be required to be provided by others. The information provided by the engineering evaluation will be useful to the retrofit designer when a decision has been made to proceed, although the designer ultimately will have to determine exactly what evaluation information is required for a complete design. 


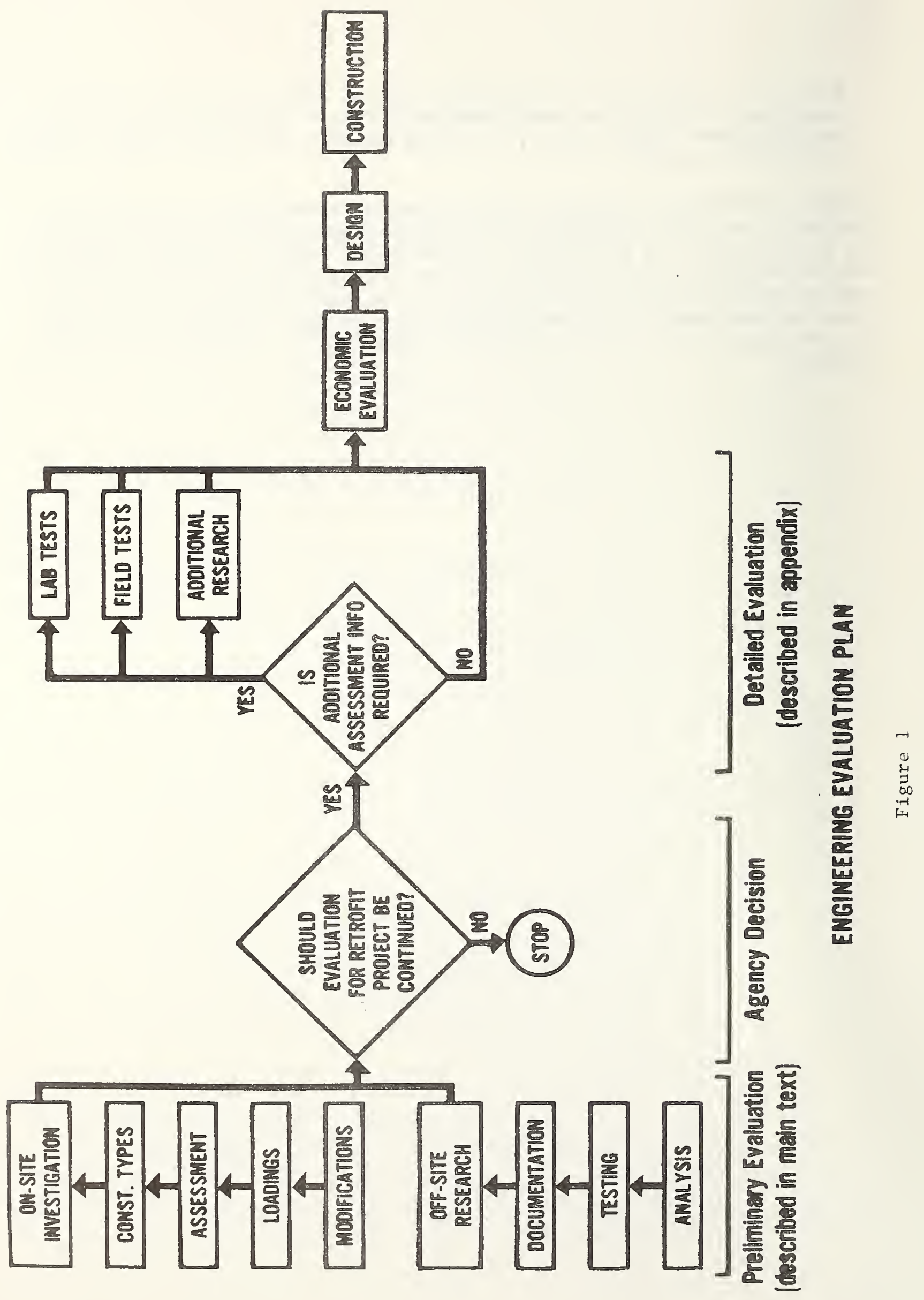




\section{PREL IMINARY EVALUATION METHODS}

\subsection{ON-SITE INVESTIGATION}

Visual inspection of a building and simple assessment procedures will provide most of the information required to determine the condition and capability of the building and its systems. Most defects (such as missing components, cracks, corrosion, misalignment, etc.) affecting solar retrofit can be detected visually.

The on-site inspection procedure generally includes:

1) General site inspection.

2) Gathering of existing documents (plans, specifications, etc.).

3) Survey of building condition, including sketches and photographs.

4) Gathering of specimens for evaluation.

5) Simple field tests.

6) Interviews with owners/occupants.

The information obtained during inspection should include:

1) A list of materials, components, and systems existing in the building (including structural; heating, ventilating, and air conditioning (HVAC); plumbing; and electrical items).

2) Condition and capacity of existing components (e.g., extent of deterioration of concrete structural members; nameplate data for fans and pumps; etc.);

3) Actual occupancy related loads (structural, heating, plumbing, etc.) to which the building is subjected.

To organize the accumulated data during the on-site investigation, a project dossier should be established consisting of a project notebook and a file containing all notes, correspondence, and documents (as well as collected reference material) concerning the prospective solar retrofit project.

\subsubsection{Project Notebook and Forms}

The project notebook should contain the following information (typical forms are shown in appendix A).

\section{1) General Building Information (See sample form A-1)}

Form A-l is designed to provide broad administrative and technical information relative to the structure under investigation. More detailed data is collected on additional forms described below.

\section{2) Component/Assembly Information (See sample form A-2)}

Form A-2 is designed to provide detailed information relative to the physical condition of specific components and assemblies of the various building systems 
(structural, plumbing, HVAC, and electrical). Data should be cross-referenced to other forms.

3) Journa1 Entry List (See sample form A-3)

Form $\mathrm{A}-3$ is used to provide a record of all important agreements, decisions or actions made by the facilities engineer, or his staff. If the remarks concerning the entry are extensive, then an attachment should be made, noted under the remarks and filed in the dossier with the Journal Entry number clearly marked.

\section{4) Contact List (See sample form A-4)}

Form A-4 is designed for the orderly collection of information from people contacted in the course of the preliminary investigation. For example, this form can be used to identify all past or present occupants of the building, the owner or manager of the building, the architect, engineers, etc.

\section{5) Document List (See sample form A-5)}

Form A-5 is used to complete information on plans, specifications, etc., which might aid in the investigation of the building.

\section{6) Photograph List (See sample form A-6)}

Form A-6 provides a record of all photographs of the building and adjacent areas taken or collected by project staff.

\section{7) Sketch List (See sample form A-7)}

Form A-7 provides for orderly collection of sketches relative to the building or component condition. It should be cross-referenced to the photograph list.

\section{8) Specimen List (See sample form A-8)}

Form A-8 provides a record of samples removed from the building in the course of the preliminary investigation. The sketches of the sample locations along with photographs and sketches of the samples themselves should be entered on forms $A-6$ and $A-7$.

\subsubsection{Project Files}

The project files should include the following items:

1) Genera1 Correspondence

2) Journal Entry Supplements

3) Collected Documents and Citations

4) Photographs and Negatives

5) Field Reports and Sketches

6) Test Results 
7) Analytical Studies

8) Evaluation Report

\subsubsection{Field Inspection Equipment}

Appendix B contains a list of items which would be useful in conducting an on-site investigation.

\subsection{OFF-SITE INVESTIGATIONS}

Additional information also is needed which is obtained away from the building site. This information compliments the on-site investigation and provides a complete picture of a building and its potential for solar retrofit. It consists of: (1) analyses of the building systems, (2) simple laboratory tests of specimens removed from the building, and (3) additional building documents. The latter includes drawings and specifications, construction records, operation and maintenance records, records of alterations made to the buildings and systems, information on material properties, and records describing site conditions. Sources of this information are the Federal agency headquarters, the building facilities engineer, the building contractor, the surveying contractor, and the building designer. Appendix C contains a more complete list of such information and potential sources.

Existing documents should not be used by themselves to evaluate a building since frequently they may not reflect actual conditions. Therefore, an on-site investigation of the as-built conditions always is recommended in conjunction with a review of existing documents.

Data obtained off-site may be handled and filed in the same manner as is described above for on-site data.

\subsection{DESTRUCTIVE VS. NONDESTRUCTIVE EVALUATION}

Throughout the structural portions of this report, evaluation methods will be referred to as nondestructive or destructive. A definition of each is provided below along with advantages and limitations.

A. Nondestructive Evaluation is the process of inspecting, evaluating, and/or measuring the performance or properties of materials or systems in a manner which will not change, damage, or destroy the properties or affect the service life of the specimens [3].

1) Advantages

- Can be performed in-situ with little or no damage to the specimen.

- Different tests can be used on the same test member simultaneously or sequentially.

- The same test can be repeated on the same test member. 
- The cumulative effect of the time in service of the test member can be measured directly.

- Little or no preparation is required to be performed on the test member.

- The equipment often is portable for in-situ use.

- Labor costs usually are low, especially for repetitive testing of similar test members.

2) Limitations

- Sometimes interpretation of the test results must be accomplished by skilled, experienced technicians.

- In the absence of proven correlation, the meaning and significance of the test results could be interpreted differently by various evaluators.

- Some nondestructive tests require very sophisticated and expensive testing equipment.

- Often only qualitative or comparative measurements of the properties of the test sample can be made.

B. Destructive Evaluation is the process of inspecting, evaluating, and/or measuring the properties of materials or systems in a manner which can change, damage, or destroy the properties or affect the service life of the test specimen [3].

1) Advantages

- Measurements are direct and usually reliable.

- Measurements are quantitative and usually are valuable for determining the existing properties of the test member.

- Skilled technicians usually are not required to interpret test results.

- There usually is a direct correlation between test results and the in-situ properties of the test sample - thus leaving little to interpretation among various evaluators.

2) Limitations

- Applicable only to a test sample. Further proof may be required that the test sample is representative of the rest of the building members. 
- Tested members are damaged or their service life is affected.

- Often it is not possible to repeat tests on the same member of the building because of the destructiveness of the test.

- The cumulative effect of the time in service of the test member cannot be measured directly, but can only be inferred from tests made on the members at different lengths of time.

- Difficult to use in-situ.

- Pre-test preparation work usually is required.

- Often the equipment and manpower costs are high. 


\section{GUIDELINES FOR STRUCTURAL SYSTEMS}

\subsection{GENERAL CONSIDERATIONS}

\subsubsection{Structural Condition Assessment}

The assessment of existing structural components should include strength, stiffness, and stability considerations. On-site inspection of a building can provide a great deal of information relative to these properties.

\subsubsection{Structural Loadings}

The addition of solar components to an existing building often will change structural loadings. These changes could be in the form of additional dead loads from collectors, absorption chillers, water storage tanks, or rock beds; dynamic or vibrational loads from rotating or reciprocating equipment; or changes in live load caused by the rehabilitation of the building (e.g., change in occupancy). Tables 1,2 and 3 provide guidance on the types of such loading to expect. Not only should new loading be considered but modifications to the structural system should be analyzed. Examples include the cutting of chases in existing floors, walls, or roof systems for the passage of mechanical/electrical support systems, and the modification to an existing building for passive solar benefits where large openings may be added to the building envelope. Good engineering practice and careful assessment should be used to evaluate the impact of revised loadings.

\subsubsection{Environmental Changes}

The addition of solar components can create serious problems for stuctural systems by changing the ambient moisture and temperature conditions. Minor structural accommodations (e.g., cracks in plaster) may occur during the time it takes for the building to adapt to the proposed new conditions. The preliminary evaluation should attempt to anticipate these problems and to. assess the degree of severity or significance of such problems on the building.

\subsubsection{Date of Building Construction}

Data relative to the properties of materials in an existing building can be estimated if the date of construction is known. Approximate strength values generally are sufficient for analytical purposes in assessing structural characteristics. The date of a building can provide clues relative to design codes, engineering standards, construction techniques and materials used, and hence the structural performance to be expected. For example, the design yield strength of structural steel has changed considerably over the 
Asbestos Shingles

Asphalt Shingles

Copper or Tin

Corrugated Ir on

Clay Tile (for mortar add 10 1b.):

2" Book Tile

3" Book Tile

Roman

Spanish

Ludowici or Shingle

Cement Tile

Composition:

Three-ply ready roofing

Four-ply felt and gravel

Five-ply felt and gravel

Wood-Sheathing, per inch thickness

Slate, $3 / 16$ inch

Slate, $1 / 4$ inch

Skylight, metal frame $3 / 8$ " wire glass

Wood shingles

Insulation, per inch thickness

Gypsum Plant, 2 inch

Metal Deck ( 1 1/2" with ribs 6" o.c.)

\begin{tabular}{c}
$\mathrm{Pa} \times 10^{-3}$ \\
\hline 120 \\
95 \\
48 \\
96
\end{tabular}

574

958

574

919

479

766

48

263

287

144

335

479

383

144

48

574

120 $\frac{1 \mathrm{bf} / \mathrm{ft}^{2}}{4}$

2

1

2

12

20

12

19

10

16

1

5.5

6

3

7

10

8

3

1

12

2.5

$1 /$ Roof loads for typical flat plate collectors and supports are in the range of $0.5-0.7 \mathrm{~Pa}\left(10-151 \mathrm{bf} / \mathrm{ft}^{2}\right)$. 
TABLE 2 [7]

SIZE AND WEIGHT OF TYPICAL CHILLERS

\begin{tabular}{|c|c|c|c|c|c|}
\hline $\begin{array}{l}\text { Derated } \\
\text { Capacity }\end{array}$ & $\begin{array}{l}\text { Maximum } \\
\text { Rated } \\
\text { Capacity }\end{array}$ & $\begin{array}{l}\text { Dimensions } \\
\mathrm{L} \times \mathrm{W} \times \mathrm{H}\end{array}$ & $\begin{array}{c}\text { Wt (lb) } \\
\text { (wet) }\end{array}$ & $\begin{array}{r}\text { Avera } \\
\text { Load } \\
(\mathrm{kPa}) \\
\end{array}$ & $\begin{array}{l}\text { (pse floor } \\
\left(1 \mathrm{bf} / \mathrm{ft}^{2}\right)\end{array}$ \\
\hline $30 t$ & $100 t$ & $11^{\prime} \times 5^{\prime} \times 7^{\prime}$ & 11,260 & 9.8 & 205 \\
\hline $60 t$ & $200 t$ & $14^{\prime} \times 5^{\prime} \times 8^{\prime}$ & 16,350 & 11.2 & 234 \\
\hline $105 t$ & $350 t$ & $19^{\circ} \times 6 \times 8^{\prime}$ & 24,700 & 10.4 & 217 \\
\hline $180 t$ & $600 t$ & $22^{\circ} \times 7^{\prime} \times 9^{\prime}$ & 35,250 & 11.0 & 229 \\
\hline $285 t$ & $950 t$ & $22^{\prime} \times 8^{\prime} \times 11^{\prime}$ & 57,400 & 15.6 & 326 \\
\hline $375 t$ & $1,250 t$ & $25^{\prime} \times 10^{\prime} \times 12^{\prime}$ & 85,700 & 16.4 & 343 \\
\hline
\end{tabular}

TABLE 3 [7]

WEIGHT OF TYPICAL STORAGE TANKS $1 /$

\begin{tabular}{|c|r|r|r|r|r|}
\hline \multicolumn{2}{|c|}{ Capacity } & \multicolumn{4}{|c|}{ Weight Including Water } \\
\hline \multirow{2}{*}{ litres } & gal & \multicolumn{2}{|c|}{ unpressurized } & \multicolumn{1}{|c|}{ pressurized } \\
\cline { 2 - 6 } 1,893 & 500 & 2,073 & 4,570 & 2,499 & 5,510 \\
3,785 & 1,000 & 4,182 & 9,219 & 4,951 & 10,915 \\
9,465 & 12,500 & 6,187 & 13,640 & 7,317 & 15,132 \\
\hline
\end{tabular}

1/ Storage tanks are sized commonly at 3.8-7.6 litres ( $1-2$ gallons) of storage per $0.1 \mathrm{~m}^{2}\left(\mathrm{ft}^{2}\right)$ of collector area. 
years. In lieu of costly testing of steel in an existing building it may be appropriate to assume conservative values based on the following relationship:

\begin{tabular}{lll}
\multicolumn{1}{c}{ Date } & \multicolumn{1}{c}{$\begin{array}{c}\text { Yield Point }(\mathrm{MPa}) \\
\left(1 \mathrm{bf} / \mathrm{in}^{2}\right)\end{array}$} \\
\cline { 2 - 3 } Constructed prior to 1905 & $\mathrm{f}_{\mathrm{y}}=172.37$ & $25,000 \mathrm{psi}$ \\
Constructed 1905-1932 & $\mathrm{f}_{\mathrm{y}}=206.84$ & $30,000 \mathrm{psi}$ \\
Constructed 1933-1963 & $\mathrm{f}_{\mathrm{y}}=227.53$ & $33,000 \mathrm{psi}$ \\
Constructed after 1963 & $\mathrm{f}_{\mathrm{y}}=248.21$ & $36,000 \mathrm{psi}$
\end{tabular}

\subsection{GENERAL INSPECTION GUIDELINES -- STRUCTURAL COMPONENTS}

As shown in figure 1 and discussed in section 2.1, the on-site investigation consists of a general site examination and a building condition survey. While the major emphasis should be on the assessment of structural components which may be affected by the solar retrofit, it is necessary to make an overall review of the condition of the whole building. This is especially significant where additional structural loadings or modifications are anticipated. The following general inspection guidelines will be useful in this assessment.

\subsubsection{Foundations}

The foundation is one of the most important structural components to assess. It should be anticipated that such things as added loads or changes in soil drainage patterns around the building can impact the building foundation detrimentally. References [8, 9, 10] provide the following guidelines:

(a) Check for soft and crumbling mortar in foundation walls. This could be serious if it is associated with any signs of sag in the structure.

(b) Foundation wall cracks usually are diagonal, starting from the top, the bottom, or the end of the wall. If the cracks do not extend to at least one edge of the wall, they probably are not caused by foundation problems, but are more likely due to other structural problems (see table 5 and table 9).

(c) Be sure the ground slopes away from the foundation wall so that rain water drains off properly.

(d) Downspouts should have splash blocks to divert water away from the building.

(e) Although it usually is difficult to determine the condition of a footing without excavating the foundation, structurally unsound footings usually will be indicated either by large cracks or by settlement in the foundation walls.

(f) Leaning, buckling, or bulging foundation or bearing walls may be the result of a number of hidden or interacting problems. For 
example, they may be the result of differential building settlement or failure of a structural beam or girder.

(g) If new heavy loads are to be added to the existing foundation, it will be necessary to check it for ability to carry the new loads. If details of the foundation design and the soil bearing value cannot be determined from existing drawings and reports of subsurface soil investigations, it may be necessary to: (1) excavate adjacent to an outside wall to determine the type of existing foundation and (2) conduct a subsurface soil investigation (soil borings). Results from the subsurface soil investigation can be used to support the need for new foundations under heavy loads or to prove the adequacy of existing foundations.

\subsubsection{Exterior Walls}

(a) Check for plumbness. Use a plumb line. Out of plumb exterior walls can be a sign of serious foundation problems.

(b) Sight along wall for any sign of bulges which could indicate major structural problems.

(c) Doors that do not line up squarely in their frames can be another sign of possible foundation problems.

(d) Check that all joints between dissimilar materials (e.g•, wood and masonry joints) around door frames, window frames, and decorative trim are tightly caulked or properly flashed to prevent water penetration.

(e) Check for vertical or zig-zag cracks through bricks and mortar that can be an indication of uneven settling.

(f) Check that mortar joints are sound (not soft and crumbling) and that no bricks are missing or loose.

(g) Look for any sign of spalling, cracking, or crumbling of exterior stonework.

(h) Check for any loose, cracked, or missing clapboards that could admit water into the building.

(i) Identify any loose, thin, or badly weathered siding or shingles which are an open invitation to water and rot.

(j) Check for rotting of the siding or erosion of the exposed portion of the cellar or basement walls which often results from missing or leaking gutters. 


\subsubsection{Roof}

(a) Inspect for sagging condition of the roof. Especially attempt to examine the rafters, purlins, collar beams, and ridge boards wherever possible. Where applicable check the condition of the roof boards from inside the attic.

(b) Look for evidences of a leaking roof. This condition will be indicated by loose plaster or peeling or stained paint and wall paper.

(c) Check condition of gutters and rain leaders around the entire building to insure proper drainage of water. Evidences of the lack of gutters (or leaking gutters) are: (1) rotting of the siding, or (2) erosion of the exposed portion of the cellar or basement walls.

(d) All existing dead and live loads on the roof should be summed to determine the accumulative existing loads and to determine whether the additional load of 0.5 to $0.7 \mathrm{kPa}$ (10 to $151 \mathrm{bf} / \mathrm{ft}^{2}$ ) imposed by typical solar components can be supported by the structure. The design capacity should be checked with respect to expected snow, ice, and wind loads for the local geographical area, as well as the dead loads of the roofing materials.

(e) If the existing roof is composed of a steel deck on steel joists, and new heavy concentrated dead loads are to be imposed on the deck by solar equipment, be sure the joists have been designed for twice the static operating weight of the equipment. Be sure there is enough room to reinforce the top chords of the joists for any new concentrated loads which may be applied between panel points. Since any new concentrated loads which must be applied to the bottom chords will have to occur at panel points, it will be necessary to check that access to these points is possible. Existing joists should be checked to be sure they can support newly imposed loads without exceeding a maximum deflection of $1 / 360 \times$ span.

(f) Be sure that existing conditions will accommodate roof mounted equipment supports which will permit easy access for roof maintenance.

\subsubsection{Attic}

(a) Look for signs of leaks (e.g., dark water stains) on the underside of the roof, especially around chimneys, valleys, and eaves.

(b) Check for proper ventilation, especially for signs of mildew on underside of roof boards. 


\subsubsection{Interior Spaces}

(a) Look for signs of damp plaster which may indicate the existence of leaks from the roof or internal pipes.

(b) Check for any loose or spongy plaster in walls or ceilings which could indicate the existence of leaks.

(c) Substantial vibration (bounce) of stairways; or gaps between treads, risers, and side stringers of stairs may indicate structural problems.

(d) Check to see if the flooring is in good condition (flooring covered with linoleum, carpet, etc., can harbor unseen problems).

(e) See if floors have a pronounced sag or tilt. A simple test can be performed with a marble (to see if it rolls) or with a level. A sag or tilt could indicate normal settling, or structural problems.

(f) Jump on floors to see whether the floors vibrate or the windows rattle (this would indicate inadequate support caused by undersized beams, inadequate bridging, cracked joists, or rotted support post, etc.).

(g) Look for signs of water leakage around window frames.

(h) If outside light can be seen through openings around window rails and door jams, the condition of the support girders, posts, and studs should be questioned. This condition often is evidence that some of these members may be termite infested or rotted and may be causing the outside wall to sag.

(i) Wherever possible, new columns or equipment supports should be placed directly over existing columns. Therefore, the interior of the building should be inspected to determine whether there are any conditions which would prevent this from being accomplished.

\subsubsection{Basement}

(a) Probe the sills (wood beams at the top of the foundation walls) with a penknife, awl, or ice pick for signs of rot or termites.

(b) If the mortar between bricks or concrete blocks in foundation walls is heavily eroded (or if other evidences of erosion of the exposed portion of the basement wall exist) check for missing or leaking gutters.

(c) Check for any signs of dampness on the underside of floors around pipes. If left uncorrected, this can cause wood rot.

(d) Signs to look for which warn of probable periodic flooding are: rust spots, efflorescence or mildew on walls, and material stored on top of bricks or boxes to raise it above floor level. 
(e) Look for sagging floors, rotted support posts, or jury-rigged props to shore up weak flooring.

(f) Check for general condition of the plumbing (e.g., patches on waste pipes indicate advanced age or structural movement).

\subsection{CONCRETE SYSTEMS}

Since concrete came into general use as a building material in the latter part of the nineteenth century, many existing buildings currently being considered for solar retrofit require application of concrete condition assessment techniques. Figure 2 summarizes the available techniques for condition assessment including visual techniques and the more complicated test procedures. The remainder of this section is concerned with visual inspection guidelines while the more detailed procedures are discussed in appendix D. 1 .

\subsubsection{Preliminary Evaluation of Concrete Systems}

Generally, visual/optical inspection is the most satisfactory, least expensive, and most commonly used method for determining the shape and dimensions of concrete components and for preliminary detection of surface flaws (such as cracks, roughness, scratches, discoloration, etc.). It can be performed with or without the use of optical aids (such as low-power magnifiers). Defects such as missing components, cracks, erosion, corrosion, and misaligned joints, of ten can be detected with the naked eye. With the use of five to ten power magnifiers, even surface flaws as small as a few microns wide can be detected. Table 4 summarizes visual inspection techniques for concrete.

The most obvious advantage of using the visual method to evaluate surface flaws in concrete is that it is inexpensive and requires no special equipment. However, the visual inspection method can be time consuming and is completely dependent upon the visual acuity, experience, and training of the inspector. It should be understood that no subsurface information can be obtained using this technique and that, even for surface conditions, a correlation already must have been established between the surface conditions and serviceability of the concrete.

During the visual/optical inspection, the following significant structural aspects should be checked or considered:

A. Concrete foundation cracks which are diagonal, starting from the top, the bottom, or the end of the wall. If the cracks do not extend to at least one edge of the wall, they probably are not caused by foundation problems, but are more likely due to other structural problems. It is important to determine the cause of these problems and to remedy the problem because the addition of retrofit solar equipment loads on the building could aggravate the problem further.

B. When new heavy loads are expected to be added to the existing concrete foundation, it will be necessary to check it for structural adequacy. If 
details of the concrete foundation design and the soil bearing value cannot be determined from existing drawings and reports of subsurface soil investigations, it may be necessary to: 1) excavate adjacent to an outside wall to determine the type of existing foundation and 2) conduct a subsurface soil investigation (soil borings). Results from the subsurface soil investigation can be used to support the need for new foundations under heavy loads or to prove the adequacy of existing foundations.

C. All existing dead and live loads on the concrete roof structure should be summed to determine the accumulative existing loads and to determine whether the additional loads imposed by the retrofit solar components can be supported by the existing concrete structure. The design capacity of the affected components of the concrete structure should be checked with respect to expected snow, ice, and wind loads for the local geographical area, as well as the dead loads of the roofing materials.

D. Wherever possible, new columns or equipment supports should be placed directly over existing columns. Therefore, the interior of the building should be inspected to determine whether there are any conditions which could prevent this from being accomplished.

\subsubsection{Concrete Problems and Potential Impact on Solar Retrofit}

A checklist (table 5) can be used to assist in determining what problems exist in a concrete structure and to make a preliminary determination of the impact that the problem may have on the solar retrofit. If it is determined that a more complete understanding of the nature or cause of the problem is necessary, further reference is given in the table to a more detailed description in appendix D. 1 . 


\section{CONCRETE TEST METHODS AND PARAMETERS}

\begin{tabular}{|c|c|c|c|c|c|c|c|c|c|c|c|c|c|c|c|c|c|c|c|c|}
\hline \multirow{2}{*}{ PARAMETERS } & & & & \multicolumn{15}{|c|}{ NONDESTRUCTIVE } & \multicolumn{2}{|c|}{$\underset{\text { TESTS }}{\stackrel{\text { DESTRLCTIVE }}{\longrightarrow}}$} \\
\hline & & & & & & & & & & & & & & & & & & & & \\
\hline$\frac{\text { D1mensional Characteristics }}{\text { Thickness of Slabs }}$ & - & & & & & ? & & & & & - & - & & & & - & & - & & \\
\hline $\begin{array}{l}\text { Size and location of rein- } \\
\text { forcing and other electrically } \\
\text { conductive components }\end{array}$ & & & & & & - & - & & & & & - & - & & & - & & 0 & & \\
\hline$\frac{\frac{\text { Quality and Strength }}{\text { Characteristics }}}{\text { Qual1ty of Concrete }}$ & 0 & - & & $\bullet$ & - & & & & & & - & - & - & & & & & 0 & ○ & \\
\hline Qual1ty of Aggregate & - & & & & & & & & & & & & & & & & & 0 & 0 & \\
\hline Uniformity & 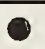 & - & & 0 & - & & & & & & - & - & & & & & & 0 & 0 & \\
\hline Variable Compaction & & & & & & & & & & & - & - & & & & & & 0 & 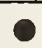 & \\
\hline Compressive Strength & & - & - & - & - & & & & & & - & & & & & & & 0 & & \\
\hline Mo1sture Content & & & & & & - & & & & & & & - & - & & & & & & \\
\hline Cement Content & & & & & & & & & & & & & & & - & & & 0 & - & \\
\hline $\begin{array}{l}\text { Density and Internal } \\
\text { Structure of Concrete }\end{array}$ & & & & & & & & & & & 0 & - & & 0 & & & & 0 & - & \\
\hline Modulus of Elasticity & & & & & 0 & & & 0 & & 0 & 0 & & & & & & & & & \\
\hline Condition of Relnforcing & - & & & & & 0 & & & & & & & & & & & & - & 0 & \\
\hline$\frac{\text { Flaws }}{\text { Surface Flaws }}$ & - & - & & & & & & & - & & 0 & & & & & & & 0 & - & \\
\hline $\begin{array}{l}\text { Interna I Flaws } \\
\text { (Vo1ds, cracks, etc.) }\end{array}$ & - & & & & & & & & - & - & - & • & & & & & ? & - & - & \\
\hline $\begin{array}{l}\text { Volds in grouting of post- } \\
\text { tensioned prestressed concrete }\end{array}$ & & & & & & & & & & & & - & & & & & & & & \\
\hline Deficlencies in foints & - & & & & & & & & & & & & & & & & & & & \\
\hline Substratum Volds & & & & & & & & & & & & & & & & 0 & & & & \\
\hline $\begin{array}{l}\frac{\text { Load D1stribution and }}{\text { Stress/Stra1n }} \\
\text { Losddistribution and } \\
\text { strain as detected by } \\
\text { surface distortion patterns }\end{array}$ & - & & & & & & & & & & & & & & & & & & & \\
\hline Bonding Stress & & & & & & & & & & & & - & & & & & & & & \\
\hline Fallures Under Stress & & & & & & & & 0 & & & & & & & & & & & & \\
\hline $\begin{array}{l}\text { Differential Structural } \\
\text { Movements }\end{array}$ & - & & & & & & & & & & & & & & & & & & & \\
\hline
\end{tabular}

FIGURE 2 


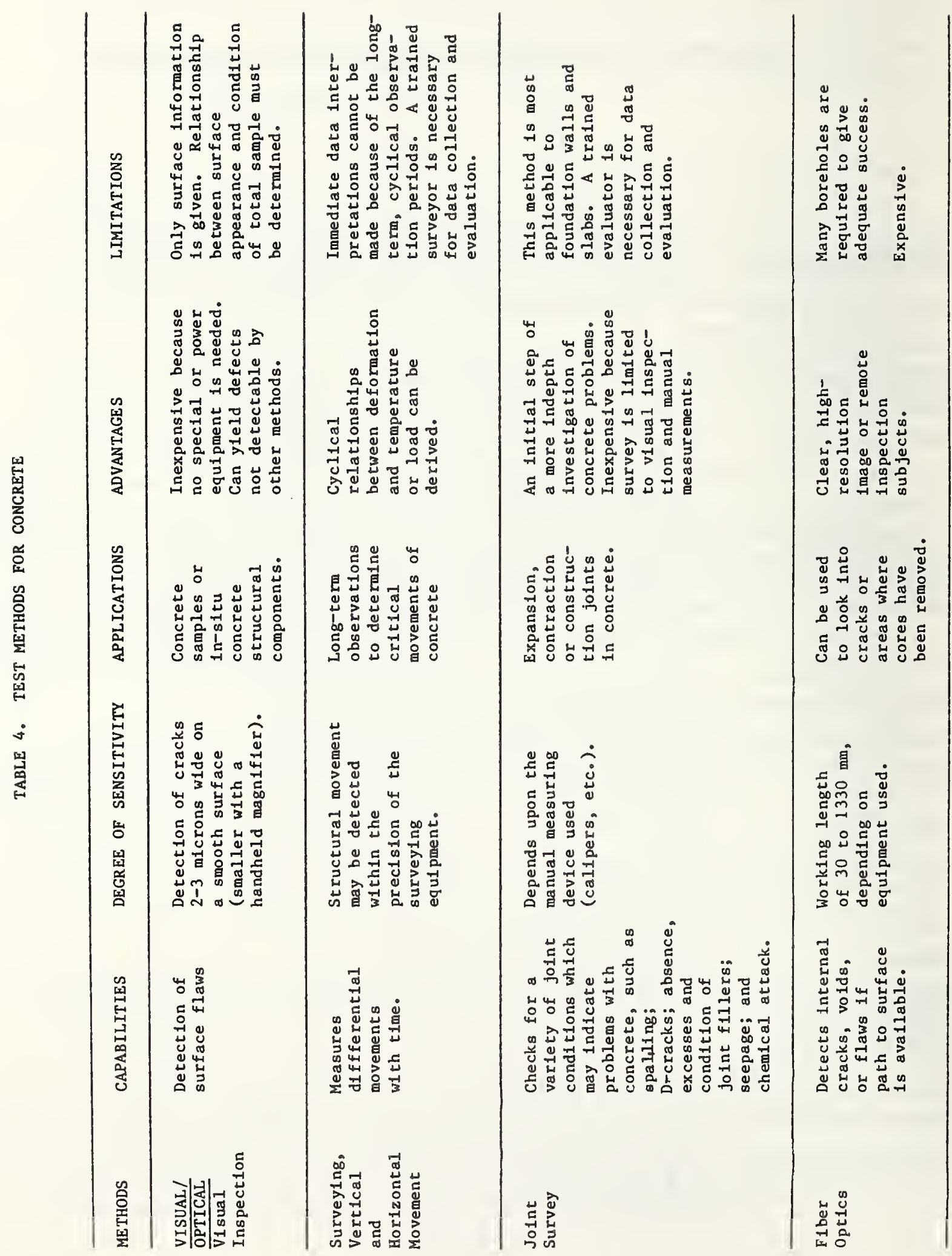




\begin{tabular}{|c|c|c|c|c|c|c|c|}
\hline 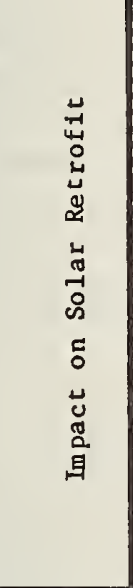 & 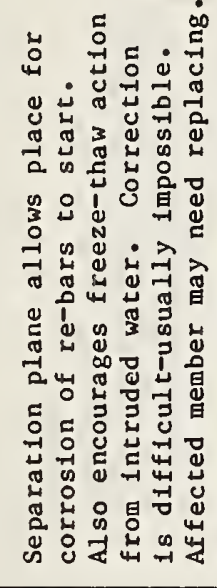 & 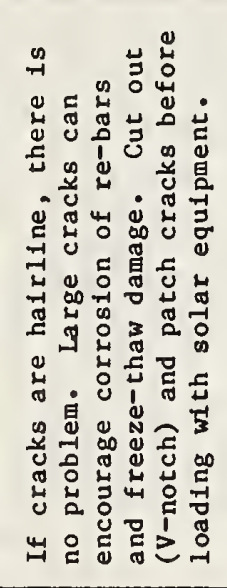 & 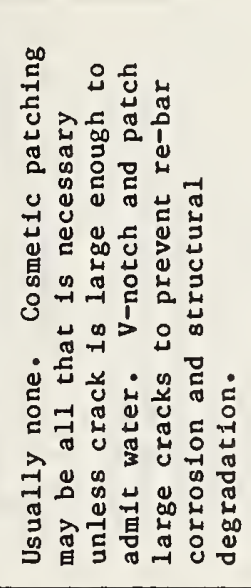 & 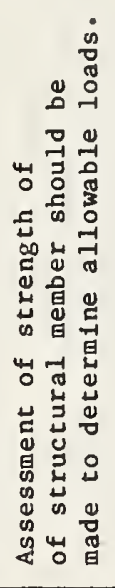 & 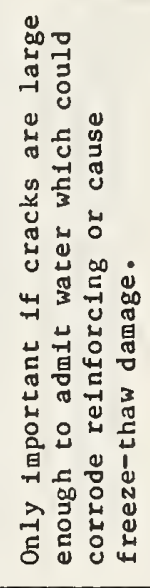 & 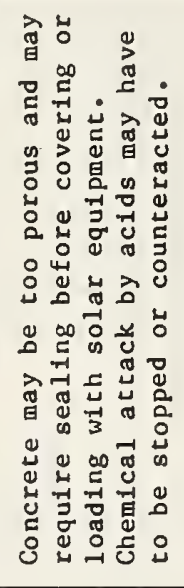 & 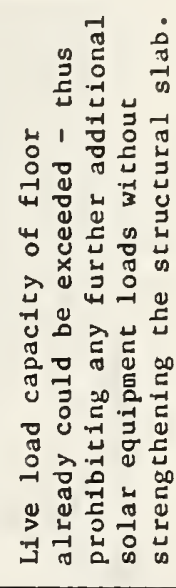 \\
\hline 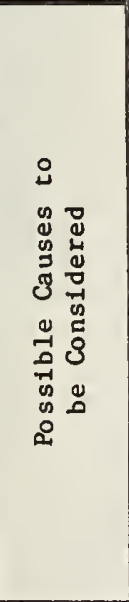 & 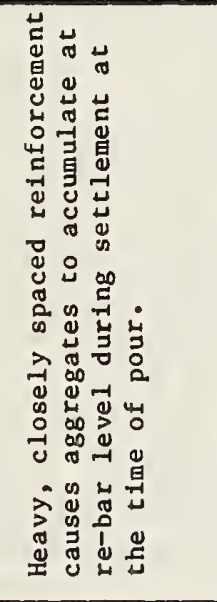 & 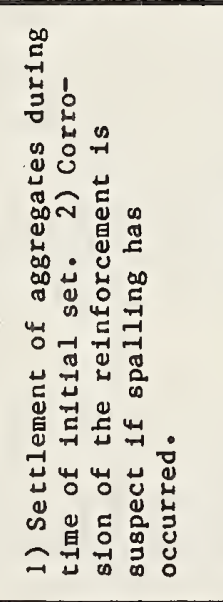 & 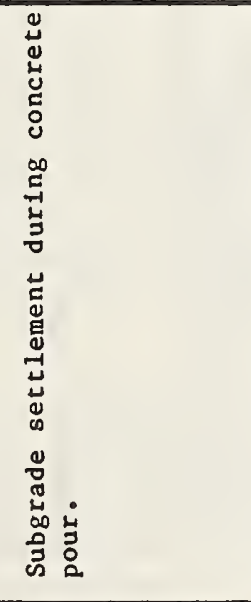 & 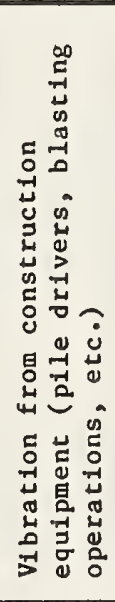 & 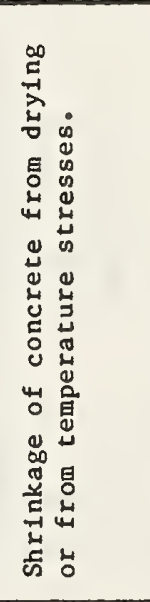 & 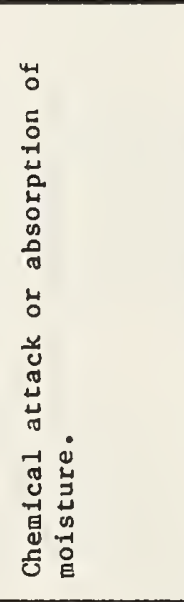 & 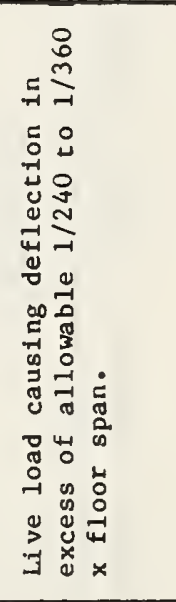 \\
\hline 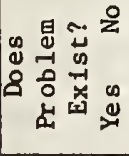 & & & & 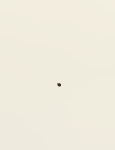 & & & \\
\hline 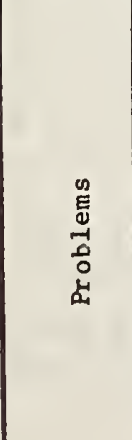 & 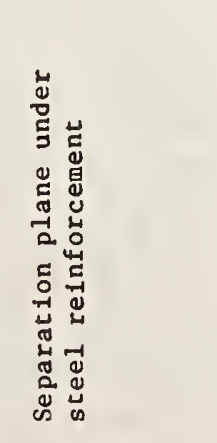 & 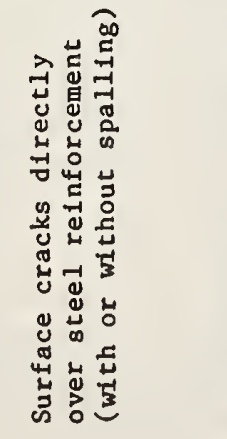 & 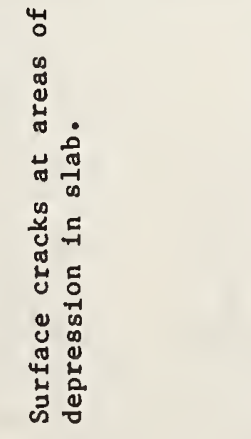 & 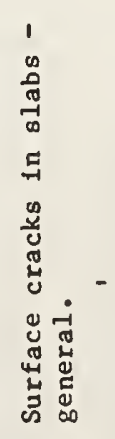 & 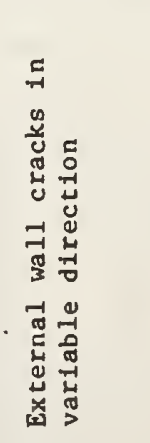 & 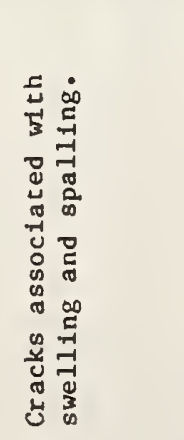 & 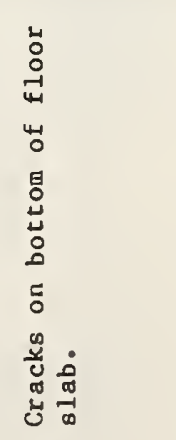 \\
\hline & $\dot{-}$ & $\dot{\sim}$ & $\dot{m}$ & $j$ & ni & $\dot{0}$ & $\stackrel{\circ}{\sim}$ \\
\hline
\end{tabular}




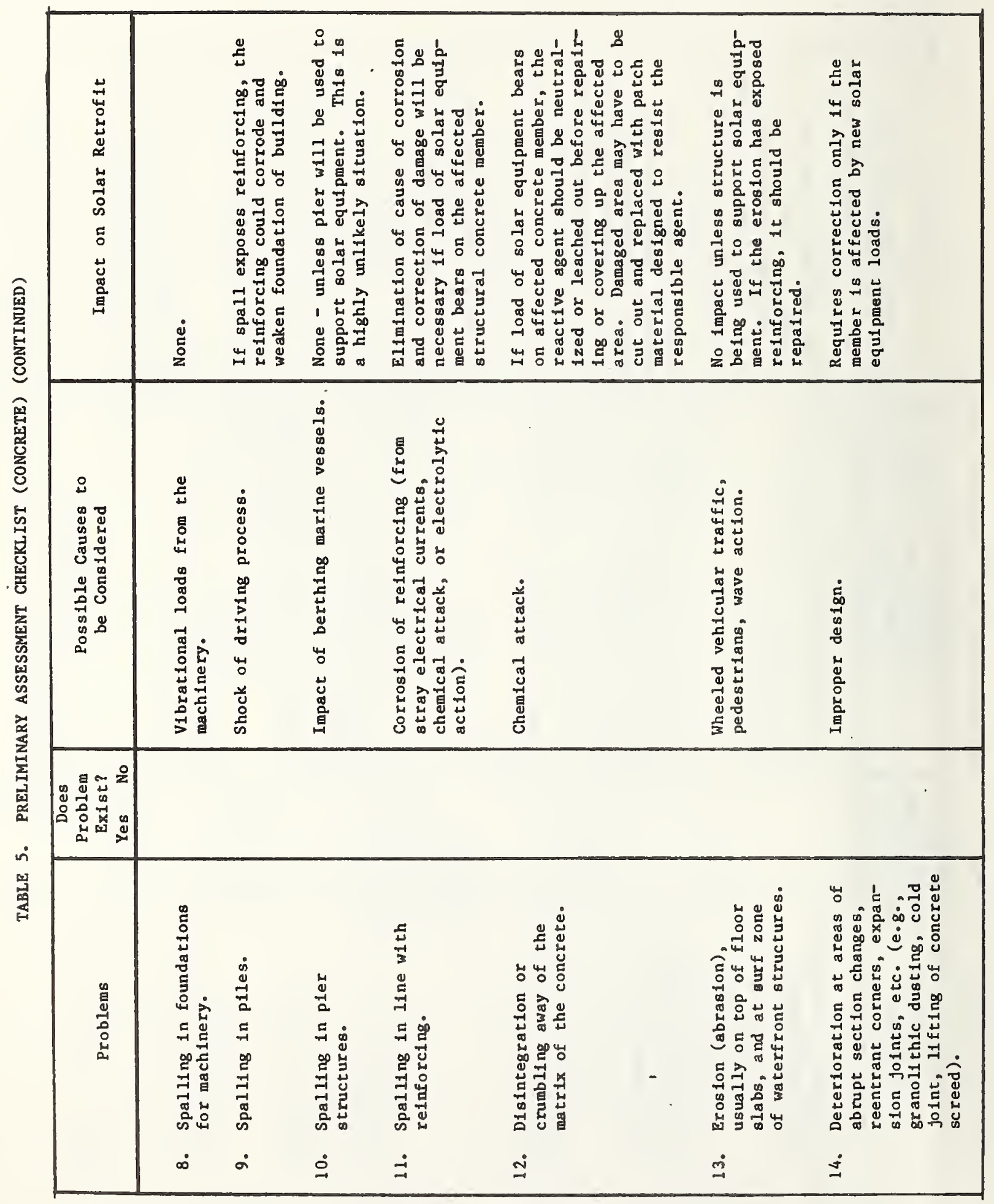




\subsection{WOOD SYSTEMS}

\subsubsection{General}

The practice of evaluating wood must focus on identification of those characteristics that define its performance (such as density, knots, moisture content, etc.). In existing buildings being considered for solar retrofit, questions of performance of wood components must address: (1) evidence of degradation of these products by the environment (e.g., moisture, temperature, chemicals, etc.); (2) presence of properly specified product grade and size; and (3) proper joining of components. Assessment techniques for wood include field inspection procedures discussed in the remainder of this section and in table 6, and the more detailed assessment procedures listed in appendix D. 2 .

\subsubsection{Problems Affecting Wood Components}

Common problems affecting the strength of structural timber are as follows:

\section{A. Moisture Degradation $[1,2,11,12,13,14,15,16,17,18,19,20,21,22]$}

In relatively dry climates with moderate temperatures, where wood is protected from deteriorating influences, the mechanical properties of wood show little change even after several centuries of aging. However, the strength of wood subjected to high moisture conditions can be adversely affected. The physical action of take-up or release of moisture causes swelling or shrinkage which can cause warpage, checking, and/or splitting, all of which have an effect on the strength of wood.

Moisture in sufficient quantity to damage wood can arise from: (a) external sources such as ground moisture and wetting from rain, and (b) internal sources such as high relative humidity, or moisture related to building occupancy (e.g•, leaking pipes). Decay due to excessive moisture can result in various types of rot, mold and fungi growth.

\section{B. Temperature Effects $[1,11,12,13,14,15,17,20]$}

The strength of wood increases as the temperature is cooled below $20^{\circ} \mathrm{C}\left(68^{\circ} \mathrm{F}\right)$, and it decreases as the temperature is raised above this point. This temperature effect is immediate and is dependent on the moisture content of the wood. When wood is exposed for prolonged periods to high levels of moisture and heat $\left(65^{\circ} \mathrm{C}\right.$ or $150^{\circ} \mathrm{F}$ ), thermal decay and related problems (such as fungus, insect infestation, etc.) are likely to reduce the strength of the wood.

\section{Insect Damage $[11,13,14,15,18,20,23,24,25,26,27]$}

This can occur in seasoned or unseasoned lumber, as well as in standing trees and logs. Generally, insect infestation is most predominant in geographical areas that are conducive to high moisture and warm temperature and, particularly, when there is a wood/soil contact condition present. There is no positive method for determining the amount of reduction in strength attributable to insect damage just from the appearance of the wood. When structural 
strength is a concern, the safest procedure is to replace all pieces of wood containing evidence of insect infestation.

The three major types of insects which attack wood are termites, power-post beetles, and carpenter ants. The most common areas where termites are found are in: (1) warm, moist, soil that has an abundance of cellulose derivatives, (2) poorly ventilated spaces below the first floor of a building, (3) areas of wood in contact with the soil, and (4) soil near walls of heated basements. Power-post beetles are found in humid locations, especially near the ground. Their presence can most readily be determined in wood by irregular burrows made by the larvae, while the surface shows only small diameter holes. The presence of carpenter ants is manifested by piles of chewed wood resembling coarse sawdust outside the wood and by the hollow, irregular, clean chambers made in wood.

D. Chemical Degradation $[1,11,12,13,14,15,18]$

Wood is generally resistant to mild acids and solutions of acidic salts. Some chemical solutions, however, may react with the chemical constituents of wood and cause a reversible swelling or irreversible changes in the wood to occur. One of the most common evidences that chemical degradation is taking place in wood is surface discoloration which occurs as it is exposed to the atmosphere and ultraviolet radiation. The chief means of combating chemically degrading forces is to coat the wood with preservatives, water repellants, or paint coatings.

\subsubsection{Preliminary Evaluation of Wood Components}

The on-site investigation conducted at the preliminary evaluation stage (figure 1) will provide information concerning the size, strength, grade, and extent of surface decay of structural timber in existing buildings. A useful aid for evaluating structural timber is the grade mark stamped on it at the mill. Because grade marks usually can be related to a recommended design value (by reference to the National Design Specification for Wood Construction, or other relevant documents), it is helpful in determining the quality and strength properties of the existing timber structure of a building if they can be discerned. If the grade marks are not discernible, it may be necessary to engage an evaluator who is experienced in identifying and grading wood products to make the evaluation of the quality and strength properties of the in-situ structural timber.

Table 6 summarizes the on-site inspection techniques for wood.

\subsubsection{Guidelines for Visual Inspection}

Visual inspection can provide information on the extent of decay in wood components. As discussed in section 3.4.1 decay can be the result of fungus or insect infestation, extreme weathering, or moisture accumulation. Characteristics of decay to be noted in different types of structural components are given in the following table: 
Component

Siding

Foundations

Roof s

Porches

Windows and Doors

\section{Characteristics of Decay}

Abnormal coloring (deeper than normal brown color); cubical checking (indicates an advanced stage of decay); bleaching (with or without the presence of fine black lines); softening (especially where siding ends butt against trim or each other).

Fanlike growth of fungi (located between subfloor and finish floor, and between joists and subfloor).

Cubical checking, warping, softening, shredding, breakage (location of all these deficiencies may be on the underside of roof sheathing).

Same as siding (check especially concavely worn areas that may trap water).

Brown or black discoloration near joints. Stain on sash (from condensation). Softening and mold growth (from accumulation of condensate).

Visual inspection will yield a good overall idea of the in-situ condition of wood and is the preliminary step in further evaluation of a member's strength properties. Any additional inspections should include an assessment of the wood member's internal stability. When conducting a visual inspection, keep in mind that this is a subjective test, and the accuracy of the results will depend completely on the skill of the inspector.

During the visual inspection, the following significant structural aspects should be checked or considered:

A. Inspect carefully for a sag in the wood roof structure. Especially, attempt to examine the rafters, purlins, collar beams, and ridge boards. Where applicable, check the condition of the roof boards from inside the building.

B. A11 existing dead and live loads on the wood roof structure should be summed to determine the accumulative existing loads and to determine whether the additional loads imposed by the retrofit solar components can be supported by the existing wood framing of the building. The design capacity of the affected components of the existing wood frame should be checked with the respect to snow, ice, and wind loads for the local geographical area, as well as the dead loads for the roofing materials.

C. Wherever possible, new columns or equipment supports should be placed directly over existing columns. Therefore, the interior of the building should be inspected to determine whether there are any conditions which would prevent this from being accomplished. 


\subsubsection{Visual Stress Grading [1]}

Visual stress grading is simply an attempt to place stock lumber in broad categories of anticipated load bearing capacities. The lumber usually is rated into classifications of 40,50, 65, and 75 percent of the strength of perfect timber. Obviously, the various grades are earmarked for varying uses according to their strength rating. The characteristics that determine a visual stress grade include size and frequency of knots, slope of grain, and wane. Visual stress grading yields an approximate, conservative estimate of a member's strength. This is because there is no allowance made for specific gravity of the wood, and only the surface is available for inspection.

The advantage of visual stress grading is that it is a fast and easy method for obtaining a general idea of in-situ timber quality. A disadvantage is that an experienced evaluator is required.

\subsubsection{Manual Probing $[19,28,29]$}

Prodding or probing a suspected piece of decayed wood with a sharp tool and observing the resistance to marring gives an idea of the stage of surface decay. A loss of hardness can be determined by comparison with sound wood of the same stock and species. Sound wood tends to lift out of the stock as one or two long silvers with splintery breaks when jabbed with a pointed tool. Decayed wood tends to lift out and break off squarely across the grain with little splintering and little resistance.

Manual probing will yield an accurate assessment of in-situ surface conditions, but it must be used in conjunction with another test method to determine the internal quality. The probing method is best suited to framework, siding, and fences. Penetrometers of ten are used to determine the quality and uniformity as well as strength properties of wood.

\subsubsection{Wood Problems and Potential Impact on Solar Retrofit}

A checklist (table 7) can be used to assist in determining what problems exist in the wood system of an existing building and to make a preliminary determination of the impact that the problem may have on the solar retrofit. 


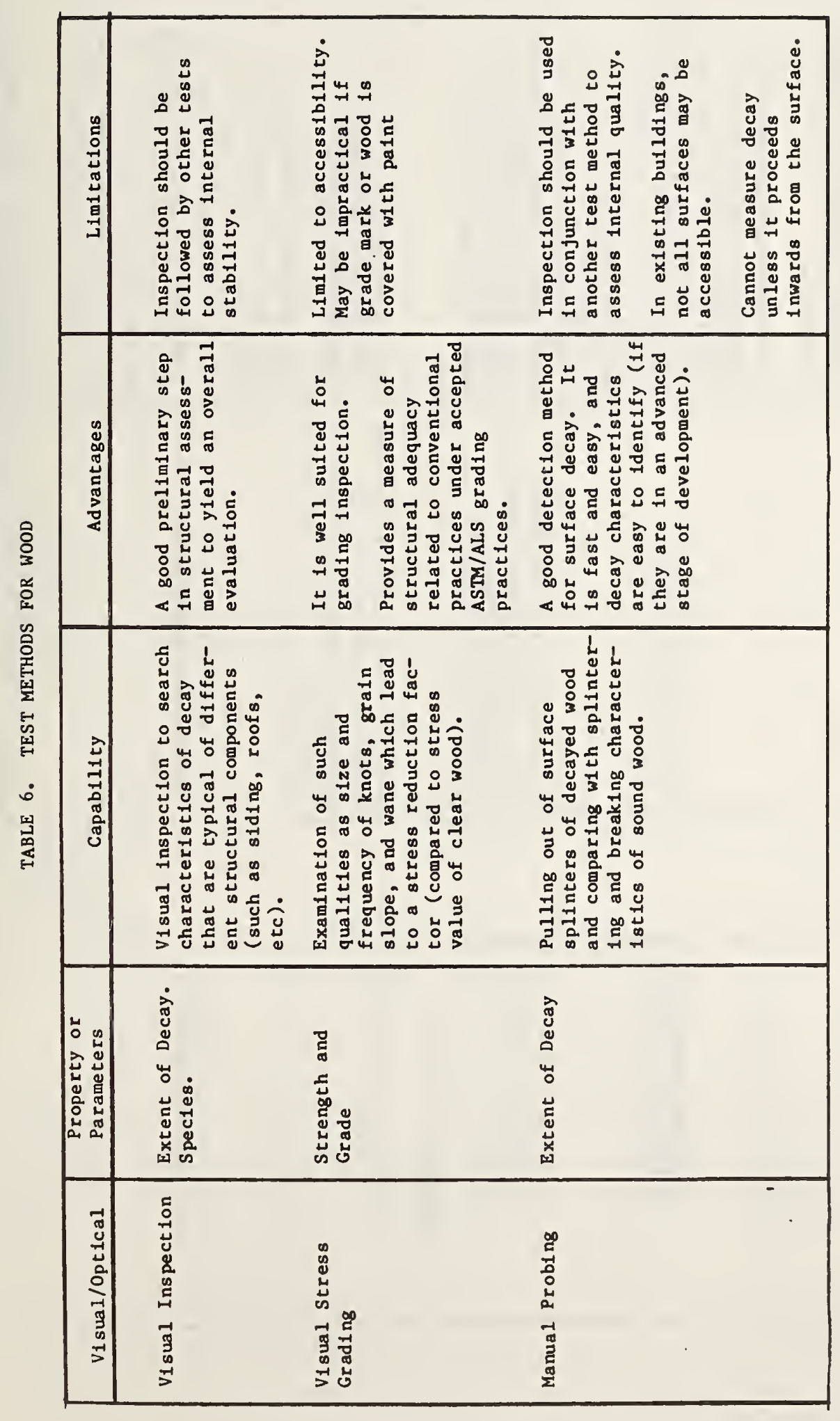




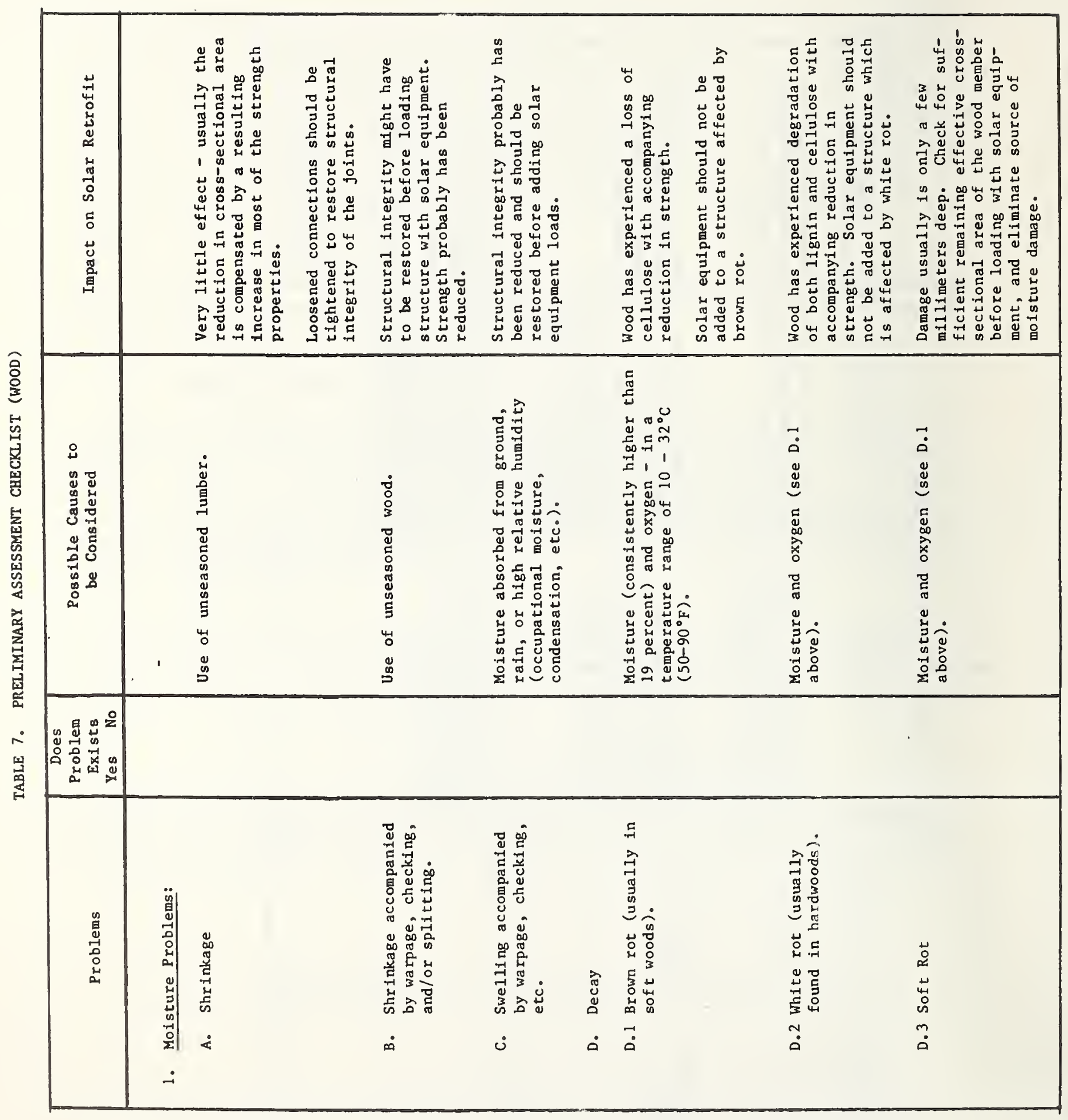




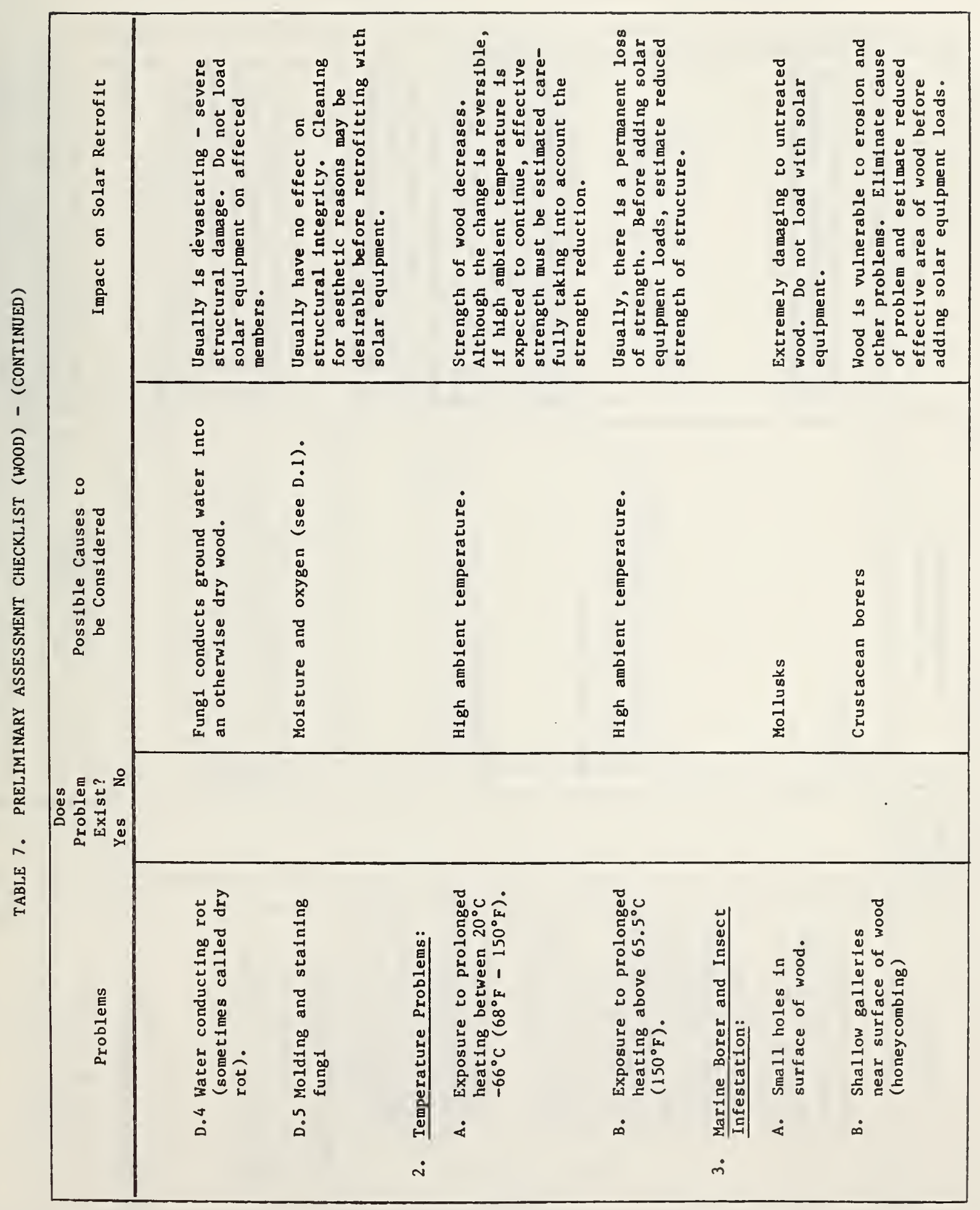




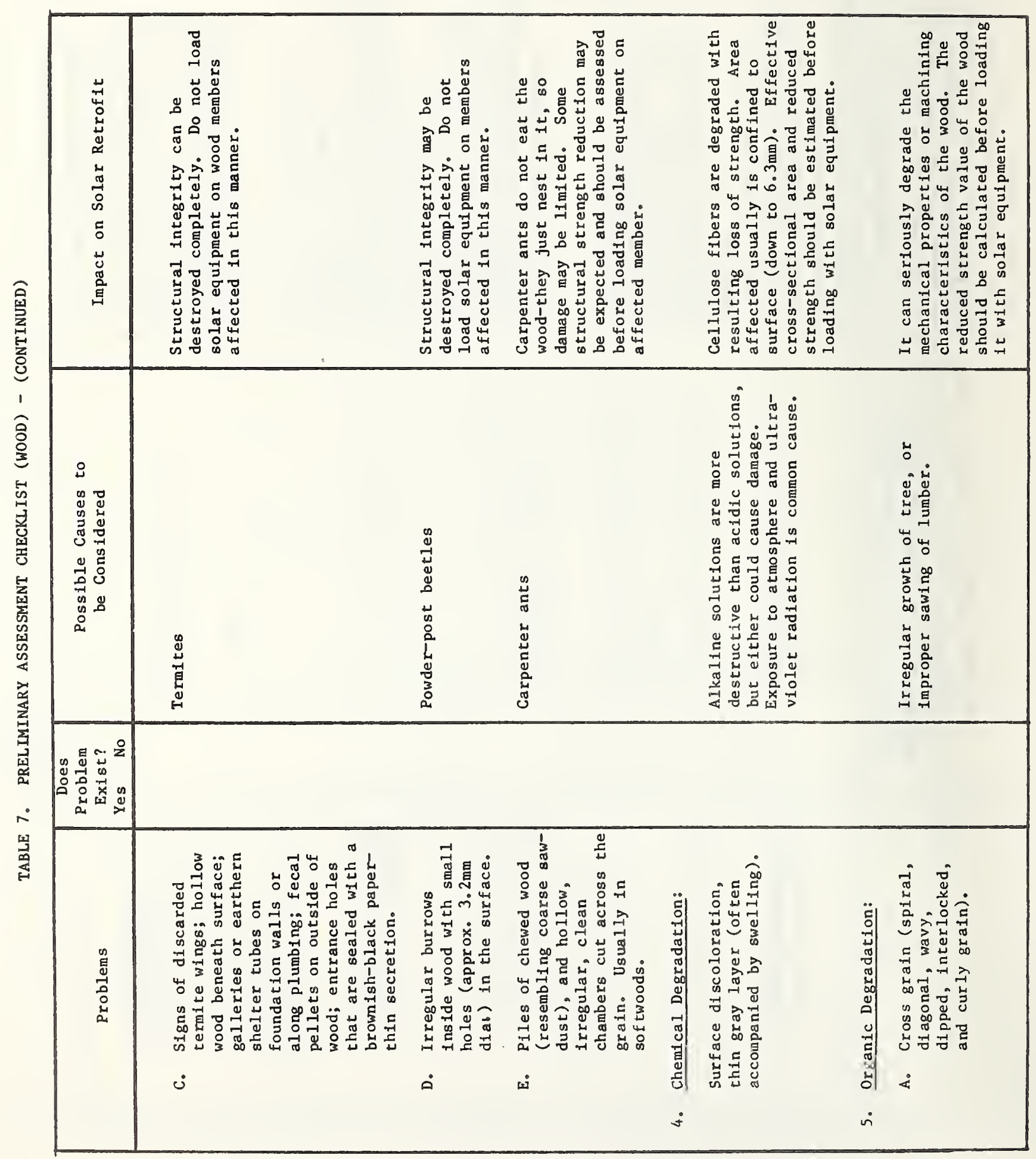




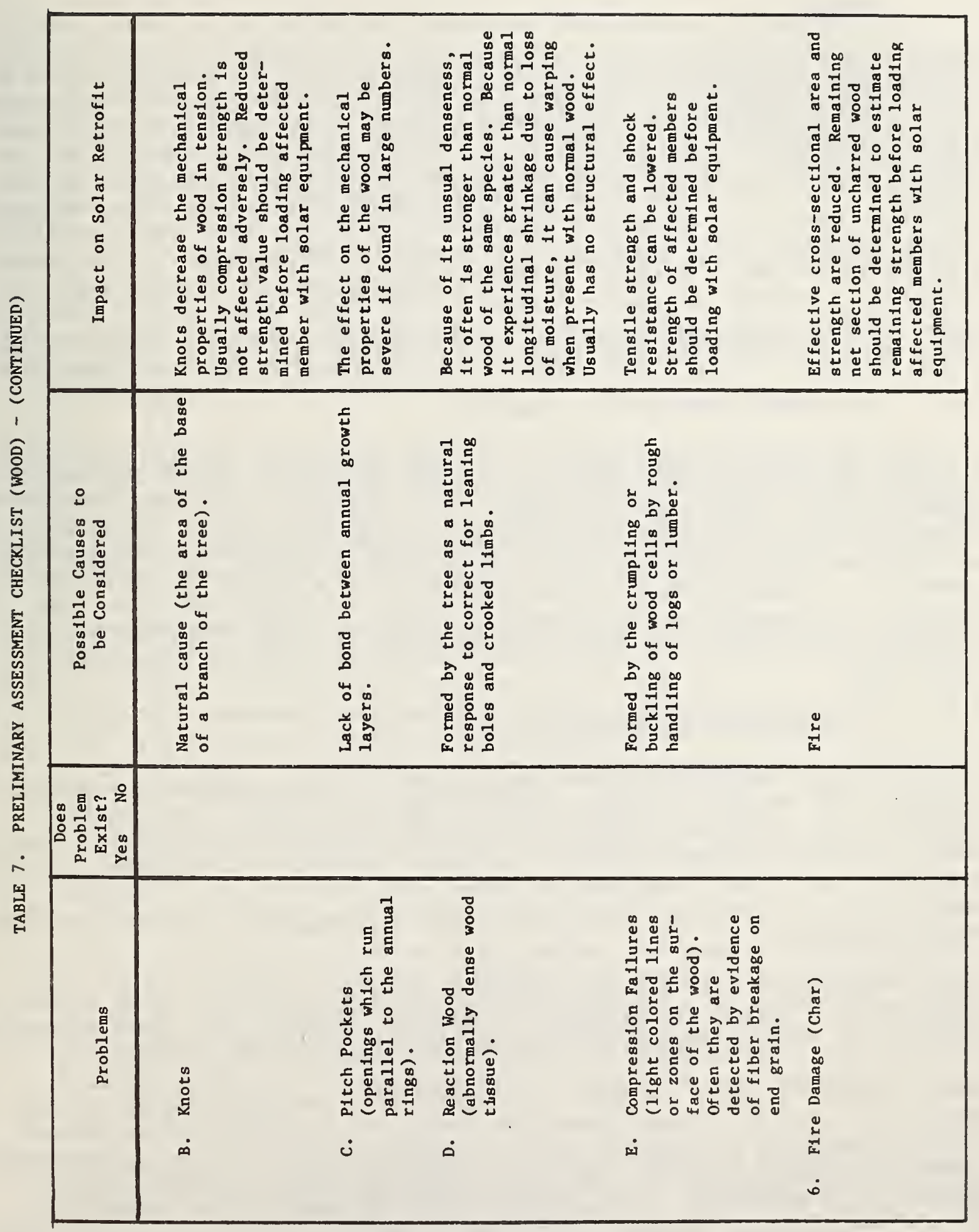




\subsection{MASONRY SYSTEMS}

\subsubsection{General}

Since many of the existing buildings being considered for solar retrofit are constructed of masonry, it becomes important to know how to evaluate the condition of the masonry and to determine whether it is capable of supporting the loads expected to be imposed by the retrofit solar equipment. This is especially true of load bearing masonry assemblages which are expected to support: (1) heavy loads (such as water storage tanks, rock beds, absorption chillers, etc.), (2) dynamic or vibrational loads from rotating or reciprocating equipment, or (3) changes in type of live loads caused by the rehabilitation of the building (e.g., change in occupancy). As used in this discussion, masonry is broadly defined to include products such as hollow and solid masonry units, gypsum masonry, glass masonry, natural building stone, adobe block, clay building bricks, concrete block, and structural clay tile.

\subsubsection{Preliminary Evaluation of Masonry}

As shown in table 8 , there are several field inspection techniques discussed in this section which can provide useful information on surface properties of masonry (flaws, discoloration, cracks, etc.), deficiencies in mortar joints, differential structural movement, dimensional characteristics, and location and uniformity of inner cell grout. More detailed assessment procedures are summarized in appendix D.3 for determining masonry properties (e.g., compressive or diagonal tensile strength, location of steel reinforcement, flexural bond strength, moisture content, modulus of elasticity, chemical resistance).

\subsubsection{Visua1/0ptica1 Inspection $[30,31,32,33]$}

Visual/optical inspection methods usually are the least expensive and most commonly used means of detecting surface flaws in masonry construction. Defects (such as surface cracks in bed mortar or at bonded interfaces, nonbonds, missing or defective mortar, erosion, corrosion, misalignment, etc.) most often can be detected with the naked eye. With the use of optical magnifiers, very small surface defects (as small as only a few microns wide) can be detected.

Visual measurement can be used to determine the size and/or warpage of masonry construction. Either a steel scale, a gauge or caliper, or a steel measuring wedge can be used to determine the size and warpage of the masonry units.

Using binoculars, focus on areas of the roof that are particularly subject to leaks (e.g., joints between converging slopes and around chimneys, exposed flashing, gutters, downspouts, etc.). Especially look for areas where mortar appears to lighten in color (an indication of patching), or where mortar appears to be crumbling. Also, scan the exterior wall of the building for any obvious signs of bulging in the brick (especially near the bottom of the wall or near openings. These bulges usually are an indication that the mortar 
has failed or (in the case of brick veneer) that the ties between the veneer and the structure of the building have deteriorated.

Inspect visually for horizontal cracks in the middle of a basement wall. If the cracks are accompanied by obvious inward bulging, this indicates excessive pressure being exerted by the soil outside the wall which could be caused by excessive ground-water pressure or by compaction from adjacent new construction work. Vertical cracks located in a corner of the basement that widen to $6.35 \mathrm{~mm}(1 / 4 \mathrm{in})$ or more at the top often are caused by a settling footing beneath the foundation. Any of these types of cracks could jeopardize the structural integrity of the entire basement wall.

During the visual/optical inspection, the following significant structural aspects should be checked or considered:

A. Check for soft and crumbling mortar in masonry foundation walls. This condition could be serious if it is associated with any signs of sag in the structure.

B. Masonry foundation cracks usually are diagonal, starting from the top, the bottom, or the end of the wall. If the cracks do not extend to at least one edge of the wal1, they probably are not caused by foundation problems. It is important to determine the cause of these problems and remedy the situation because the addition of retrofit solar equipment loads on the building could aggravate the problem further.

C. When new heavy loads are expected to be added to the existing masonry foundation, it will be necessary to check it for structural adequacy. If details of the masonry foundation design and the soil bearing value cannot be determined from existing drawings and reports of subsurface soil investigations, it may be necessary to: 1) excavate adjacent to an outside wall to determine the type of existing foundation, and 2) conduct a subsurface soil investigation (soil borings). Results from the subsurface soil investigation can be used to support the need for new foundations under heavy loads or to prove the adequacy of existing foundations.

D. A11 existing dead and live loads on the roof structure and affected masonry supporting walls should be summed to determine the accumulative existing loads and to determine whether the additional loads imposed by the retrofit solar component can be supported by the existing masonry structure. The design capacity of the affected components of the masonry structure should be checked with respect to expected snow, ice, and wind loads for the local geographical area, as well as the dead loads of the roofing materials.

E. Whenever possible, new columns or equipment supports should be placed directly over existing columns. Therefore, the interior of the building should be inspected to determine whether there are any conditions which would prevent this from being accomplished. 


\subsubsection{Hammer Test [34]}

The hammer test is an inexpensive and unsophisticated method of estimating the condition of a masonry unit or assemblage by the sound that it produces when tapped lightly with a hammer. Although the results are questioned by many evaluators, some very experienced people (who have a keen sense of hearing and touch) claim to have the ability to determine the structural soundness of masonry units and mortar and to determine whether the cells of the units are filled, by the use of this test method. Experience and credibility on the part of the evaluator is required, however, before any degree of reliance should be placed on the interpretation of the results. Even then, it may be desirable to use test borings to confirm the findings.

\subsubsection{Probing [34]}

The location and uniformity of the inner cell grout and wall thickness of a masonry unit or assemblage can be determined by penetrating the area of investigation with a small masonry drill bit and probing the hole with a stiff wire. Small holes may be patched easily leaving only minor surface damage.

Probe the mortar joints with an awl or ice pick to determine whether it is soft and sandy or falls out easily.

\section{5 .2 .4 Ink Test [35]}

Using permanent blue-black fountain pen ink, it is possible to estimate the imperviousness and opacity of ceramic glazed facing tile, brick, and solid masonry units. To test for imperviousness, the ink is applied to the glazed surface of 5 dry specimens for 5 minutes. The surface then is washed and examined for stain of the finish. Opacity may be determined by applying the ink along a $50 \mathrm{~mm}$ ( $2 \mathrm{in}$ ) length of the edge of the finished surface. After 5 minutes, the finish is examined visually for opacity. ASTM C 126 describes these two tests in greater detail.

\subsubsection{Problems Affecting Masonry Components}

Some of the most common problems affecting the strength of masonry units or assemblages used in building construction are as follows:

\section{A. Cracking $[31,33]$}

Cracking usually is not an indication that a building is becoming structurally unsafe. It is normal therefore to find some cracking in the masonry of almost every building. In fact, it is very rare for a building to collapse soon after the appearance of even large cracks.

Cracks usually result from forces being applied to the building which are greater than the loads for which the building was designed. These loads may include: 
1. Overloading due to excessive external forces such as snow, wind, etc.; or internal forces such as heavy equipment loads, change in occupancy loads, etc.

2. Forces induced by temperature changes causing differential movement of the building materials.

3. Ground movement (subsidence, slippage, shrinkage, or quakes) causing part of the building to become displaced from the rest of the building.

4. Changes in moisture content of the masonry materials. This can lead to chemical reactions (such as corrosion of the reinforcement or sulphate attack on Portland cement) or volume changes (swelling or shrinkage).

5. Atmospheric pollution such as carbon dioxide attack which causes carbonation of Portland cement and subsequent shrinkage.

\section{B. Spalling}

As used in this report, spalling is a chipping or scaling of the surface of masonry similar to the same effect in concrete. Often, it is caused by vibrational, impact, or shock loads.

\section{Deterioration}

Deterioration is described in this report as a break-down or disintegration of the material properties of masonry. A typical example is the softening (or crumbling away) of the matrix in the brick or mortar due to chemical attack.

\section{Moisture}

Moisture can be a problem in itself (causing swelling or shrinkage of the masonry), or it can be the cause of other problems previously mentioned (cracking, spalling, or deterioration).

All of these problems can have a serious detrimental effect on the structural integrity of the masonry units or assemblages and should be investigated thoroughly to determine whether they significantly limit the addition of the proposed solar retrofit equipment.

\subsubsection{Masonry Problems and Potential Impact on Solar Retrofit}

A checklist (table 9) can be used to assist in determining what problems exist in a masonry structure and to make a preliminary determination of the impact that the problem may have on the solar retrofit. If it is determined that a more complete understanding of the nature or cause of the problem is necessary, further reference is given in the table to a more detailed description in appendix D. 3. 


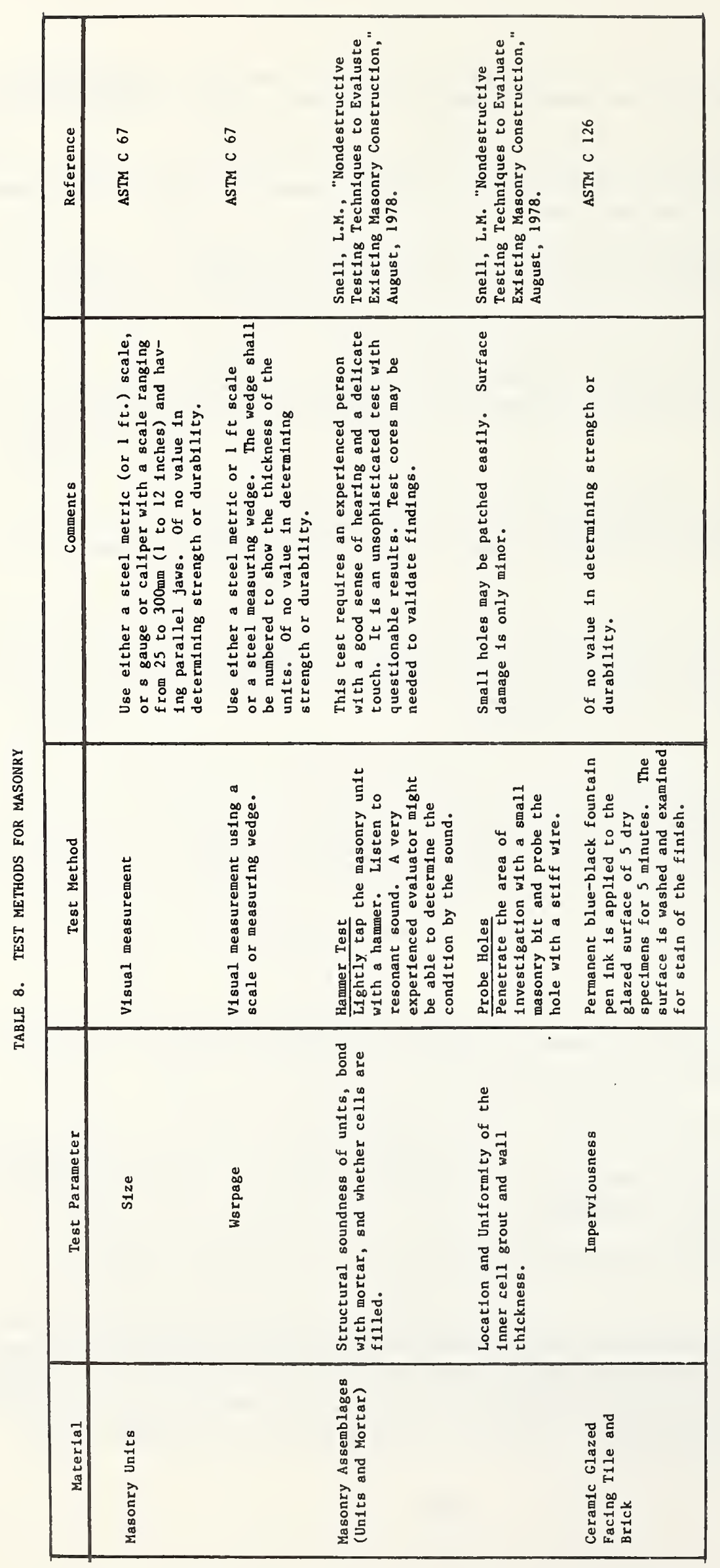




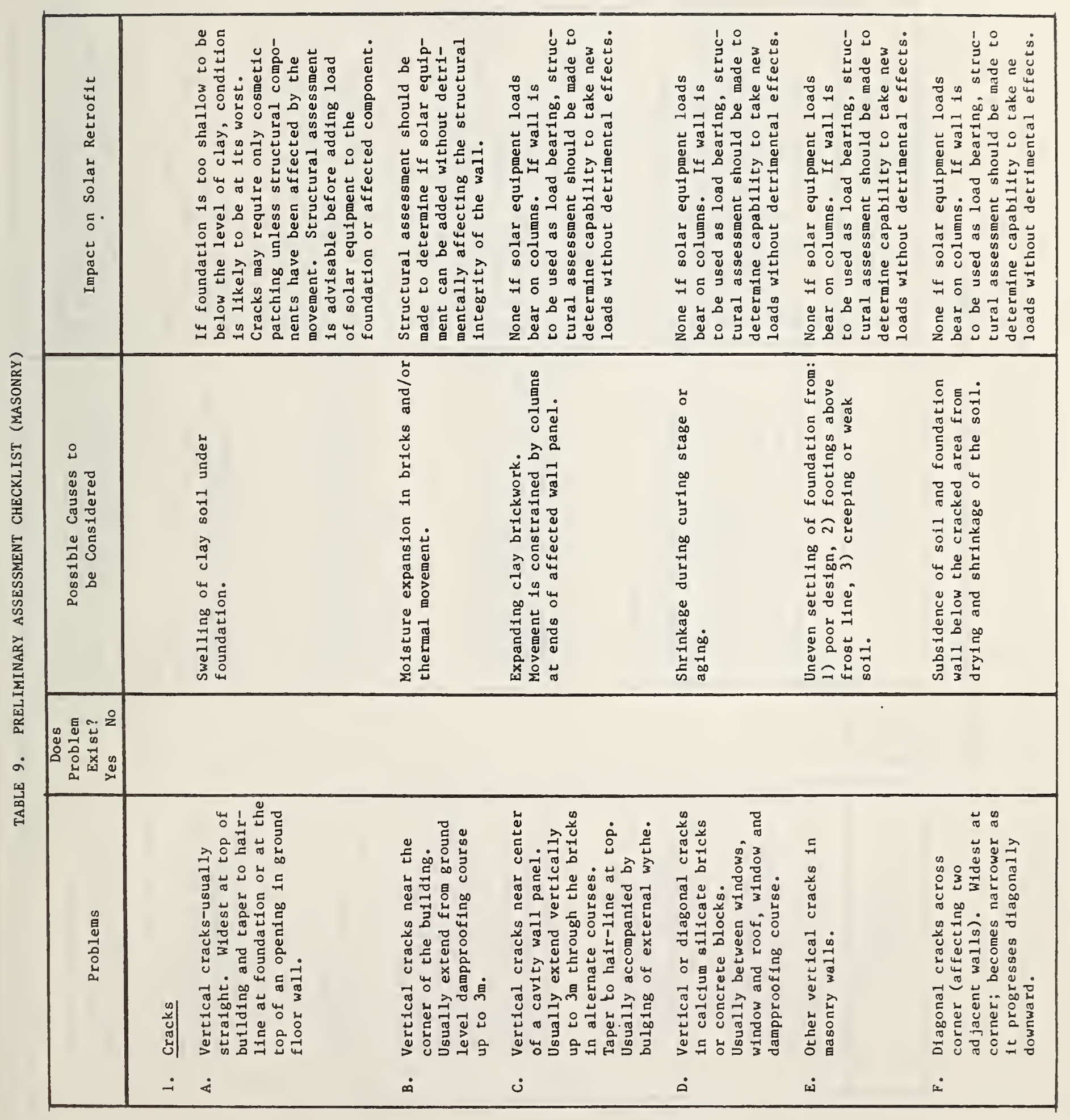




\begin{tabular}{|c|c|c|c|c|c|c|}
\hline 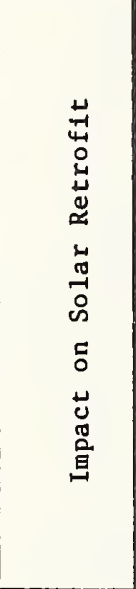 & 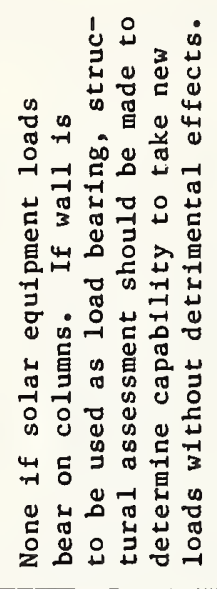 & 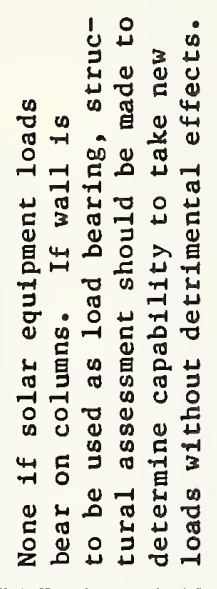 & 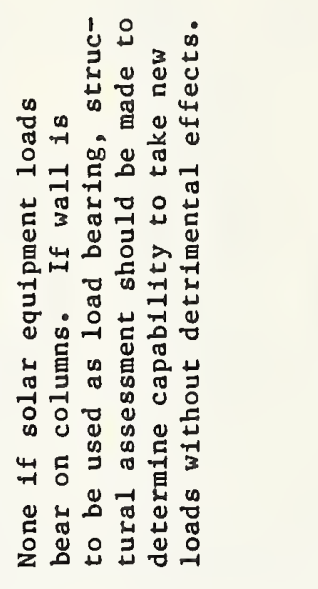 & 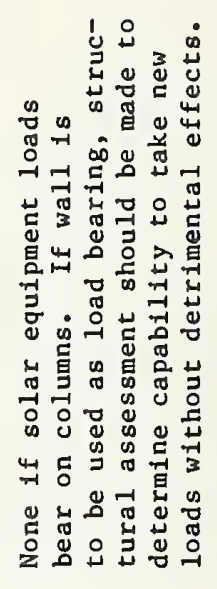 & 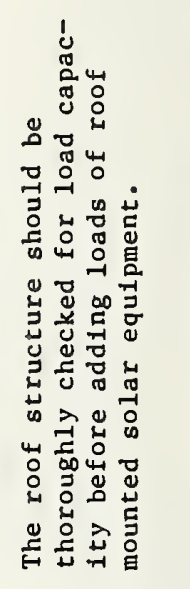 & 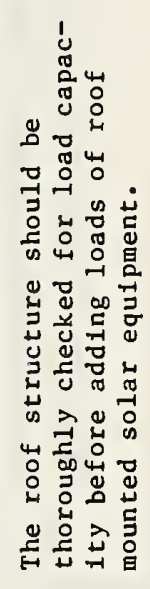 \\
\hline 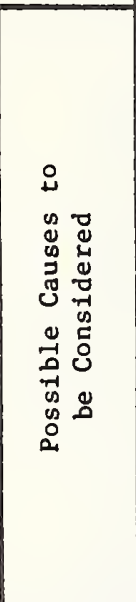 & 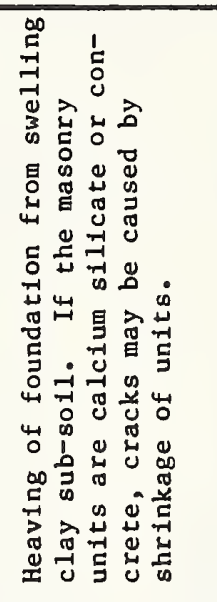 & 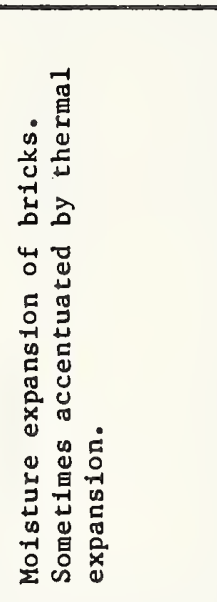 & 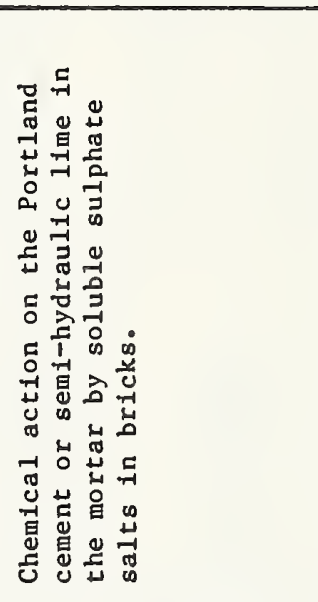 & 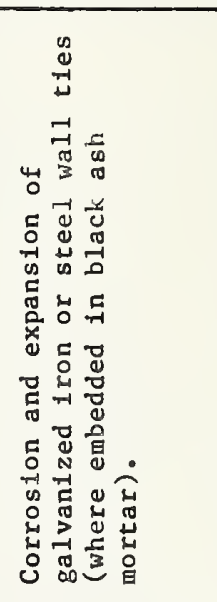 & 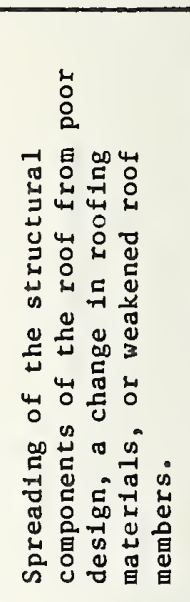 & 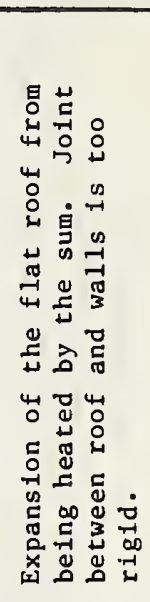 \\
\hline 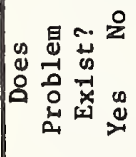 & & & & & & \\
\hline 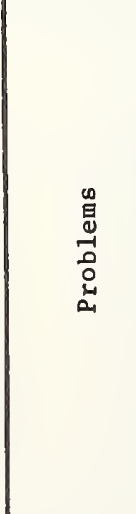 & 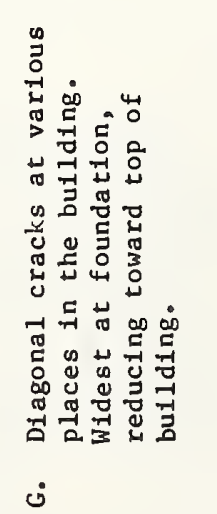 & 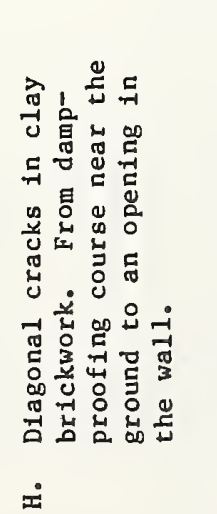 & 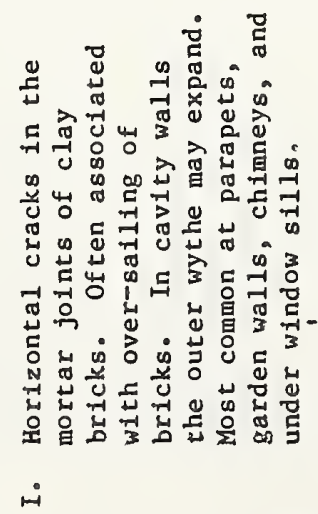 & 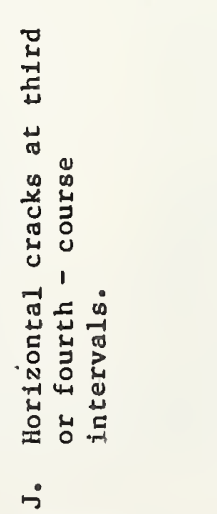 & 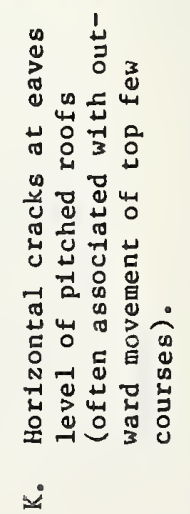 & 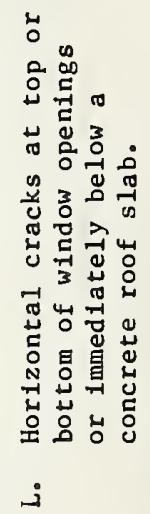 \\
\hline
\end{tabular}




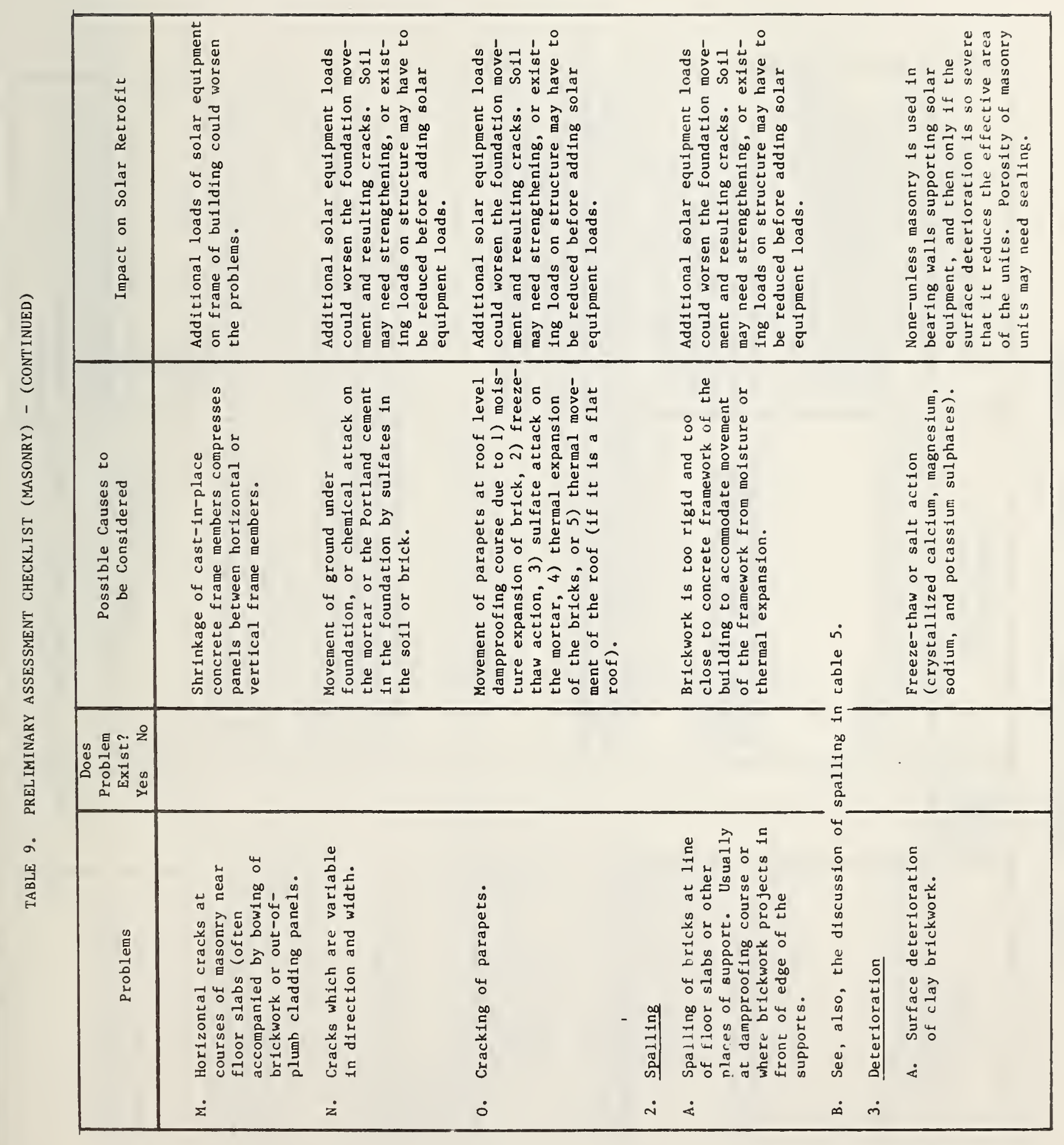




\begin{tabular}{|c|c|c|c|c|c|c|c|}
\hline 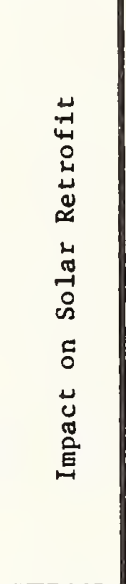 & 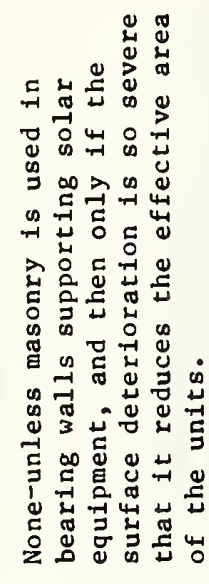 & 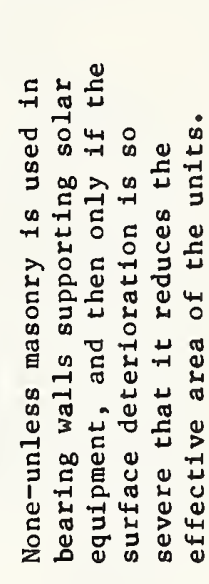 & 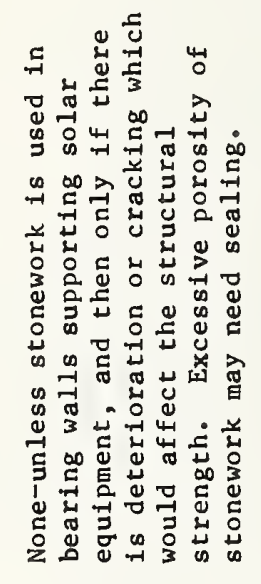 & & 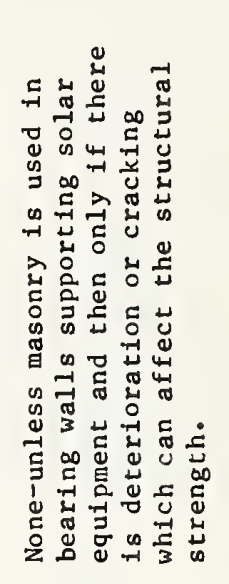 & 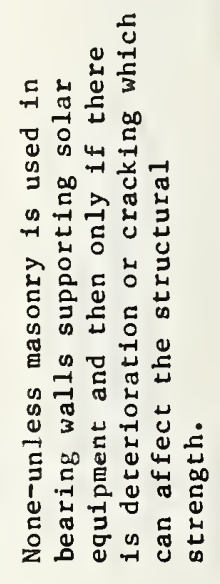 & 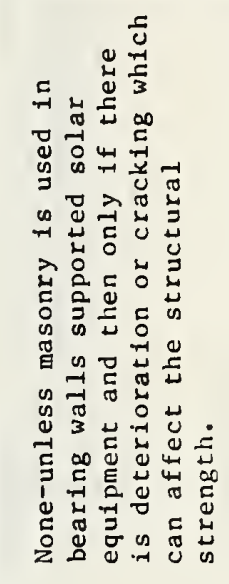 \\
\hline 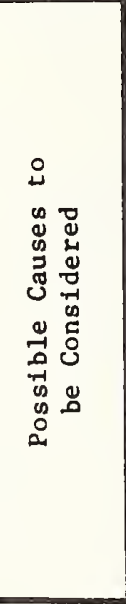 & 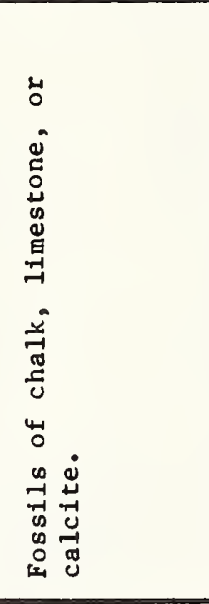 & 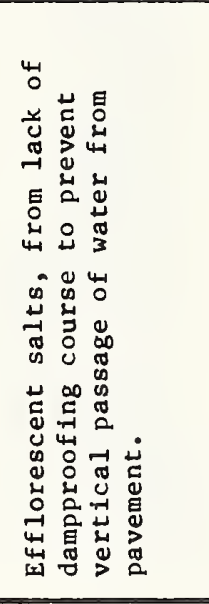 & 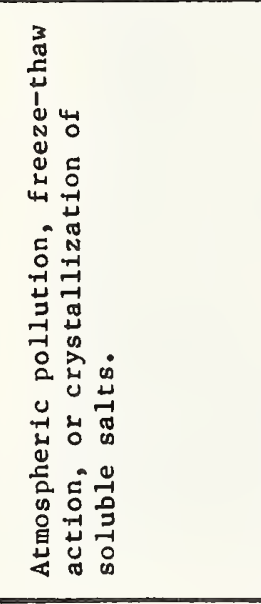 & 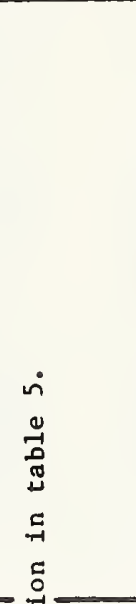 & 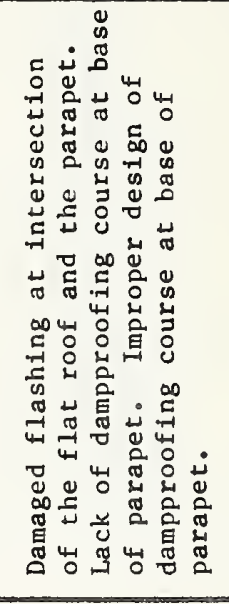 & 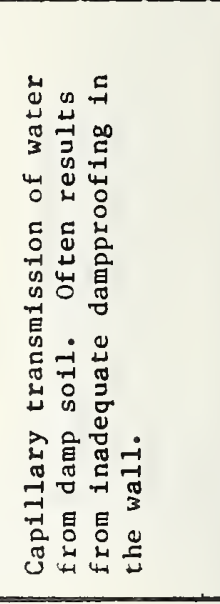 & 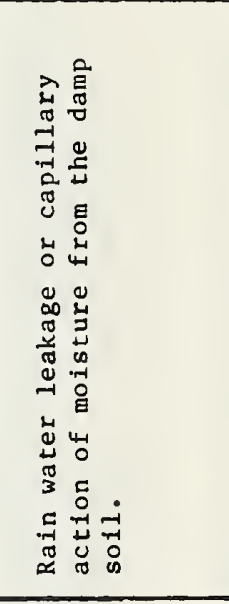 \\
\hline 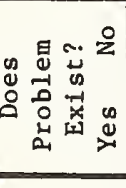 & & & & 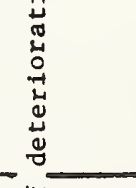 & & & \\
\hline 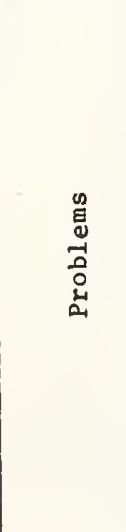 & 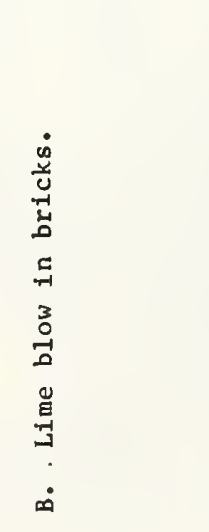 & 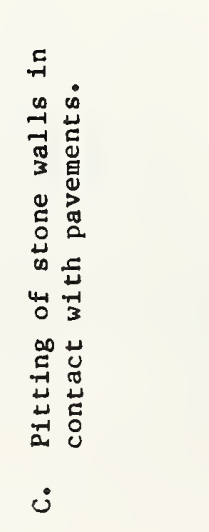 & 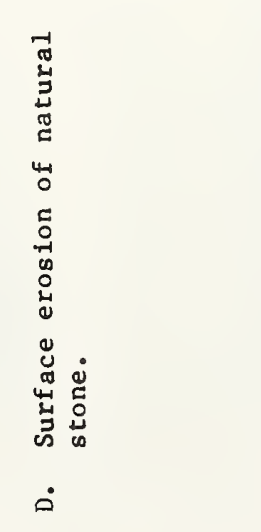 & 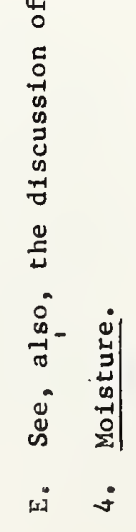 & 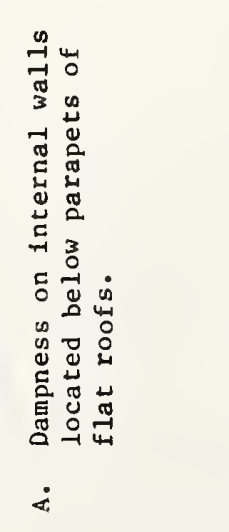 & 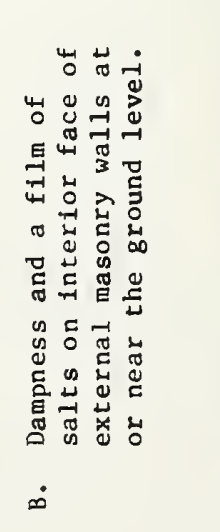 & 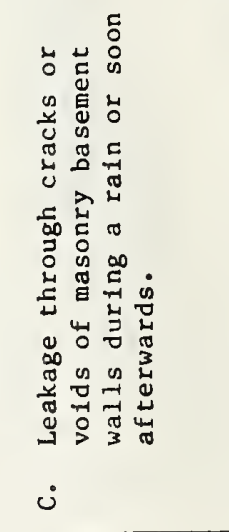 \\
\hline
\end{tabular}




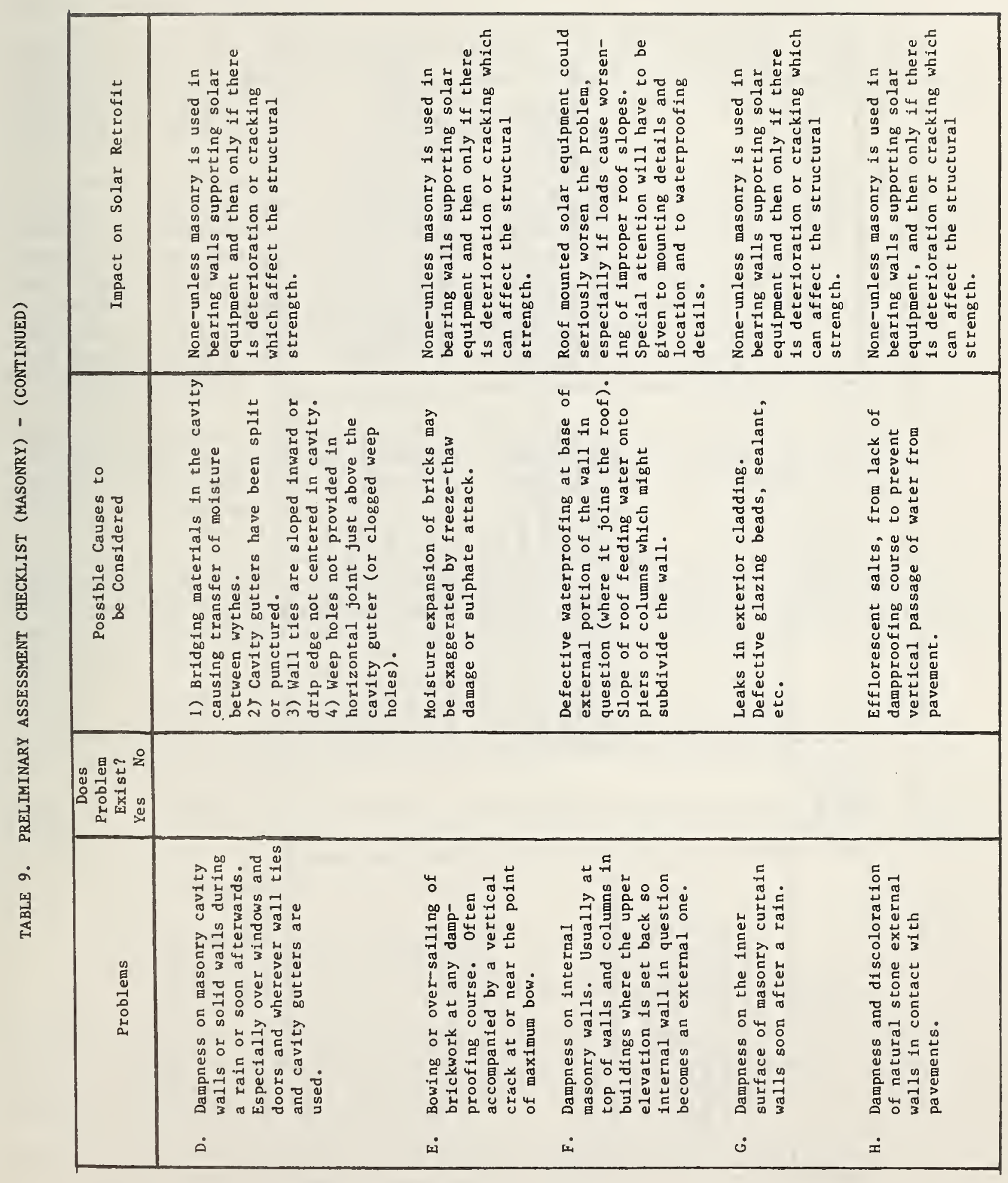




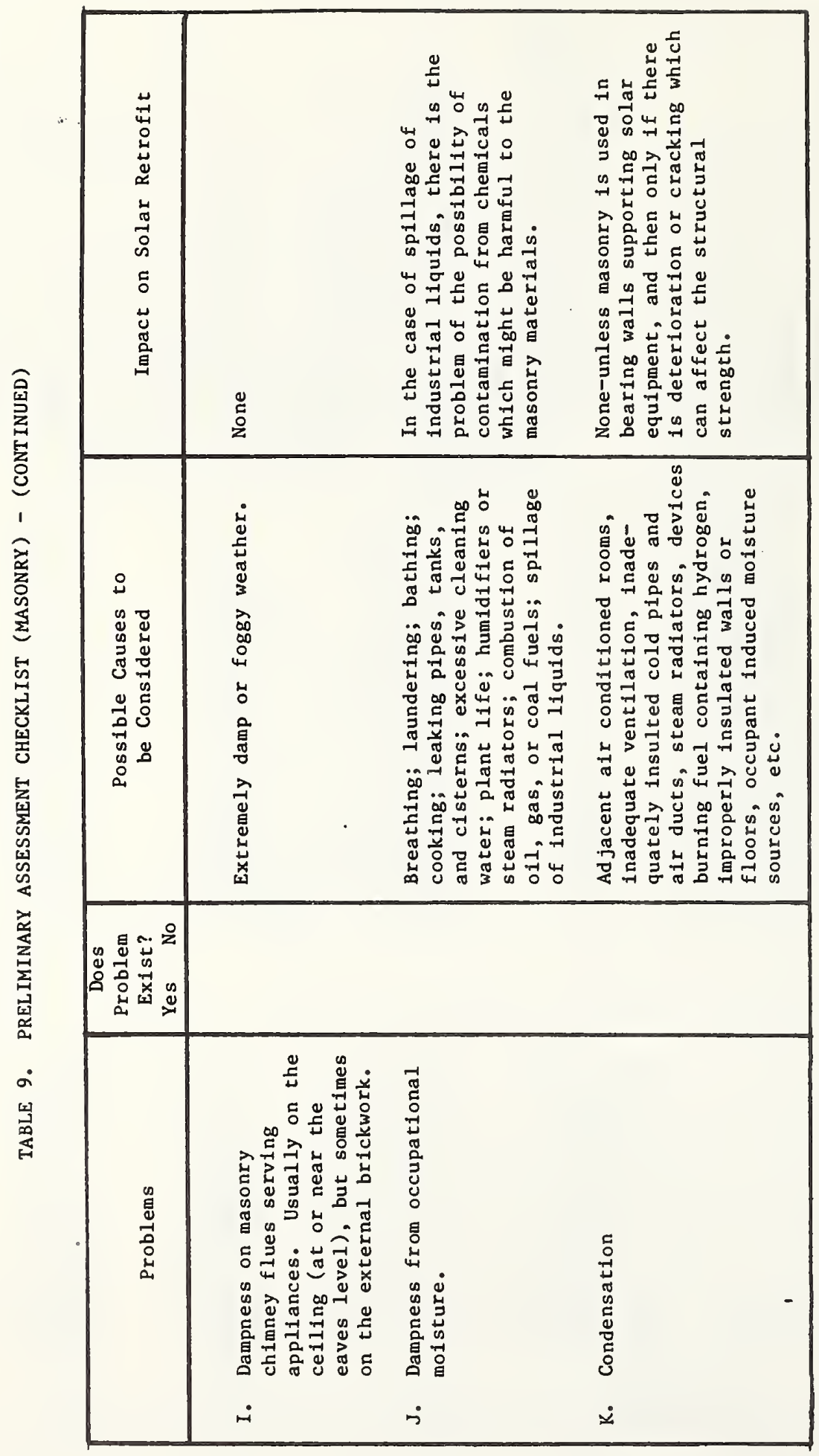




\subsection{METAL SYSTEMS}

3.6.1 General $[36,37]$

Flaws in the steel structure of a building are not as subject to fatigue (from cyclic vibrations, etc.) as flaws in other structures (such as bridges). Therefore, it may not be critical to evaluate them in relation to their ability to support new solar equipment loads.

If, however, it has been determined that a structural component (weldment, splice plate, etc.) is suspected of degrading the structural integrity of the building, nondestructive evaluation methods can be extremely useful. As a result of improved techniques, these test methods are becoming increasingly more important for evaluating the metal structure of buildings. It is important, to evaluate other flaws than cracking. Corrosion, voids, pits, fabrication discontinuities, and porosity can affect structural integrity and the ability of the existing structural system to support new solar retrofit equipment.

Most nondestructive test methods offer more than a superficial examination of the surface conditions of metals. Such tests may reveal properties, quality, and dimensions of both the surface and internal regions of many metal test specimens.

Although most of the test methods for metals mentioned in this report will be used primarily for structural steel, many are applicable to other types of ornamental and structural metals (e.g•, cast-iron, aluminum, etc.) as indicated in the summary tables in this section and in section D.4 (detailed evaluation methods).

Usually, the most important factors of structural steel to determine are: 1) dimension, 2) type of steel, and 3) the age of the steel in order to determine its strength.

Factors to consider in selecting an appropriate nondestructive test of metals are:

1) What is the material to be tested?

a. Is it magnetic or nonmagnetic?

b. Is it electrically conductive?

c. Does the metal have a nonconductive or nonmagnetic coating?

An easy method to determine whether a structural member is made of wrought iron or steel is to apply dilute nitric acid to a clear section. If the member is made of steel, the test section will turn black; whereas, the wrought iron will not be affected.

2) How was the metal fabricated (cast, wrought, powder metallurgy, welded, soldered, etc.)? 
3) What is the geometry of the component (dimensions, shape, surface irregularities etc.)?

4) What types of defects are possible or expected in this type of metal?

5) What degree of sensitivity and resolution is required from the test equipment?

6) What are the equipment, testing, and materials costs?

7) How accessible is the component (e.g•, behind a wall; concealed by ductwork, etc.)?

There are several on-site testing methods which can be used during the preliminary evaluation stage (figure 1). These can provide useful information concerning surface defects (cracks, voids, fabricating discontinuities, pits, poor bonding, porosity, laps, seams, and other irregularities). Some of the most commonly used are included in the following table. Other methods which are part of the detailed evaluation stage, are summarized in appendix D.4 and can be used to assist in determining additional properties.

\subsubsection{Preliminary Evaluation of Metal Systems}

Several preliminary evaluation procedures exist to determine the surface properties of metal structural components. It should be realized, however, that these test methods have limited application in that they do not provide information on the internal physical condition of the metal structural member. In order to obtain an estimate of the internal condition and the strength of the metal, the more complex test methods described in appendix D. 4 will have to be used.

As with the other structural materials, the most important areas to investigate are the areas of high shear and low moment. It is at these stress points where the defects and structural failures are most likely to occur. Therefore, the investigator should concentrate on inspection of these particular areas of concern.

\subsubsection{Visual Inspection}

Visual inspection is the least expensive and most commonly used means of detecting surface flaws in metal construction. Surface flaws (such as cracks, voids, fabricating discontinuities, pits, poor bonding, porosity, laps, seams, etc.) usually can be detected using simple visual inspection techniques.

During the visual inspection, certain instruments (such as borescopes, fiber optical equipment, panoramic cameras, etc.) can be used to examine areas of the metal which are inaccessible to the naked eye. Simple magnifiers can be used to detect flaws which are too small to be seen by the naked eye. During this inspection, the following significant structural aspects should be checked or considered: 
A. If the existing roof is composed of a steel deck on steel joists, and new heavy concentrated dead loads are to be imposed on the deck by solar equipment, the joists must be designed for twice the static operating weight of the equipment. Also, there must be enough room to reinforce the top chords of the joists for any new concentrated loads which may be applied between panel points. Since any new concentrated loads which must be applied to the bottom chords will have to occur at panel points, access to these points is essential. Existing joists should be checked to be sure they can support newly imposed loads wthout exceeding a maximum deflection of $1 / 360$ times the span.

B. Wherever possible, new columns or equipment supports should be placed directly over existing columns. Therefore, the interior of the building should be inspected to determine whether there are any conditions which would prevent this from being accomplished.

C. All existing dead and live loads on the metal roof structure should be summed to determine the accumulative existing loads and to determine whether the additional loads imposed by the retrofit solar components can be supported by the existing metal structure. The design capacity of the affected components of the metal structure should be checked with respect to expected snow, ice, and wind loads for the local geographical area, as well as the dead loads of the roofing materials.

3.6.3 Table No. 10 has been developed to assist the evaluator during the visual inspection to determine the possible causes of problems encountered and to realize the impact that they may have on the proposed solar retrofit. 


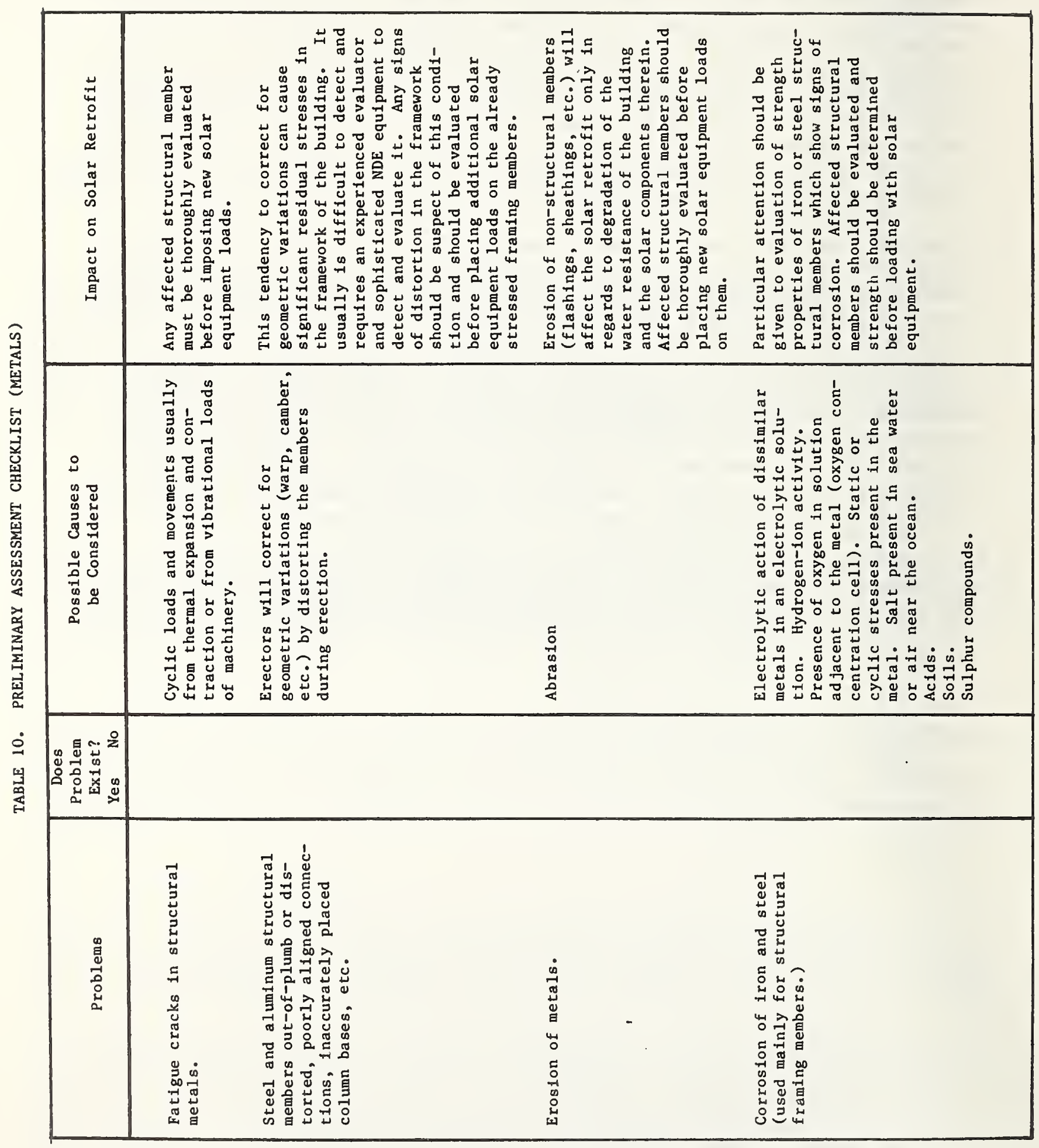




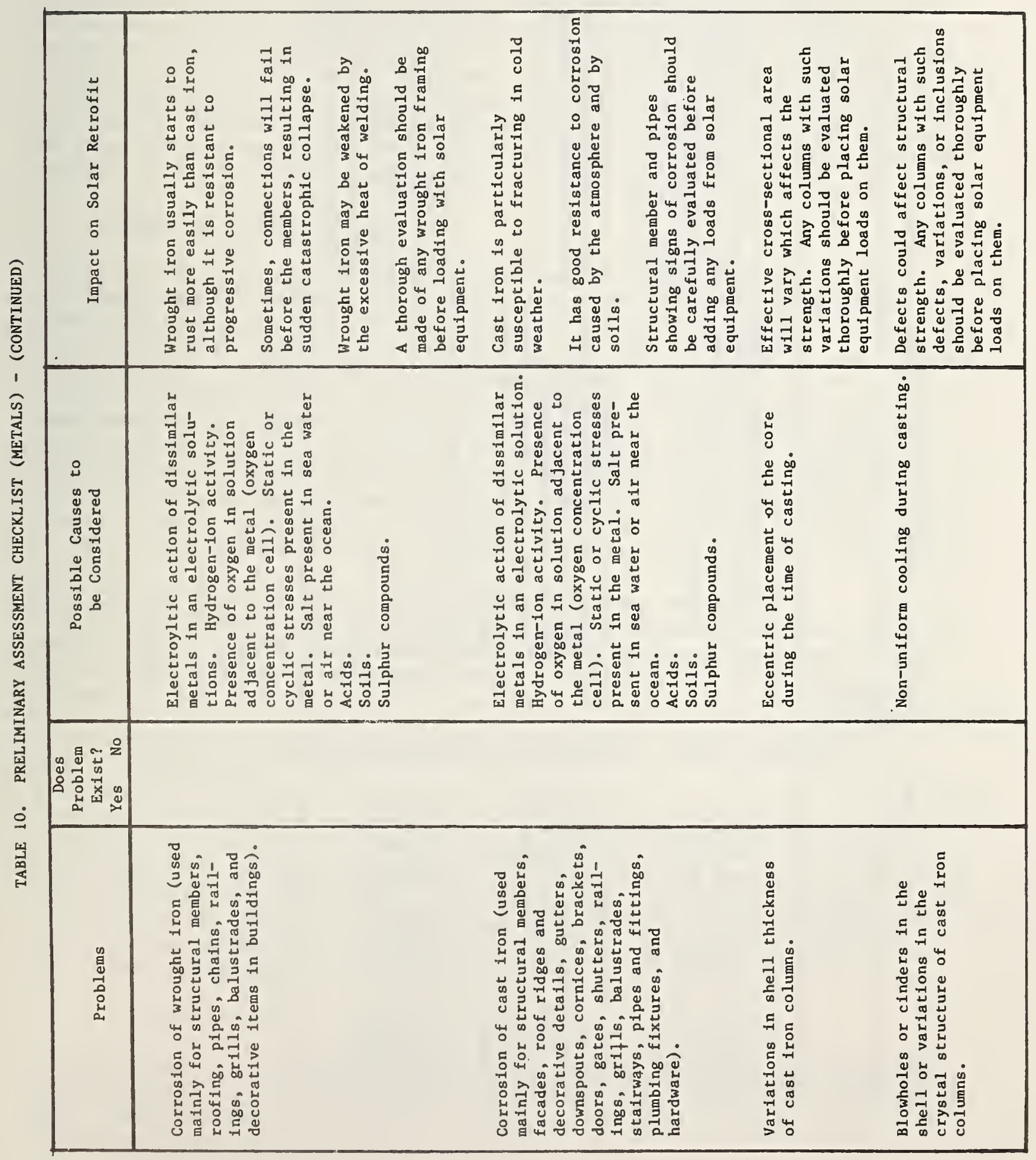




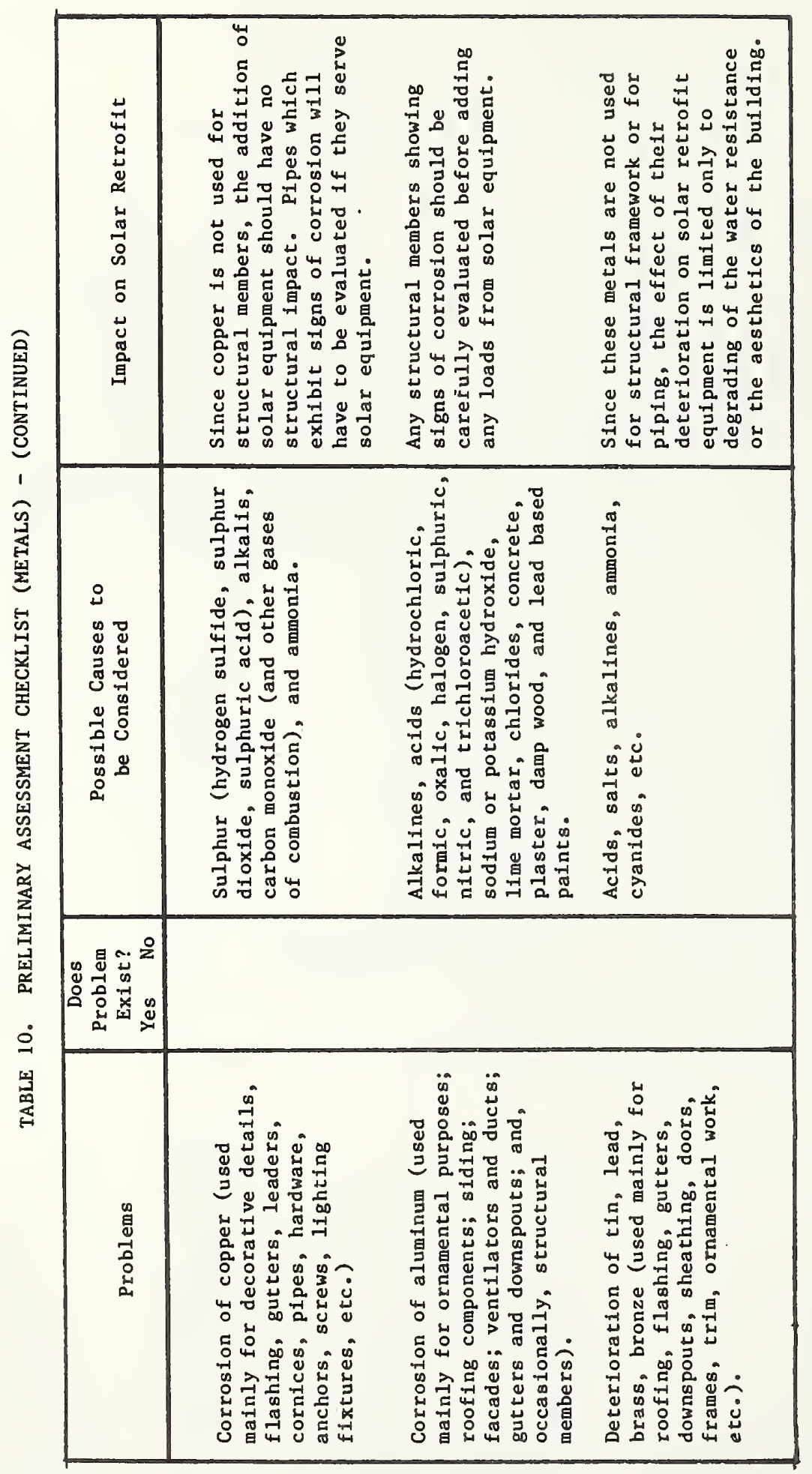


4. GUIDELINES FOR HEATING, VENTILATING AND AIR CONDITIONING (HVAC) SYSTEMS

This section provides methods for evaluating existing building HVAC systems being considered for solar retrofit. These methods are intended for use in a feasibility study to help determine whether the existing HVAC systems are suitable for solar retrofit. The data and information obtained will be valuable also for the final design of the proposed retrofit solar and HVAC system. This evaluation is developed in two stages: (1) preliminary information derived from reasonably unsophisticated procedures, and (2) secondary information derived from more detailed or sophisticated procedures. This section covers the preliminary evaluation only. The secondary or detailed evaluation is contained in appendix D.5.

\subsection{GENERAL CONSIDERATIONS}

Some solar energy systems can be retrofitted into existing buildings to supplement energy demands for space heating, space cooling, and ventilation preheating. In general, the temperature levels in solar energy systems are lower than those commonly found in fossil fuel HVAC equipment. Also temperatures tend to fluctuate as the availability of solar energy varies. Consequently, greater care is needed in evaluating existing systems and in designing a solar system for an existing building. For example, properly oriented space will be required on the roof for solar collectors. Additional (or replacement) heat exchangers, pumps and blowers will be needed also, together with appropriate heat storage equipment, piping, ducting, and controls. Unless the existing HVAC equipment is in good condition, of suitable capacity, and adapted to solar retrofit, a solar system may not be feasible.

This section does not cover the solar design, but concentrates on methods for evaluating the existing HVAC systems and equipment. The evaluation will be based on information obtained from building system records, examination of the HVAC equipment, and measurement of system performance. Forms for collecting data are included in appendix $\mathrm{A}$, and were discussed in section 2.1 .

\subsection{PRELIMINARY ON-SITE INVESTIGATION GUIDELINES - HVAC SYSTEMS}

The on-site investigation of an HVAC system consists of a general examination of the entire HVAC system as well as the individual HVAC components (air handlers, ductwork, etc.). While the emphasis should be on the HVAC components which may be affected by the solar retrofit, the entire system becomes involved where additional HVAC loads or modifications are anticipated or where load reductions occur as a result of energy conservation measures taken. The following general inspection guidelines will be useful in making the preliminary assessment.

\subsubsection{Utility Bills}

Energy consumption of a building can be determined from the utility payment records of the past several years. This history of energy usage will establish a base line for a life-cycle analysis. Figure 3 provides a format for recording annual energy consumption. 
FIGURE 3 [7]

HISTORIC ENERGY CONSUMPTION RECORD

For Year 19 , Annual Degree-Day

\begin{tabular}{lll} 
Electricity & $\frac{\text { Natural }}{\text { Gas }}$ & Fuel 0il \\
\hline (Kw) (\$) & $\frac{\text { (Therms) }(\$)}{\text { (Gallons) (\$) }}$
\end{tabular}

Jan

Feb

March

Apri1

May

June

July

Aug

Sept

Oct

Nov

Dec

Tota I

(Use separate sheets if different components of the HVAC system are metered separately. This helps to estimate the loads on each components). 


\subsubsection{Operating and Maintenance Records}

Operating and maintenance records covering the HVAC equipment will provide information such as: (1) equipment repair and replacement costs, (2) number of times the equipment was out of service, (3) frequency and nature of user complaints, and (4) changes in the functional use of building space. For example, complaints from occupants may provide clues concerning inadequate ventilation or uncomfortable temperatures, which may indicate inefficient system performance or demands which have outgrown the capacity of existing equipment. Repeated repairs or frequent replacement of equipment may indicate that the existing system is not worth retrofitting. A consulting engineer can help the building facilities engineer to interprete the operating and maintenance records.

\subsubsection{Visual Inspection of HVAC System}

Visual inspection of the HVAC system is essential where the original construction drawings and specifications are either no longer available, or if available, the HVAC system has been significantly modified or enlarged. Such an inspection may reveal that solar retrofit should not be considered because the existing system is obsolete, inadequate for the present load, or is not economically feasible with present equipment or fuels. Moreover, an existing HVAC system which is approaching or has exceeded its expected service life is generally not a candidate for solar retrofit. It may, however, be a good candidate for solar replacement.

\subsubsection{Visual Inspection of HVAC Equipment}

In evaluating the HVAC equipment, it is important to obtain as much data as possible. The nameplate data for each piece of equipment, including pumps, blowers, air handlers, terminal units, compressors, etc., should be recorded, and each piece of equipment should be evaluated with regard to age, condition and potential performance output. Even though some of the equipment is old or out of production, local dealers, the original manufacturer, or professional engineers within established local HVAC engineering firms may be able to provide an assessment of such equipment.

Figure 4 provides a form which will assist in conducting a visual inspection of the HVAC system and its existing equipment. Some specific matters which need to be covered include: [38]

1. Determine whether the heating plant was originally designed to burn coal. If it was, then it probably is more than 30 years old and may be a good candidate for replacement.

2. Test the heating system. Even on a hot day, it can be tested by moving the thermostat above room temperature. Heat from a hot-air furnace should appear at registers within a few minutes. In a steam or hot-water system, radiators should heat up in 15-20 minutes. 
FIGURE 4. EXISTING HVAC DESIGN IDENTIFICATION [7]

\section{Identification}

Residential

Non-Residential

Forced Air System

Radiant System

Water

St eam

Electric

Natural Convection

Steam

Hydronic

Electric

Unitary

Number of Control

Zones

Terminal Units

Constant Air Volume

(CAV)

Variable Air Volume

(VAV)

Fan Coil

Induction Terminal

Perimeter Baseboard

Distribution Systems

Al1 Air Systems

CAV

VAV

Single Path

Dual Path

Multizone

Air and Water Systems

Two Pipe

Three Pipe

Four Pipe

All Water Systems

Two Pipe

Three Pipe

Four Pipe

Heat Pump Systems

Air to Air

Water to Air

Water to Water
Estimated Air \&

Water Temperature Range
Btu

Estimated Output

Equipment Age Range 
3. Determine or estimate the capacity and condition of the domestic hot water heater.

4. Look for signs of leaks or rust spots around and on the bottom of the hot-water heating tank, especially where a gas flame impinges.

5. On steam or hot water heating systems, examine floor around radiators and convectors for signs of stain or rot from water leaks.

\subsubsection{Space Considerations for HVAC Equipment}

During the inspection tours in the existing mechanical rooms, note and record all available space for potential future installation of solar heating and replacement equipment. Photographs should be taken of the area available for the use of a prospective solar designer.

Appendix D.5.2.9 provides schematic drawings of typical solar heating systems. These should be examined to determine whether overall space is available or can be provided for such systems. In particular, space will be required for heat storage units, pumps, air handlers, and heat exchangers. The building facilities engineer should be able to provide the prospective system designer with photographs and dimensional sketches so that a decision can be reached concerning the availability of space for a particular retrofit.

In addition, where existing equipment may need to be replaced, consideration must be given to such required space. For example, if new heat exchangers are anticipated, the facilities engineer must check the adequacy of the existing space to accommodate them. A U-tube heat exchange may be required for some spaces (rather than a straight-tube type) if access is limited to only one side for cleaning or replacing the tubes.

\subsubsection{Furnace/Boilers/Heating Systems [38, 39, 40, 41]}

The current trend toward energy conservation and subsequent reduction in heating loads in buildings has had an effect on the efficiencies of furnaces and boilers. Older units tend to be oversized and often yield lower efficiencies. In such cases, a replacement may be desirable. Before such a decision is made, several actions should be taken to evaluate the efficiency of the existing heating components. The combustion system should be cleaned carefully and checked for leaks. The air should be allowed to enter the combustion chamber at controlled rates. The oil nozzle size may need to be reduced or the gas burner may need to be replaced if the system is to accommodate a replacement.

The required air-fuel ratio should be determined for the existing or replacement system, and adjusted for proper combustion. The $\mathrm{O}_{2}$ and $\mathrm{CO}_{2}$ content may be determined with an Orsat apparatus or with other flue gas analyzers such as the nondispersive infrared spectrometer for carbon dioxide, or by utilizing oxygen-specific electrodes to determine oxygen. These, coupled with the stack temperature readings, will provide data for determining 
the system combustion efficiency. The final decision on system replacement generally is made on the annual operating savings that can be expected as a result of purchasing and installing a new system.

The above procedure provides only steady-state information, whereas in reality, most systems operate far from steady-state. Nevertheless, a combustion performance test should be undertaken whenever major retrofits of a building are planned in order to obtain hands-on operating experience and an immediate sense of condition of the furnace or boiler and other components of the HVAC system. The person carrying out this condition assessment should be technically experienced so that any decision made for replacement of furnace, boiler, or components is based on qualified information.

4.2.7 Evaluation of Amount of Air Leakage through the Building Envelope, Utilizing Pressurized Air [42, 43, 44, 45]

In general, simple conservation measures (such as the reduction of building air leakage) are more cost effective than solar retrofit measures and should be investigated first. Uncorrected heat losses can seriously reduce the potential gains to be expected of a solar retrofit system.

Pressurization of the space within a building, either positive or negative with respect to atmospheric pressure, is one means of gaining a quantitative measure of the air leakage of a structure. A fan, a metering station to determine air flow rate, and pressure sensors, along with temperature measurements, are needed to make the determination of leakage rate for a given pressure differential. Generally, a window or door opening can be fitted with a plywood partition through which the air required to pressurize the structure is introduced. The pressurized air will seek points of penetration, in an effort to equalize the pressure between the space and the surrounding atmosphere. The amount required to maintain the pressure differential provides an indication of the overall air leakage performance of the structure. It is possible to isolate major points of leakage by selectively taping cracks and joints during a sequence of tests. Internal air leakage paths can be identified using a fan to generate differential pressures and an infrared scanner to trace the path through the construction (see paragraph 4.2 .8 below).

This technique is rather simple and not necessarily expensive (expense will vary with the complexity and detail of measurements). The results of the air pressurization test will not necessarily indicate the rate of infiltration obtained under natural (unpressurized) conditions, but, they do provide a relative measure for determining whether the structure is leaking excessively. Consult references [45] and [46].

\subsubsection{Determining Paths of Leakage Using Thermography [47, 48, 49]}

Sources of high heat losses can be determined through the use of thermography. This is a technique for "seeing" thermal energy radiating from the surface of a heated object. The infrared energy radiated from the object is displayed on a cathode ray tube. If a black and white cathode ray monitor is used, the intensity of the gray scale is proportional to the temperature of the object. 
Within a given range, colder objects appear dark and hotter objects appear light. If a color monitor is used, the gradation of colors (red, green, blue) of the image indicates the surface temperature variations. Thus, areas of heat leakage may be detected by observing the building surface temperatures. A photograph record can be taken of the image on the screen of the monitor and surface temperatures may be inferred from the thermal image.

4.2.9 Measurement of Air Flow Rate in Air Distribution Systems by the Velocity Head Method [7]

Velocity head is measured by placing a pitot tube directly in the air steam in a duct. This should be done at several locations in the duct cross-section, each location being the center of an increment of equal area in the duct. Rectangular ducts should be divided into 12 or more incremental areas, and large round ducts into equal concentric areas, four measurements being taken within each quadrant. Pitot positions are shown in figure 5 for both rectangular and round ducts. For smal1, round, ducts such as $127 \mathrm{~mm}$ (5 in) branch ducts in a residential heating system, one velocity head measurement may be taken at the center of the duct. The average velocity is taken to be 90 percent of the centerline velocity, and the flow rate is computed using the average velocity.

Instructions are provided with the pitot tube and manometer equipment for converting velocity head to air velocity. Some manometers read directly in velocity. A11 of the velocity readings at one duct position are averaged to get the final average duct velocity. The air flow rate in a round duct of diameter, $D_{\text {inches, }}$ for an average velocity, $V_{a v g}$, is calculated as follows:

$$
A C F M=\frac{V_{\text {avg } x} D^{2}}{183.35},(\text { actual cubic feet per minute }) .
$$

The air flow rate in a rectangular duct with inside dimensions of $A$ and $B$ inches becomes:

$$
A C F M=\frac{A \times B \times V}{144}
$$

The measured flow rate can be converted to flow rate at standard conditions (SCFM) as follows:

$$
\mathrm{SCFM}=\mathrm{ACFM} \times \mathrm{ADR}, \text { (standard cubic feet per minute) }
$$



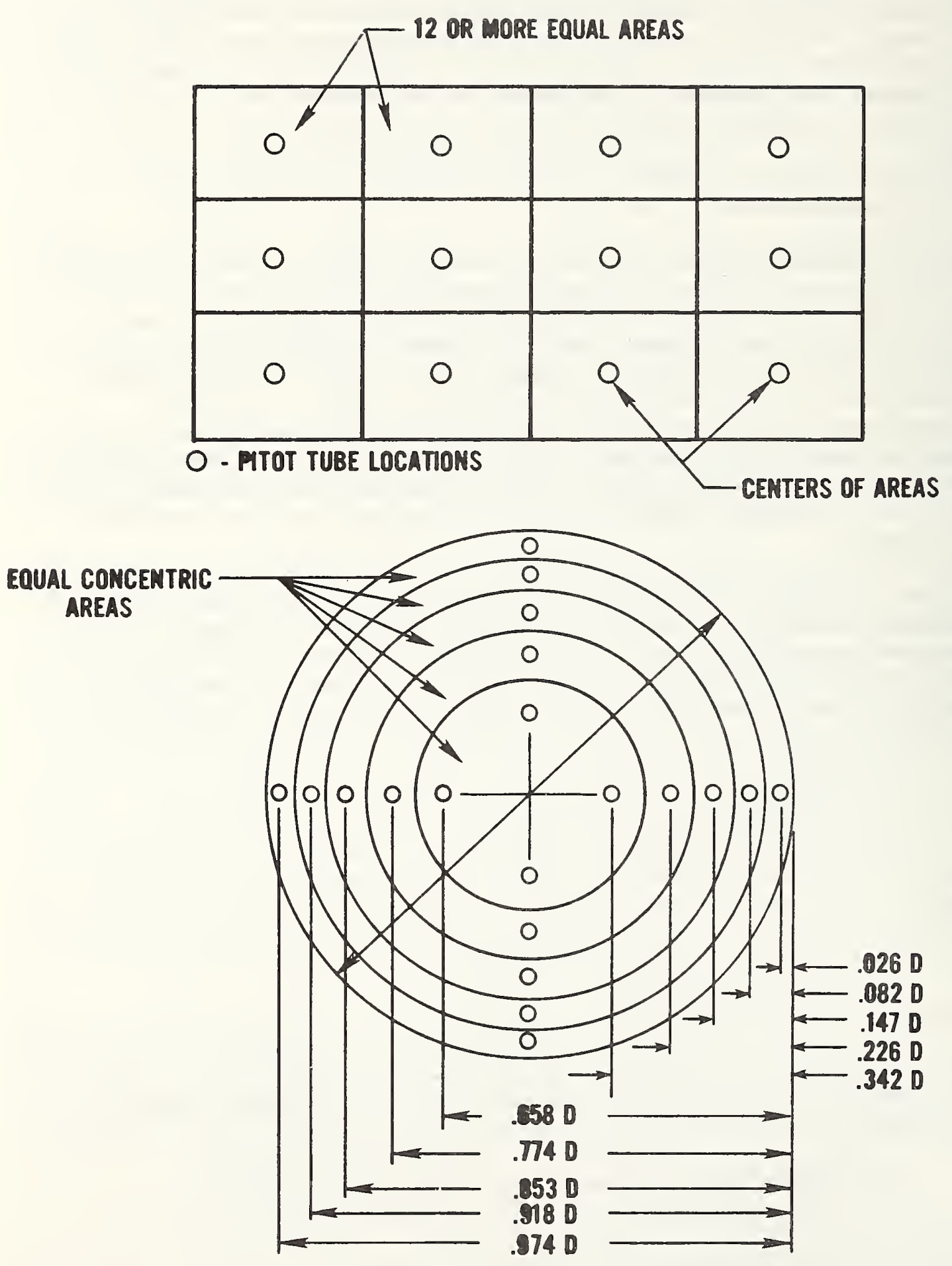

PITOT TUBE MEASUREMENT LOCATIONS FOR RECTANGULAR AND LARGE ROUND DUCTS 
where $\mathrm{ADR}$ (air density ratio):

$$
=\frac{530}{(460+\mathrm{T}) \exp \frac{(\mathrm{ALT})}{27,000}} \text {, }
$$

and

$$
\begin{aligned}
\mathrm{T} & =\text { air temperature }\left({ }^{\circ} \mathrm{F}\right) \text { during measurements } \\
\mathrm{ALT} & =\text { site elevation ( } \mathrm{ft} \text { MSL }) \text { relative to mean sea level } \\
\exp & =\text { exponential, or } \mathrm{e}(\mathrm{alt} / 27,000)
\end{aligned}
$$

4.2.10 Measurement of Air Flow Rate by Pressure Rise Across the Supply Blower [7]

Air flow may be determined by measuring the pressure rise across the blower, using a manometer and two static pressure probes. One probe should be placed near the blower inlet, and another down stream from the blower discharge, in a straight, constant area section of the discharge duct (see figure 6 ). Some fan manufacturers specify where static pressure measurements should be taken.

Estimated air flow rate in cubic feet per minute (CFM) may be determined from the manufacturer's blower performance characteristics curves for any given operating condition, consisting of: 1) discharge air temperature, 2) measured blower revolutions per minute ( $\mathrm{rpm}$ ), and 3) static pressure rise differential (or rise as determined above). See appendix D.5.2.6. Air flow at standard air conditions then may be obtained by using the conversion formula in paragraph 4.2 .9 above.

\subsection{HVAC PROBLEMS AND POTENTIAL IMPACT ON SOLAR RETROFIT}

Table 11 is a checklist of typical problems for an existing HVAC system. For each problem listed, the tabulation offers possible causes, and the impact which the problem may have on a proposed solar retrofit. 


\begin{tabular}{|c|c|c|c|c|c|c|c|}
\hline 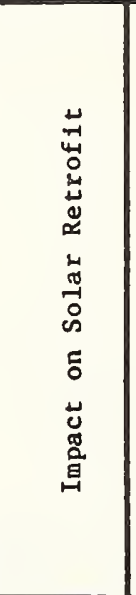 & 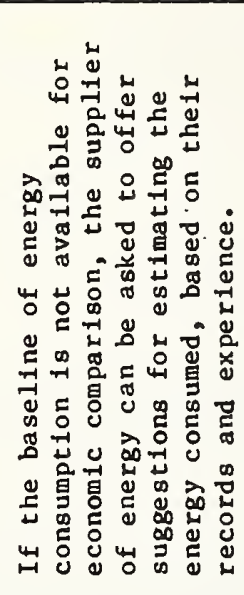 & 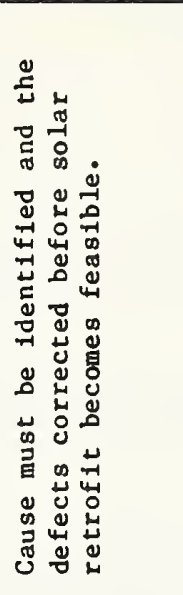 & 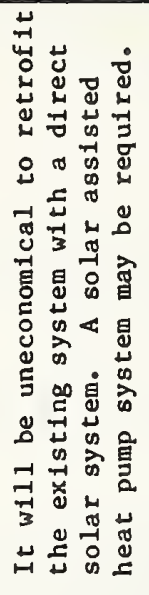 & 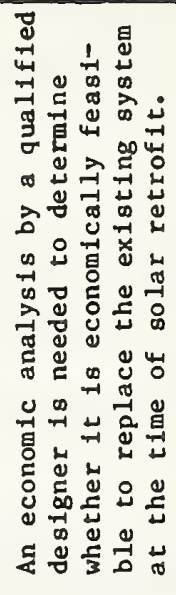 & 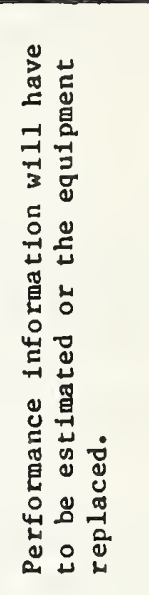 & 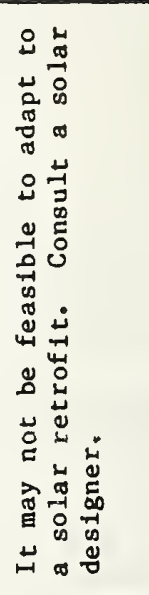 & 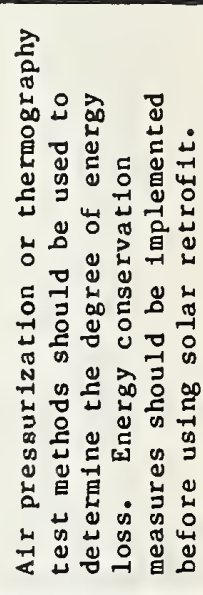 \\
\hline 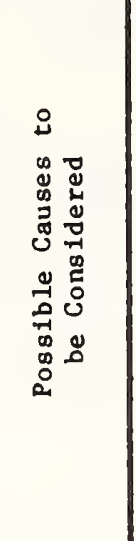 & 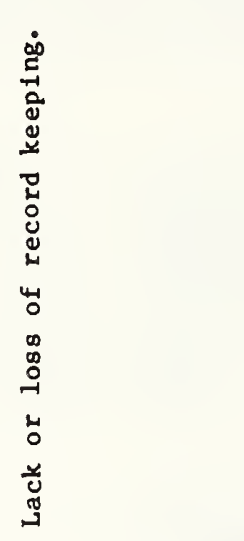 & 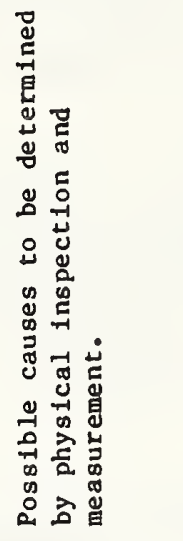 & 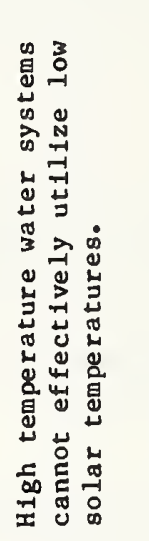 & 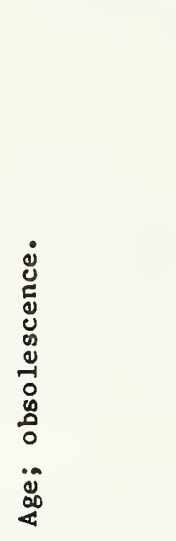 & 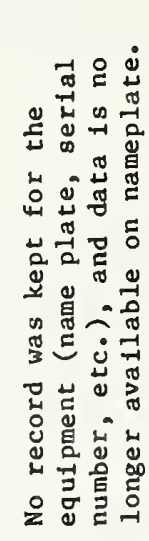 & 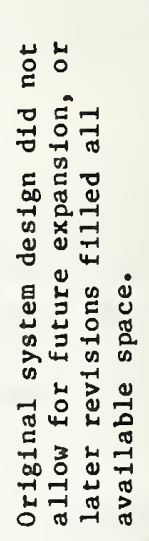 & 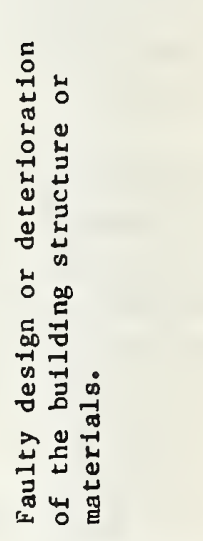 \\
\hline 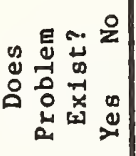 & & & & & & & \\
\hline 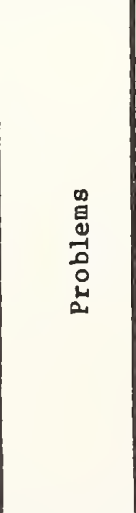 & 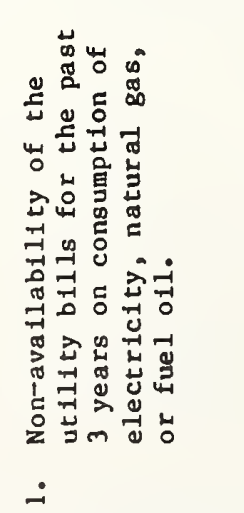 & 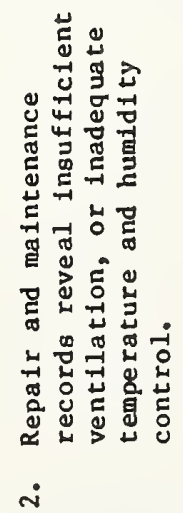 & 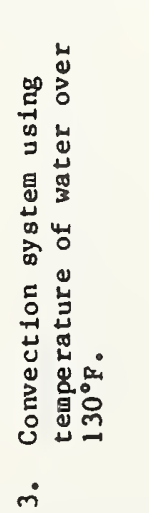 & 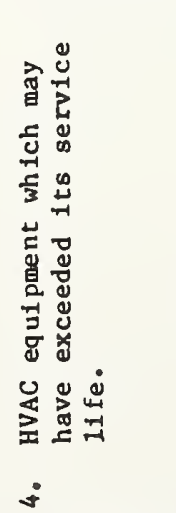 & 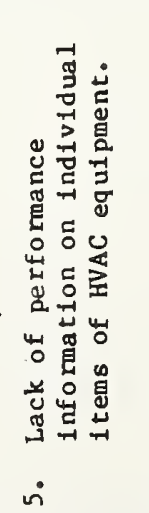 & 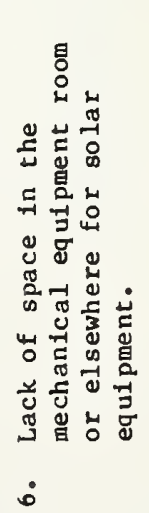 & 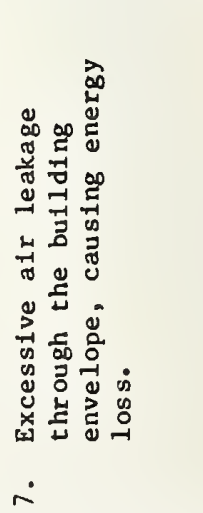 \\
\hline
\end{tabular}




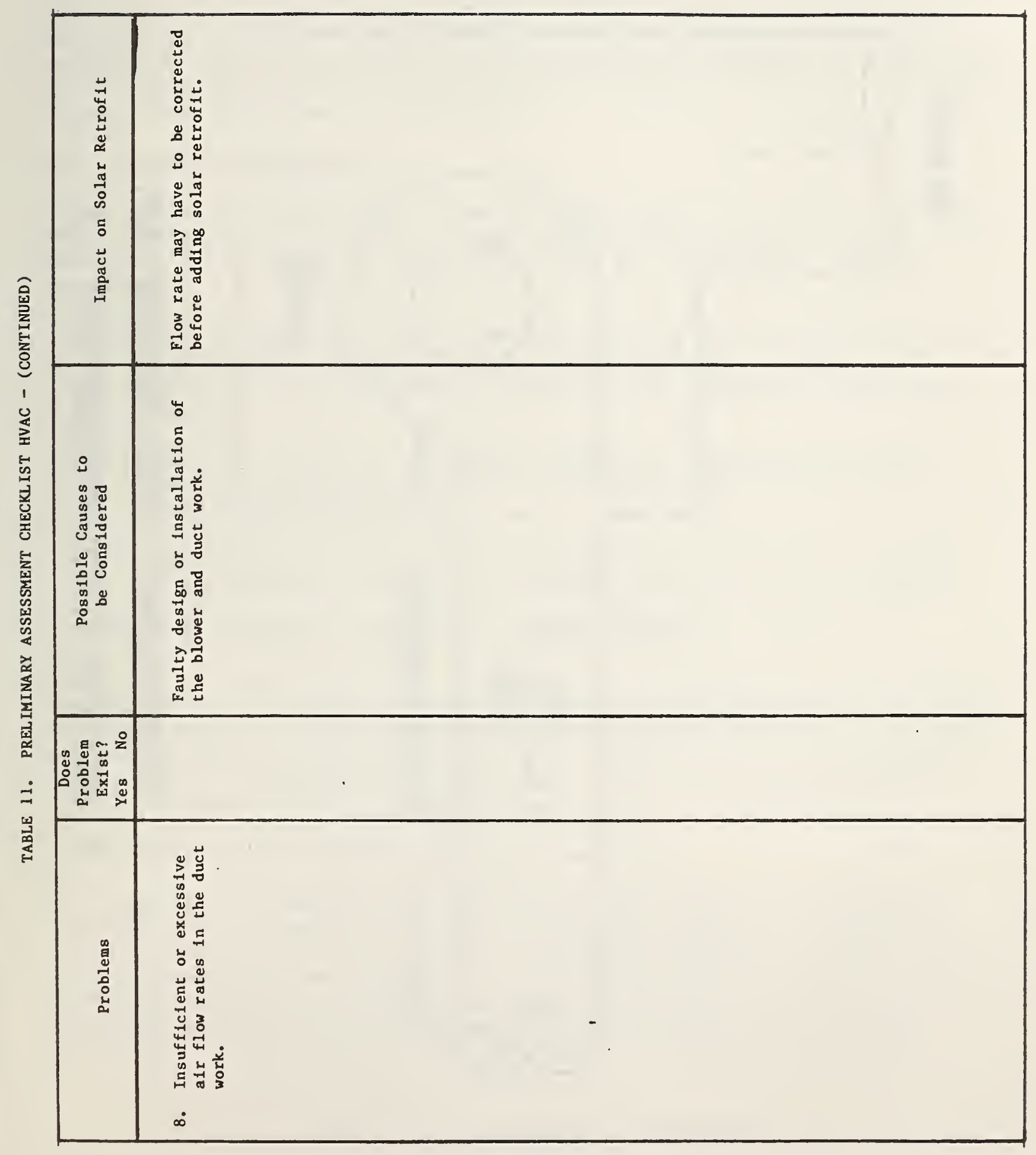




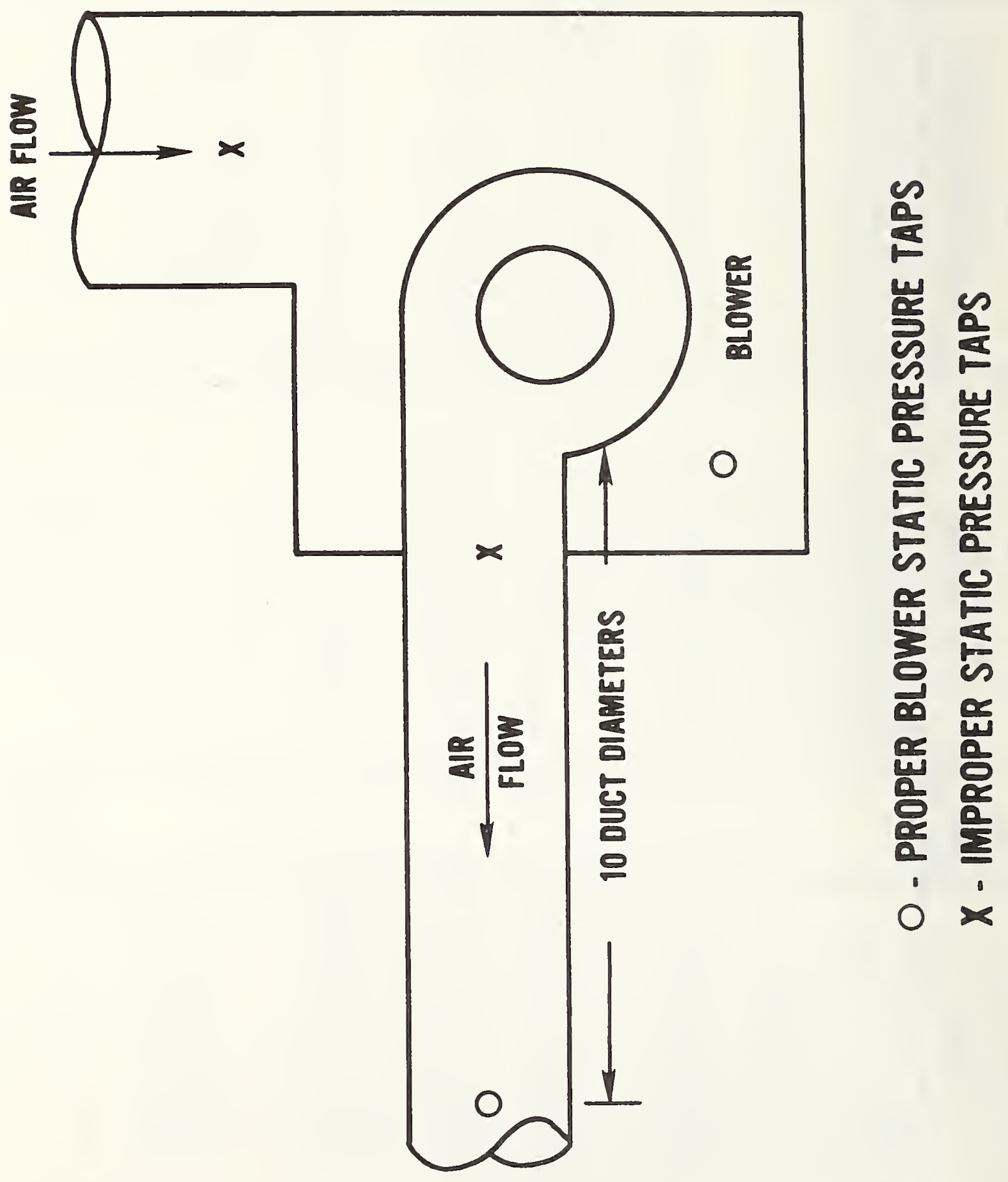

BLOWER STATIC PRESSURE TAP LOCATIONS

FIGURE 6 [7] 


\section{GUIDELINES FOR PLUMBING SYSTEMS}

The existing plumbing system in the building should be evaluated to determine its adequacy to support system additions or modifications resulting from a solar retrofit. This includes the water supply and drain-waste-vent (DWV) components. This section provides guidelines for the preliminary evaluation of the plumbing system. See appendix D.6 for further information to accomplish a more detailed assessment of the system.

\subsection{GENERAL CONSIDERATIONS}

Plumbing DWV and water supply systems can become major problems in building rehabilitation. Modification of these systems when considering solar retrofit of ten lead to extensive additional structural and finish work. This is because:

1. The plumbing system in an existing building may not comply with the requirements of current local codes and standards, and also may need additional equipment to meet the load imposed by added solar equipment.

2. The installation of new piping, vents, etc., required for solar equipment may be constrained by the space available and the existing piping configuration.

3. The methods of connecting new plumbing to the existing system can cause problems relative to materials and construction techniques.

\subsection{ON-SITE EVALUATION GUIDELINES - PLUMBING SYSTEMS}

The on-site investigation of the plumbing system consists mainly of a general examination of the plumbing components. While the emphasis should be on the plumbing components which may be affected by the solar retrofit, it is necessary also to make an overall review of the condition of the entire plumbing system. This is especially important where additional plumbing loads or significant modifications are anticipated.

\subsubsection{Operation and Maintenance Record Examination}

The operation and maintenance records for the past several years should be examined, and any complaints of leaks, clogging, sweating, air hammering, etc., should be noted and analyzed. Any existing additions or modifications to the plumbing systems should be noted on the construction as-built drawings if they are available. This examination should provide information concerning the adequacy of the existing plumbing system which, in turn, will assist in making the decision regarding a proposed solar retrofit. 
5.2.2 Visual Inspection of Existing Plumbing System [38, 50, 51, 52, 53, $54,55]$

A thorough inspection of the plumbing system should be carried out by a qualified plumbing inspector to gain a professional opinion on the ability of the system to function in a satisfactory manner and for compliance with the local code. Physical inspection should include observations regarding the following matters:

1) Conditions which could cause an unsafe building environment:

a. Excessively hot water (inadequate performance of temperature control devices).

b. Explosion hazard due to inadequate temperature and pressure limiting devices.

c. Plumbing wall construction which could allow fire spread and passage of smoke or toxic gases in case of a building fire.

d. Water or drainage leaks, including leaks around fixture connections which could result in deterioration of structural elements or materials.

2) Conditions which could cause an unsanitary building environment:

a. Leaks in sanitary drains and vents (which can contribute to the development of vermin, mold, odors, noxious or explosive gases, sewage accumulation, etc.).

b. Overflowing of sewage from fixtures.

c. Emission of sewer gas or detergent suds from fixtures.

d. Inoperative fixtures.

e. Inoperative domestic water heater, or inadequate supply of hot water.

f. Poor performance of water closets.

g. Inadequacy of potable water supply.

h. Backflow hazard including absence or malfuction of vacuum breakers and backflow preventer.

Although the value of inspection may be diminished where portions of the system are concealed, the personal judgment of an experienced plumbing inspector can usually be relied upon for an opinion whether the existing system can be adapted to solar retrofit. 
5.3 PLUMBING PROBLEMS AND POTENTIAL IMPACT ON SOLAR RETROFIT

The following checklist (table 12) may be helpful for determining the impact of typical problems on a proposed solar retrofit. 


\begin{tabular}{|c|c|c|c|c|c|c|c|c|c|}
\hline 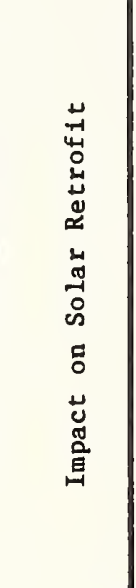 & 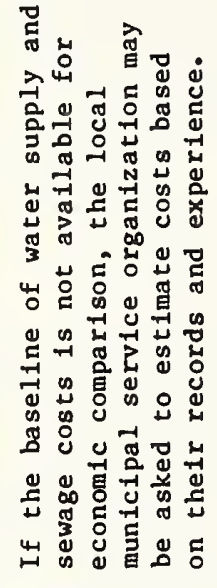 & 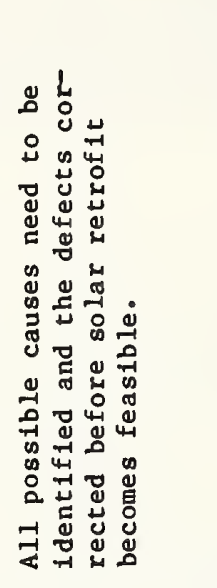 & 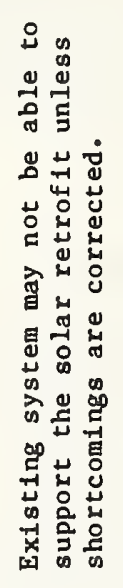 & 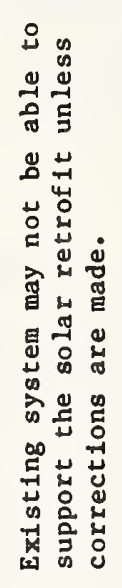 & 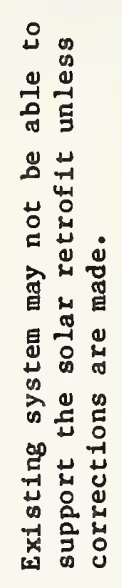 & 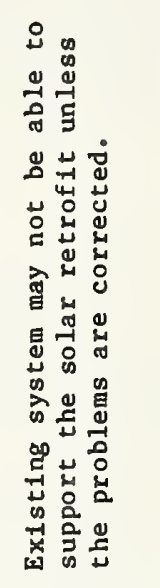 & 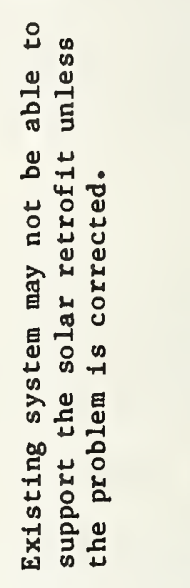 & 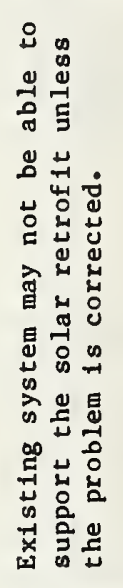 & 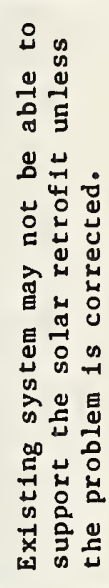 \\
\hline 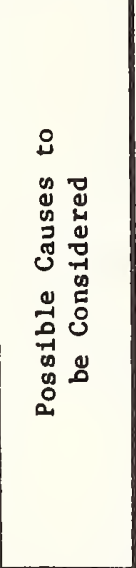 & 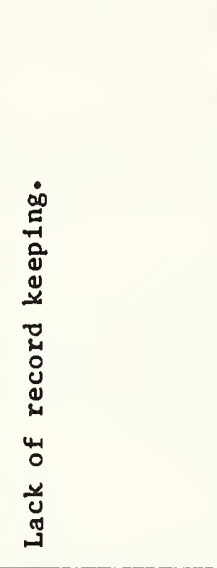 & 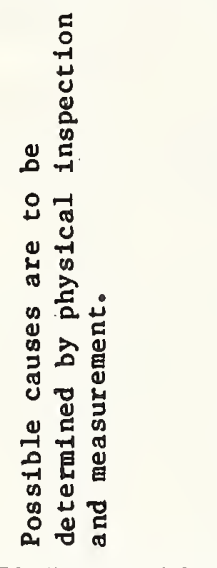 & 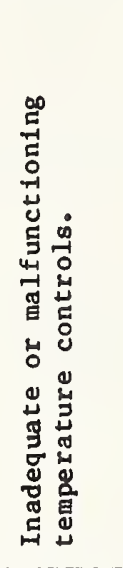 & 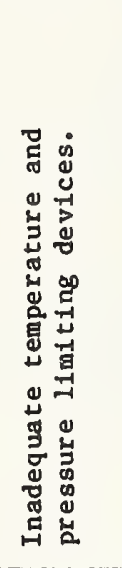 & 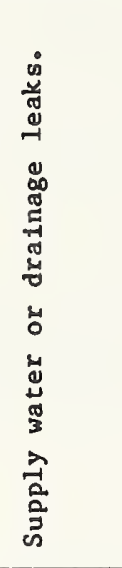 & 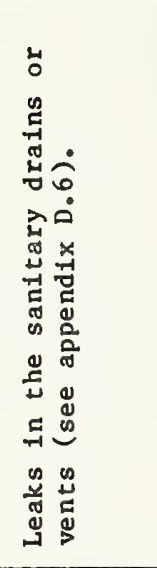 & 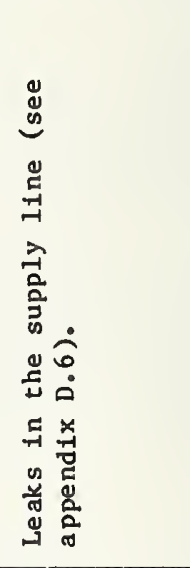 & 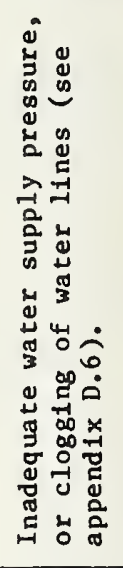 & 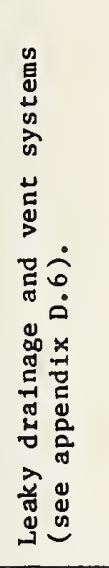 \\
\hline 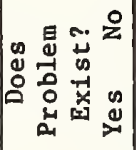 & & & - & & & & & & \\
\hline 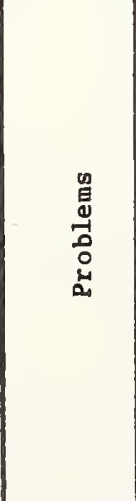 & 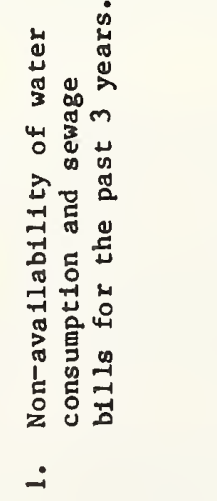 & 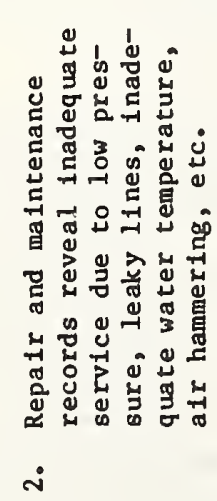 & 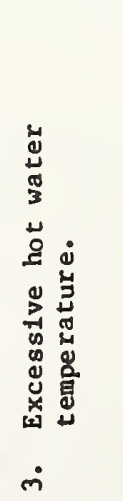 & 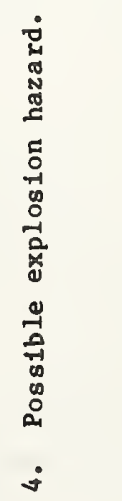 & 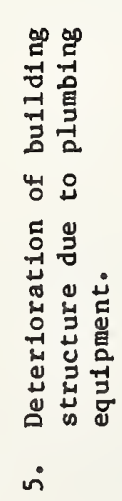 & 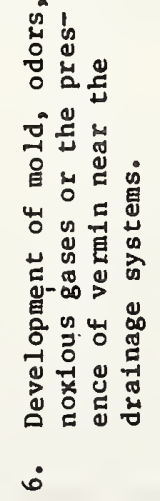 & 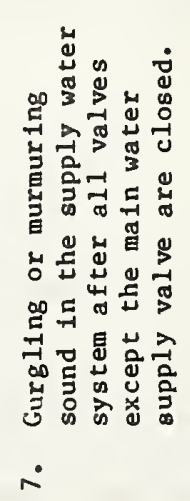 & 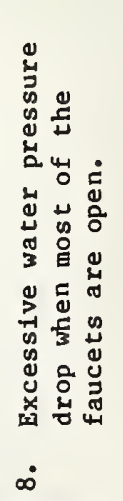 & 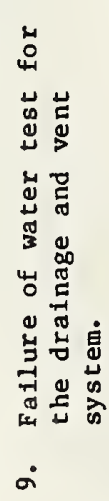 \\
\hline
\end{tabular}




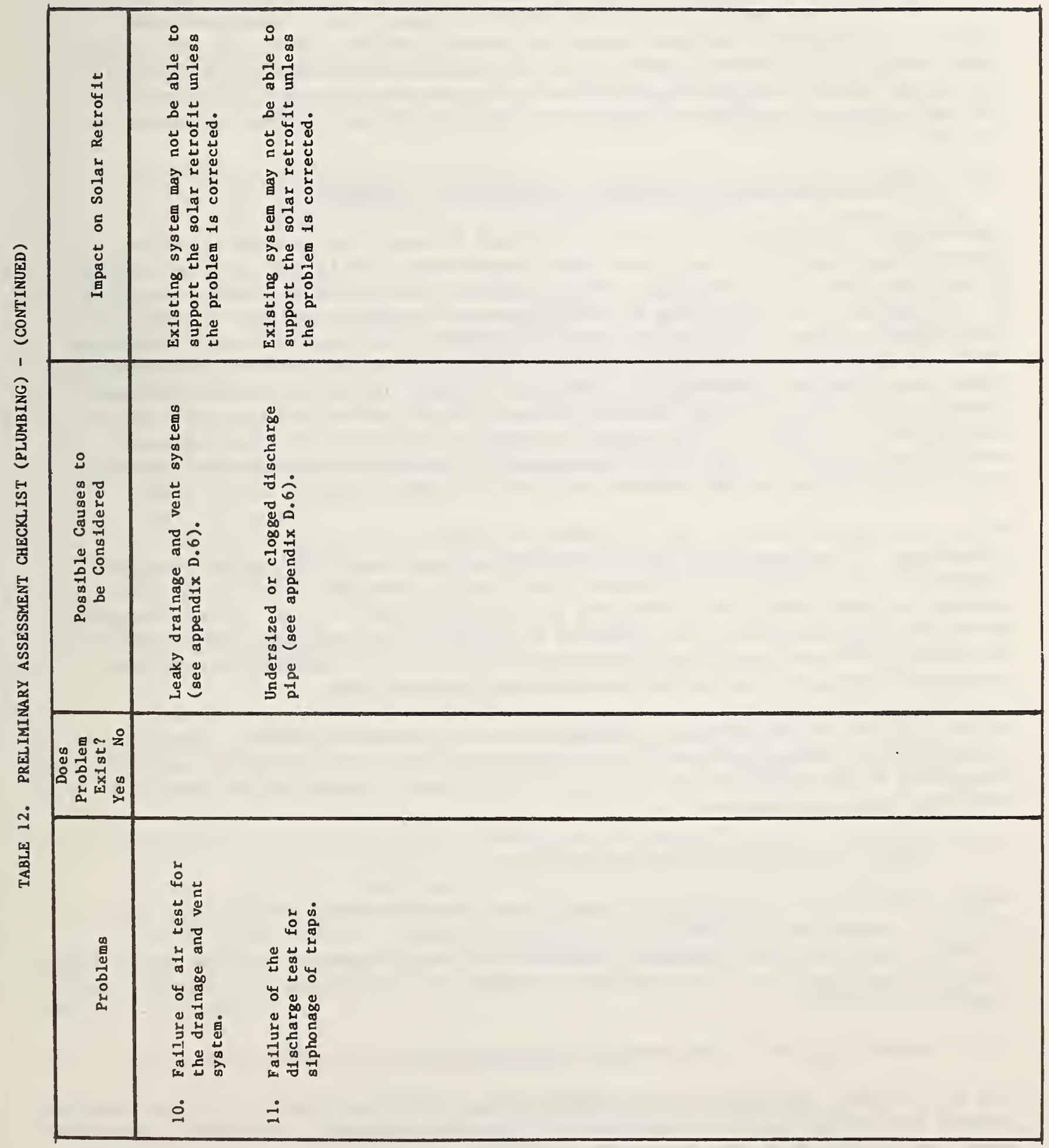


This section provides general information for the preliminary evaluation of the electrical system including its potential impact on a proposed solar retrofit. Evaluation methods covering circuit faults, insulation deterioration, and circuit breaker condition are listed and discussed. The general electrical requirements for solar retrofit also are included. Information on the more detailed evaluation techniques for electrical systems is given in appendix D.7.

\subsection{ON-SITE EVALUATION GUIDELINES - ELECTRICAL SYSTEMS}

The on-site investigation of the electrical system consists mainly of a general examination of the electrical components. While the emphasis should be on the electrical components which may be affected by the solar retrofit, it is necessary also to make an overall review of the condition of the entire electrical system. This is especially important where additional electrical loads or modifications are anticipated. If a system is outmoded or is grossly under capacity to accomodate the power demands of potential solar equipment (electric booster heaters, blowers, pumps, etc.), solar retrofit may not be economically feasible. Even though electrical construction drawings and specifications of the existing building are available, the existing arrangement and condition of the electrical installation should be determined.

Since most electrical wiring is concealed inside the walls, a complete inspection of all parts of the electrical system in a building may not be feasible. Some components, however, are easily checked, which will aid in evaluating the electrical shock and fire safety risks of the system compared with the requirements of the National Electrical Code and the local code. Potential problems resulting from system overloads (as new appliances and oversized fuses are installed) also should be considered.

While the evaluation methods mentioned in this section generally are recognized as being good practice, local codes and local officials should be consulted to determine whether special requirements apply to the specific building being evaluated.

\subsubsection{Operation and Maintenance Records}

Before a building inspection is undertaken, operation and maintenance records should be examined to identify potential problems. Incidences of power failure, insufficient lighting, electrical shock, excessive voltage drop, or short circuiting should be noted with respect to the appropriate circuit and component involved.

\subsubsection{Assessing Electrical Branch Circuits [38]}

One of the best techniques for assessing the condition of an existing electrical system is through visual inspection of the wiring system. It helps to determine the condition of the insulating material, as well as the quality of the connections made. It is important also to evaluate how the system is used during normal operation. The following items are considered essential: 
1) Overfusing - Check for proper size fuse or circuit breaker in branch circuits. A fuse of greater capacity than originally designed will permit a potential overload of the circuit. This could result in a fire hazard.

2) Overlamping - Note the wattage of lamps compared to wattages permitted for the fixture. This is critical in confined spaces such as recessed lighting fixtures and may result in ignition of nearby combustibles.

3) Overloaded Circuits - Determine whether the proper size wire and fuses are installed to conform to the local code or to the National Electrical Code. Make note of spare circuits for potential use with solar equipment.

Common symptoms of circuit overloading include: (1) an excessive number of 30 ampere fuses or breakers; (2) the smell of burned insulation within a panel; (3) glass top fuses which are warm; (4) discolored copper contact points under the fuses; (5) overheating of wires as evidenced by melted or brittle insulation, (6) evidence of heat discoloration due to fire around outlet boxes, switches, thermal insulation, etc.; (7) fuses which blow frequently or circuit breakers which trip frequently; and (8) presence of extensive surface mounted lamp cord extension wiring and multiple outlet cubes plugged into single outlets.

4) Type of Wiring - Determine whether the appropriate type of wiring and connectors have been used.

5) Type and Condition of Insulation - Determine whether the insulation around conductors is in satisfactory condition. Brittleness, flaking, or cracking are unacceptable, and wiring in this condition must be replaced. Examine insulation in exposed areas of the basement, in or near circuit breakers or fuse boxes, and inside outlet or switch boxes. Turn power off before removing outlet or switch plates and before probing wires.

6) Connectors - Check circuit connectors for excessive heat and power losses. Look for discolored metal, deteriorated insulation, and evidence of fire. Resistance losses cause low voltages which can impair appliances and shorten the life of components.

Visual inspection provides valuable information regarding the condition and adequacy of circuits and components, but only an experienced technician should conduct the inspection.

\subsubsection{Blower Motor Horsepower Measurement [7]}

The first step is to obtain the following information from each motor nameplate: 
1) Rated motor horsepower

2) Number of phases

3) Cycles

4) Voltage(s)

5) Rated amperes at full load

6) Operating speed(s)

7) Type of motor and serial number

8) Power factor

9) Diagrammed electrical connections

If the motor nameplate cannot be located, obtain the above information from the manufacturer. It will be necessary to help him identify each motor by describing its size and appearance, mounting, color, components, number and location of leads, character of load (type of blower), rotational speed, number and size of belts and sheaves, and any other such information the manufacture may need.

The next step is to determine the existing operating motor horsepower (OHP) using the following nameplate and field test data:

\section{$\underline{\text { Reading }}$}

Nameplate HP

Nameplate Volts

Nameplate Amperes per phase

Measured Operating Volts

Measured Operating Amperes per phase

Measured No-Load Volts

Measured No-Load Amperes per phase

\section{Abbrev. Value}

NHP

NV

NA

OV

$O A$

NLV

NLA

The above nameplate data may be read directly from the motor nameplate or may be obtained from the manufacturer as discussed earlier. The remaining data is obtained by measuring the operating volts and amperes directly at the motor, using a simple alternating current voltmeter and a snap-on type AC ammeter. Readings are needed with the motor operating at its existing normal load, and again with the motor operating while mechanically disconnected from the load.

Using the above data, the existing operating motor horsepower (OHP) may be calculated from the following relationship:

$$
\mathrm{OHP}=\mathrm{NHP}(\mathrm{OA}-0.5 \mathrm{NLA} / \text { Corrected NA }-0.5 \mathrm{NLA})
$$

where

$$
\text { Corrected } \mathrm{NA}=\mathrm{NA}(\mathrm{OV} / \mathrm{NV}) \text {. }
$$


The nameplate and measured voltage and current values obtained for the above tabulation will be affected by the type of power supplied to the motor and the wiring system. These are discussed as follows:

1) 110 Vo1t, Single Phase System

There are two power leads connected to the motor; one is hot and the other is neutral or ground. Measure the operating voltage across the two leads, and measure the operating current in either lead. The nameplate voltage and nameplate current should be similar to these measurements.

2) 220 Volt, Single Phase System

There are three leads or wires connected to the motor, one neutral and two $110 \mathrm{~V}$ hot wires. The voltage is measured across the two hot wires and the operating current is determined by summing the current measured in both hot wires. The nameplate voltage should be close to 220 volts, and the nameplate current is approximately double the measured current in one hot wire.

3) 220V, Three Phase, 3 Wire System

Each of the three wires are $220 \mathrm{~V}$ hot wires. The operating voltage is measured between any of these three wires and ground. The operating current per phase is measured in any one of the hot wires. The nameplate voltage should be close to 220 volts, and the nameplate current should be approximately three times the measured current in any one wire.

4) 220V, Three Phase, 4 Wire System

There are three $220 \mathrm{~V}$ hot wires and one neutral wire. The voltage is measured between any of the hot wires and the neutral. The current per phase is measured in any one of the hot wires. The nameplate voltage should be close to 220 volts, and the nameplate current should be approximately three times the measured current in any one wire.

\subsection{ELECTRICAL PROBLEMS AND POTENTIAL IMPACT ON SOLAR RETROFIT}

The following checklist (table 13) can be used to determine the problems in the electrical system of an existing building, and to make a preliminary determination of the impact that the problems may have on the solar retrofit. 


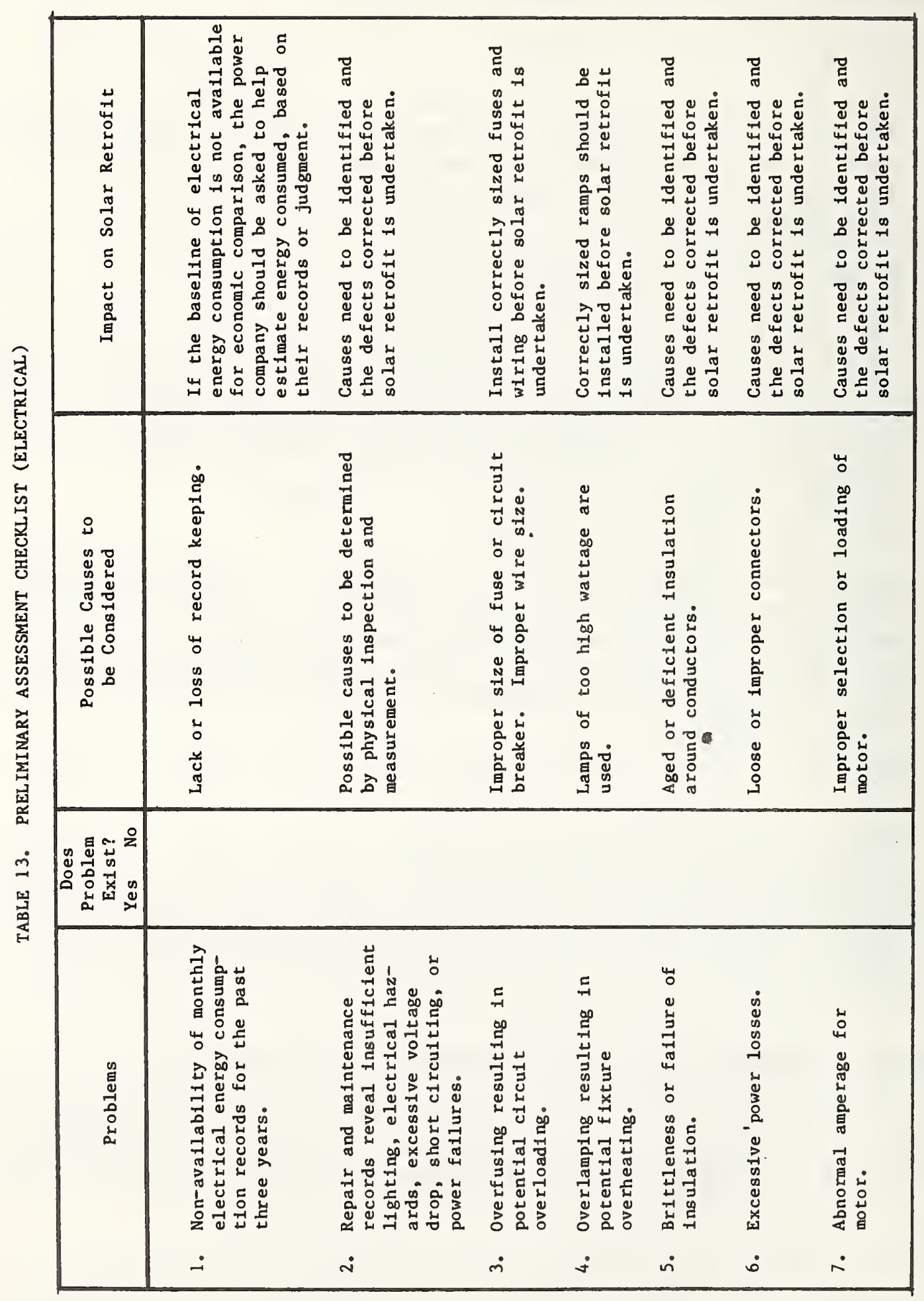


REFERENCES AND SUGGESTED ADDITIONAL READINGS (Nos. 1-76 are references)

1. Applied Technology Council, Tentative Provisions for the Development of Seismic Regulations for Buildings, SP-510 (Washington, D.C.: National Bureau of Standards, June, 1978), 514 pages.

2. FitzSimons, N., "Research Support for Building Rehabilitation Studies in the Area of Strength and Stability Evaluation," unpublished, (July 1, 1979).

3. Definition by Clifton, Dr. J.R., "Research Chemist, National Bureau of Standards, Center for Building Technology, Washington, D.C.

4. Fisher, D. A., "The Epic of Steel," Harper and Rowe Publishers, N.Y., Evanston, and London, (1963), pp. 152-196.

5. Smith, C. S., Editor, "The Sorby Centennial Symposium on the History of Metallurgy," Sponsored by the Society for the History of Technology; American Society for Metals; and the Metallurgical, Society, American Institute of Mining, Metallurgical, and Petroleum Engineers; Cleveland, Ohio, (October 22-23, 1963).

6. Aitchison, L., "A History of Metals," Vols. 1 \& 2, New York, Interscience Publishers, (1960).

7. Unpublished report performed by the Solar Environmental Engineering Co., Inc., Ft. Collins, Colorado, 1980.

8. Jacobs, P., "Technical Assessment of Existing Federal Buildings for Solar Energy Retrofit," Solar Environmental Engineering Co., Inc., (May 1980).

9. "Inspection Checklist for Vintage Houses - A Guide for Buyers and Owners," THE OLD-HOUSE JOURNAL, (1975).

10. "Basic Housing Inspection, Community Environmental Management Series, U.S. Department of Health, Education, and Welfare, Public Health Service, Bureau of Community Environmental Management, 1970.

11. Baechler, R. H., Gjovik, L. R., "Selection, Production, Procurement, and Use of Preservative-Treated Wood," Forest Products Lab., USDA, Specification TT-W-571.

12. Anderson, L. 0., "Selection and Use of Wood Products for Home and Farm Building," Forest Products Lab., USDA, Vol. 311, (February, 1967).

13. Scheffer, T. C., Verrall, A. F., "Principles of Protecting Wood Buildings from Decay," Forest Products Lab., USDA, FPL 190, (1973).

14. DeGroot, R. C., "Your Wood can Last for Centuries," Forest Products Lab., USDA, (1976). 
15. "Wood Handbook: Wood as an Engineering Material," Forest Products Lab., USDA, Handbook No. 72, (1974).

16. Black, Fiest, Gjovik, Rowel1, "Protecting Log Cabins from Decay," Forest Products Lab., USDA, (1977).

17. Anderson, L. 0., Sherwood, G. E., "Condensation Problems in your House: Prevention and Solution," Forest Service, USDA, Agriculture Bulletin No. 373, (September 1974).

18. Sherwood, G. E., "New Life for Old Dwellings," Forest Products Lab., USDA, Vol. 非81, (December 1975)。

19. "PILODYN Wood Tester, Operating Instructions," ProceQ SA Zurich, Switzerland.

20. Scheffer, T. C., "A Climate Index for Estimating Potential Decay in Wood Structures Above Ground," Forest Products Lab, USDA, Vol. J21(10).

21. Dampness in Basements and Ground Floors, LC 813 (Washington, D.C.: National Bureau of Standards, August 17, 1953), 17 pages.

22. McMaster, R., Editor, "Nondestructive Testing Handbook, " Ronald Press, New York, (1959).

23. Haverty, M. I., "You Can Protect Your Home from Termites," USDA.

24. Smythe; Williams; "Structural Pest Control Regulations," USDA, (1974).

25. "Subterranean Termite Control Proposal", Orkin Exterminating Co., Inc., (February 1973).

26. Haverty, M. I., "Have Termites? Don't Panic!" U.S. Forest Service, USDA.

27. Johnson, S., "Deterioration, Maintenance, and Repair of Structures," McGraw-Hill, Inc. (1965).

28. "PILODYN, "A Non-destructive Wood Tester," Manufacturer's Literature, Carl Bechgaard, Hovegaden 26, DK 2970 Horsholm, Denmark.

29. Proceedings of the Fourth Nondestructive Testing of Wood Symposium, Held at Vancouver, Washington, August 28-30, 1978, published by the Engineering Extension Service, Washington State University.

30. Berger, H., Mordfin, L., Editors, Annual Report 1978, Office of Nondestructive Evaluation, NBSIR 78-1581, (Washington, D.C., Nationa1 Bureau of Standards, January 1979), 51 pages. 
31. Eldridge, H., "Common Defects in Buildings," Department of the Environment, Property Services Agency, Her Majesty's Stationery Office, London, (1976).

32. "Practices for Evaluation of Concrete in Existing Massive Structures for Service Condition," No. ACI 207R-79, CONCRETE INTERNATIONAL, (March 1979).

33. Sevall, G., "Nondestructive Testing of Construction Materials and Operations," $\mathrm{AD}-774$ 847, U.S. Department of Defense, Army Cnstruction Engineering Research Laboratory, (December 1973).

34. Snel1, L., "Nondestructive Testing Techniques to Evaluate Existing Masonry Construction," (August 1978).

35. "Standard Specification for Ceramic Glazed Structural Clay Facing Tile, Facing Brick, and Solid Masonry Units," C-126, American Society for Testing and Materials, (1976).

36. "Nondestructive Testing," Reference Manual for a Home Study and Extension Course, by the American Society for Metals, the American Society for Nondestructive Testing, and the Metals Engineering Institute, Metals Park, Ohio, (1972).

37. Vary, A., "Nondestructive Evaluation Technique Guide," National Aeronautics and Space Administration, Washington, D.C., (1973).

38. "Home Repair and Improvement - The 01d House," by the Editors of Time-Life Books, (1979).

39. Dubin, F., Long, G. G., Jr., "Energy Conservation Standards for Building Design, Construction, and Operation," McGraw Hill Book Co., (1978).

40. ASHRAE Handbook and Product Directory, 1977 Fundamentals.

41. ASHRAE Handbook and Product Directory, 1979 Equipment.

42. Crenshaw, R., Clark, R., Chapman, R., Grot, R., and Godette, M., CSA Weatherization Demonstration Project Plan, NBSIR 79-1706 (Washington, D.C.: National Bureau of Standards, March 1979).

43. Tamura, G. T., "Measurement of Air Leakage Characteristics of Home Enclosures," ASHRAE Transactions, V81, Part 1, American Society of Heating, Refrigerating, and Air Conditioning Engineers, New York, N.Y., (1975).

44. Stricker, S., "Measurements of Air-tightness of Houses," ASHRAE Transactions, V81, Part 1, American Society of Heating, Refrigerating, and Air Conditioning Engineers, New York, N.Y. (1975). 
45. Kronva11, J., "Testing of Houses for Air Leakage Using a Pressure Method," ASHRAE Transactions, V81, Part 1, American Society of Heating, Refrigerating, and Air Conditioning Engineers, New York, N.Y., (1975).

46. Grot, R. A., "A Method for Collecting Air Infiltration Rates in a Large Scale Dwelling," Proceedings of ASTM Conference on Air Infiltration, American Society for Testing and Materials, Philadelphia, PA, (March 1978).

47. Grot, R. A., Harrje, D. S., and Johnston, L. C., "Application of Thermography for Evaluating Effectiveness of Retrofit Measures," Proceedings of the 3rd Biennial Infrared Information Exchange, AGA Corp., Lecancus, N.J., (1976).

48. Hurley, E. W., and Kreider, K. G., Application of Thermography for Energy Conservation in Industry, NBS Technical Note 923 (Washington, D.C.: National Bureau of Standards, October 1976).

49. Pettersen, B., and Paljak, J., "Thermography of Buildings, "The National Swedish Institute for Building Research, AGA Corp., Stockholm, Sweden.

50. "Basic Plumbing Code," (BPC) 1978. Building Official and Code Administrators International, Inc., 17926 South Halsted, Homewood, Illinois, 60430 .

51. "National Standard Plumbing Code," (NSPC) 1978. National Association of Plumbing-Heating-Cooling Contractors (NAPHCC) and American Society of Plumbing Engineers (ASPE), 1015 20th Street, N.W., Washington, D.C. 20036.

52. "Standard Plumbing Code (SPC) 1979," Southern Building Code Congress Internationa1, Inc. (SBCC), 900 Montclair Road, Birmingham, Alabama 35213.

53. "Uniform Plumbing Code (UPC) 1976," International Association of Plumbing and Mechanical Officials (IAPMO), 5032 Alhambra Avenue, Los Angeles, California, 90032.

54. Manas, V. T., "National Plumbing Code Handbook - Standards and Design Information," McGraw Hill Book Company, Inc.

55. "Uniform Building Code - Interpretation and Inspector's Manual," 1st Edition, International Association of Plumbing and Mechanical Officials, (1971).

56. Blinn, B. C. "Properties and Uses of Color Change Humidity Indicators," Humidial Company, Colton, CA.

57. ASHRAE Handbook of Fundamentals, Chapter 13, (1977). 
58. Sonderegger, R. C., Modera, M. P., "Electric Co-heating: A Method for Evaluating Seasonal Heating Efficiencies and Heat Loss Rates in Dwel1ings," Lawrence Berkeley Laboratory, University of California, Berkeley, California. (Draft Report - Presented at the 2nd CIB Conference, Copenhagen, Denmark, June 1979).

59. Fowler, K. A., Elfbaum, G. M., Husarek, V., Castel, J., "Applications of Precision Ultrasonic Thickness Gauging, "Panametrics, Waltham, MA.

60. Sunley, J. G., "Review of Nondestructive Testing of Timber," Symposium on Nondestructive Testing of Concrete and Timber, London, (1969).

61. "Basic Building Code 1978," Section P-1802.5 1a, Building Officials and Code Administrators, International, Inc., 17926 South Halsted, Homewood, I1linois, 60430 .

62. "Tentative Guide Specification, Plumbing," GSA, Public Buildings Service, Section 15410 T, pp. 30-32, (Nov. 1978).

63. "Standard Plumbing Code 1979," Section 107.5a, Southern Building Code Congress, International, Inc., 900 Montclair Road, Birmingham, AL, 35213.

64. "Standard Plumbing Code 1979," Section 1602.10e, Southern Building Code Congress, International, Inc., 900 Montclair Road, Birmingham, AL, 35213.

65. Performance Criteria Resource Document for Innovative Construction, NBSIR 77-1316, (Washington, D.C.: National Bureau of Standards, November 1977), p. 123, 13.6.7.5, "Criterion: Hydraulic and Pneumatic Performance - DWV Stack and Building Drain Assembly."

66. Orloski, M. J., Wyly, R. S., Hydraulic Performance of a Ful1-Scale Townhouse System with Reduced Sized Vents, Building Science Series BSS 60, (Washington, D.C.: National Bureau of Standards, August 1975).

67. Konen, T. P., "The Evaluation of Several Plumbing Drainage, Waste and Vent Systems," Report DL-74-1776, Stevens Institute of Technology, (1974).

68. Jackson, R., Konen, T. P., "An Investigation of the Adequacy of Performance of Reduced-Sized Vents Installed in a Ten Story Drain, Waste and Vent System," Stevens Institute of Technology Report SIT DL-1708, (July 1973).

69. Konen, T., "A Test Procedure for Evaluating the Capacity of the Building Drainage Systems," Report DL-75-1841, Stevens Institute of Technology, (1975). 
70. Wyly, R. S., Rorrer, D. E., Field Test of Hydraulic Performance of a Single-Stack Drainage System at the Operation BREAKTHROUGH Prototype Site in King County, Washington, NBSIR 73-161 (Washington, D.C.: National Bureau of Standards, May 1973.

71. Maybeck, E., "Demonstration of Performance for a Sovent System Installed at Townsend Towers Near East Side Urban Renewal Project, Syracuse, N.Y.," Barnard and Maybeck, Rochester, N.Y॰, (1972).

72. Performance Criteria Resource Document for Innovative Construction, NBSIR 77-1316 (Washington, D.C.: National Bureau of Standards, November 1977 ), page 122 .

73. "Inspection Guide, Electrical Systems," GSA, Public Buildings Service, PBS P 3480.2, Section 1605.

74. "National Electrical Code 1978," Paragraph 210-19, Conductors - Minimum Capacity and Size, National Fire Protection Association, 470 Atlantic Avenue, Boston, Massachusetts, 02210.

75. AMP, Incorporated, Harrisburg, Pennsylvania.

76. Multi-Amp Corporation, Dallas, Texas, 75237.

77. James, W., "Electric Moisture Meters for Wood," U.S. Forest Service, General Tech. Report FPL-6, (1975).

78. Duff, J. L., "A Probe for Accurate Determination of Moisture Content of Wood Products in Use," U.S. Forest Service Research Note FPL-0142, (1966).

79. Pellerin, R. F., "Nondestructive Testing of Timber at Washington State University," Symposium of Nondestructive Testing of Concrete and Timber, Lond on, (1969).

80. Elvery, R. H., "Strength Assessment of Timber for Glued Laminated Beams", Symposium on Nondestructive Testing of Concrete and Timber, London, (1969).

81. "Bugs:Blights:Blazes . Enemies of the Southern Forest," U.S. Forest Service, USDA, (1978).

82. Beal, Johnson, Smith, "Subterranean Termites, Their Prevention and Control," USDA Bulletin, Vo1. 64, (January 1972).

83. Schaeffer, E. L., "Review of Information Related to the Charring Rate of Wood", U.S. Forest Service, USDA, (November 1966). 
84. "Fundamentals of Nondestructive Testing," by the American Society for Metals and the American Society for Nondestructive Testing, Reference Manual for an Extension Course of the Metals Engineering Institute, Metals Park, Ohio, (1979).

85. DiGiacomo, G., Crisci, J., Goldspiel, S., "An U1trasonic Method for Measuring Crack Depth in Structural Weldments," MATERIALS EVALUATION, Vol. XXVII, No. 9, (September 1970).

86. Nondestructive Evaluation Equipment Literature from the Olympus Corp of American, New Hyde Park, N.Y.

87. Nondestructive Evaluation Equipment Literature from the KrautkramerBranson Co., Stratford, CN.

88. "Nondestructive Testing: Trends and Techniques," Proceedings of the Second Technology Status and Trends Symposium, Marshall Space Flight Center, NASA, Publication No. SP-5082.

89. "Annual Book of ASTM Standards, Part II, Metallography: Nondestructive Testing," by the American Society for Testing and Materials, (1977).

90. "Review of Preconstruction Data, Construction, Operation and Maintenance Records," CONCRETE INTERNATIONAL, (March 1979), pp. 48-50.

91. Dick, P., "Introduction to Nondestructive Testing," General Electric Company, Written for the Metals Engineering Institute, (1979), page 1.4.

92. "Solar Federal Building Program Plan," Unpublished Report by U.S. Dept. of Energy, (February 1, 1980).

93. "Building Code Requirements for Reinforced Concrete," ACI 318, American Concrete Institute, (1977).

94. "Standard Specification for Blended Hydraulic Cements," C 595, American Society for Testing and Materials, (1976).

95. Kemp, E., "An Introduction to the Structural Evaluation of Historic Reinforced Concrete Structures," CONCRETE INTERNATIONAL, (October 1979).

96. Hansome, E., Saurbrey, A., "A Selection of Historic American Papers on Concrete, 1876 - 1926," American Concrete Institute.

97. Lesley, R., "History of the Portland Cement Industry in the United States, (1924), page 33.

98. Turner, C., "Concrete Steel Construction," (1909), pages 245-284.

99. Urquhart, L., "Civil Engineering Handbook," (1962). 
100. Draffin, J., "A Brief History of Lime, Cement, Concrete, and Reinforced Concrete," JOURNAL OF THE WESTERN SOCIETY OF ENGINEERS, Vo. 48, No. 1, (March 1943), pages 14-47.

101. Maples, W., Wilde, R., "A Story of Progress - Fifty Years of the American Concrete Institute," Title No. 50-25, JOURNAL OF THE AMERICAN CONCRETE INSTITUTE, Vol. 25, No. 6, Proceedings Vol. 50, (February 1954).

102. Kerekes, F., and Reid, H., "Fifty Years of Development in Building Code Requirements for Reinforced Concrete," Title No. 50-26, JOURNAL OF THE AMERICAN CONCRETE INSTITUTE, Vol. 25, No. 6, Proceedings Vol. 50, (February 1954).

103. Perkins, P., "Concrete Structures: Repair, Waterproofing and Protection," (1977).

104. "Concrete Manual," A Water Resource Technical Publication, U.S. Department of the Interior, Bureau of Reclamation, (1975).

105. Hough, B., "Basic Soils Engineering," (1957)。

106. Malhotra, V., "Testing Hardened Concrete: Nondestructive Methods," American Concrete Institute Monograph No. 9, (1976).

107. Vassitch, P., "Outline of the Various Possibilities of Nondestructive Mechanical Tests on Concretes: New Proposals of the Author," Proceedings of the International Symposium on Nondestructive Testing of Materials and Structures, Vol. 2, RILEM, Paris, (1954), pages 301-306.

108. Leslie, J., Cheeseman, W., "An Ultrasonic Method of Studying Deterioration and Cracking in Concrete Structures," ACI JOURNAL, (September 1949).

109. "Strength Evaluation of Existing Concrete Buildings," ACI 437, American Concrete Institute, (1975).

110. "Standard Method of Obtaining and Testing Drilled Cores and Sawed Beams of Concrete," C-42, American Society for Testing and Materials, (1977).

111. NDE (Nondestructive Evaluation), LC 1080 (Washington, D.C.: National Bureau of Standards, April 1978).

112. Promotional Information, Olympus Corporation of American, New Hyde Park, New York.

113. "Standard Method of Sampling and Testing Bricks and Structural Clay Tile," C-67, American Society for Testing and Materials, (1978).

114. Fattal, S., Cattaneo, L., Evaluation of Structural Properties of Masonry in Existing Buildings, NBS BSS 62 (Washington, D.C.: National Bureau of Standards, March 1977), 127 pages. 
115. "Durability," British Standard Code of Practice CP3 - Chapter IX, by the Council for Codes of Practice for Buildings, (1950).

116. "Nondestructive Inspection and Quality Control," Metals Handbook, 8th Edition, Vol. I \& II, American Society for Metals, Metals Park, Ohio, (1976).

117. Krautkramer, J., Krautkramer, H., "Ultrasonic Testing of Materials," Springer - Verlag, New York, 2nd Edition, (1969).

118. Halmshaw, R., Editor, "Physics of Industrial Radiology," Heywood Books, London, (1966).

119. "Radiography in Modern Industry," Eastman Kodak Co., Rochester, New York, 3rd Edition, (1970).

120. McGonnagle, W., "Nondestructive Testing," Pergamon Press, New York.

121. Sharp, R., Editor, "Research Techniques in Nondestructive Testing," Academic Press, London, (1980).

122. McKay, J., "Effect of Moisture Gradients on the Accuracy of Power Loss Meters," Forest Products Lab., USDA, FPJ 26(3), pages 49-52.

123. "Standard Test Methods for Moisture Content of Wood," D 2016 , American Society for Testing and Materials, (1974).

124. "Standard Methods for Establishing Structural Grades and Related Allowable Properties for Visually Graded Lumber," D 245, American Society for Testing and Materials, (1974).

125. "Standard Method for Establishing Clear Wood Strength Values," D 2555, American Society for Testing and Materials, (1976).

126. McDonald, K., "Ultrasonic Location of Defects in Softwood Lumber," USDA, Technical Article in the TIMBER TRADES JOURNAL, (January 1973).

127. McDonald, K., "Lumber Defect Detection by Ultrasonics," Forest Products Lab., USDA, Research Paper FPL 311, (1978).

128. Gerhards, C., "Stress Wave Speed and MOE of Sweetgum Ranging from 150 to 15 percent MC," Forest Products Lab., USDA, FPL Journal, Vol. 25, No. 4, (1975).

129. Fala, M. J. "Principles of Residential Plumbing Inspection," lst Edition, American Society of Sanitary Engineering, (1973).

130. "Draft Rehabilitation Guidelines," Department of Housing and Urban Development, Federal Register Volume 44 - No. 215, Book 2, November 5, 1979. 
131. McMaster, R. C., Ed., "Nondestructive Testing Handbook," Ronald Press, New York, (1959).

132. Krautkramer, J., Krautkramer, H., "Ultrasonic Testing of Materials," Spring-Verlag, New York, 2nd Ed., (1969).

133. Halmshaw, R., Ed., "Physics of Industrial Radiology," Heywood Books, London, (1966).

134. "Radiography in Modern Industry," Eastern Kodak Co., Rochester, New York, 3rd Ed., (1970).

135. McGonnagle, W. J., "Nondestructive Testing, Pergamon Press, New York.

136. Sharp, R. S., Ed., "Research Techniques in Nondestructive Testing," Academic Press, London, (1970), (1973), (1976), (1980).

137. Vary, A., "Nondestructive Evaluation Technique Guide," National Aeronautics and Space Administration, Washington, D.C., (1973).

138. "Standard Methods of Tension Testing of Metallic Materials," ASTM E 8, American Society for Testing and Materials, (1977).

139. "Standard Methods of Compression Testing of Metallic Materials at Room Temperature," ASTM E 9, American Society for Testing and Materials, (1977).

140. Kaiserlik, J., "Nondestructive Testing Methods to Predict Effect of Degradation on Wood: A Critical Assessment," Forest Products Lab, USDA, General Tech. Report FPL 19, (1978). 
APPENDIX A

Typical Forms for

Collection of Data During Preliminary On-Site Investigation 
The accumulation of data during the on-site investigation should be done in an organized manner. At this point it may be helpful to establish a Project Dossier. The Dossier is made up of a project notebook and a file which contains all correspondence pertaining to the project as well as collected reference material.

The forms which should be kept with the Dossier are as follows:

A. Project Notebook

1. General Building Information Form (see sample attached)

2. Member/Assembly Information Form

3. Journal Entry List

4. Contact List

5. Document List

6. Photo List

7. Sketch List

8. Specimen List

B. Project Files

1. General Correspondence

2. Journal Entry Supplements

3. Collected Documents and Citations

4. Photographs and Negatives

5. Field Reports and Sketches

6. Test Results

7. Analytical Studies

8. Evaluation Report 


\section{Form $\mathrm{A}-1$}

GENERAL BUILDING INFORMATION

Project \# :

Date : Investigator:

1) Building Name:

2) Street Address:

3) Place:

4) Country: 5) State: 6) Zip:

7) Building Authority:

8) Architect/Engineer:

9) Builder:

10) Documentation:

11) Construction Dates:

12) Vacancy Date:

13) Site Description:

14) Area: Ground Plan: Gross: Net:

15) Stories:

16) Structure:

17) Roof :

18) Exterior Walls:

19) Interior Walls:

20) Fenestration:

21) Floors:

22) Girders :

23) Columns:

24) Basement:

25) Footings:

26) Supplemental Information: 
Form A-2

COMPONENT/ASSEMBLY INFORMATION

Project 非: Date: Investigator:

1) Building Name:

2) Street Address:

3) Place:

4) Country:

5) State:

6) Zip:

7) General Description:

8) Condition:

9) Deficiencies:

10) Causes of Deficiencies:

11) Loads:

12) Agents:

13) Materials Qualities:

14) Member/Assembly Properties:

15) Remarks:

Include detailed sketches of the member/assembly on the reverse side of the form. Include its location in the overall system. Scales must be shown for each sketch. Original outlines may be shown as dashed lines over the as-is state. 
Form A-3

JOURNAL ENTRY LIST

JOURNAL ENTRY LIST \#

Client:

Project:

Project Name:

Entry By:

Entry Date:

Location:

Remarks :

Form A-4

CONTACT LIST

CONTACT LIST 非

Client:

Project:

Project Name:

Name:

Title:

Association:

Telephone: ( )

( )

( )

Dates:

A-5 
DOCUMENT LIST \#

Client:

Project:

Project Name:

Number:

Description:

Repository:

Date Mark:

Author/Authority:

Remarks :

Form A-6

PHOTOGRAPH LIST

PHOTO LIST \#

Client:

Project:

Title:

Description:

Reference \#:

Reference Sketch:

Camera: Location:

Orientation:

Site Conditions:

Date:

Time:

Photographers:

Repository:

Remarks : 
SKETCH LIST \#\#

Client:

Project:

Project Name:

Number:

Subject:

Objective:

Scale:

Photo Ref. 非:

Date:

Time:

Sketcher:

Remarks :

Form A-8

SPECIMEN LIST

\section{SPECIMENT LIST 非}

Client:

Project:

Project Name:

Number:

Specimen:

Description:

Cond. Removal:

Means of Removal:

Loc. Removal:

Sketch Ref. 非:

Photo. Ref. 非:

Sketch Ref. 非:

Remarks : 

APPENDIX B

Recommended Equipment for Field Inspection

B -1 
Camera, 110 (pocket type) with flash and film

Camera, $35 \mathrm{~mm}$ ( $f 3.5 / 50 \mathrm{~mm}$, or larger aperture) with flash \& film

Lens, telephoto

Lens, wide angle

Tripod, camera

Recorder, Cassette (Pocket Type)

Binoculars, $7 \times 35 \mathrm{~mm}$ or better

Monocular, $8 \times 20 \mathrm{~mm}$

Magnifier, pocket style, $4 \mathrm{x}$ to $10 \mathrm{x}$

Mirror, inspection

Optical distance-measurer

Fiberscope, flexible

Reticle, millimeter tenths scale

Level, hand

Level, circular

Level, vial

Level, carpenter's $4 \mathrm{ft}$.

Caliper, inside/outside 5 in.

Rule, 5 in. with millimeter scale

Rule, folding $6 \mathrm{ft}$.

Tape, $50 \mathrm{ft}$.

Scale, Engineer's

Scale, Architect's

Gauge, feeler

Flashlight

Penlight

Flexilight

Calculator, pocket

Hammer, masonry

Hammer, ball peen

Awl or ice pick (to check for rot in wood)

Plumb bob

Screwdriver

Pen knife

Handbook, Engineering (pocket-type)

Project Notebook with blank forms

Clipboard with blank, ruled and graph paper

Pocket Notebook (3-3/4" x 6-3/4")

Bags, Specimen

Tape and gummed labels

Felt markers and crayons

Heavy string and thumb tacks (to check sag or bulge)

Tape, plastic

Tape, "scotch"

Cards, Marking (5" $\left.\times 8^{\prime \prime}\right)$

Hairspray, Aerosol 
Penetrant dyes

Glass cover slips

Glue, cyanoacrylate or comparable

Hat, safety - shoes, safety - gloves, canvas

Electrical analyzer (plug-in type)

Magnet

Matches (to check draft)

Pencil and paper

Insertion thermometer

Manometer

Pitot tube

Tachometer

Clamp on ammeter with voltage scales

Differential pressure gage 



\section{APPENDIX C}

Potential Sources of Information on Buildings Being Considered for Solar Retrofit 


\section{APPENDIX C \\ Potential Sources of Information on Buildings Being Considered for Solar Retrofit [2]}

A. At the building site (facility engineer's files):

- Original drawings and specifications, including elevations, structural, mechanical/electrical, plumbing, HVAC)

- Operation and maintenance records

- Remodeling and maintenance records

- As-built drawings

- Fire inspection details

- Photographs

- Contracting officer's files, including laboratory records, certificates of compliance with specifications, batch plant reports, inspection reports, etc.

B. Building Contractor Files:

- Original drawings

- Preconstruction data

- Construction progress reports

- As-built drawings

- Final completion report

- Progress photographs and final photographs

- Landscaping and exterior details

- Operation and maintenance records

C. Surveying Contractor Files:

- Property line survey records

- Lot location information

- Elevations 
- Topographical map of site and drainage area

- Geological maps, profiles, and cross sections

- Water table elevations

- Geohydrological data

- Seismic data

D. Local Weather Bureau:

- Temperatures: maximum, minimum, and mean daily

- Precipitation: maximum, mean annual, snow accumulation

- Average humidity and range

- Solar index

- Air quality index: maximum and mean daily

- Other climatological data

E. Local and Major Federal or State Newspapers:

- Photographs (usually only final)

- Articles on design features

- Renovation or alteration articles

- Construction progress articles

F. Local and State Historical Societies and Local Library Historical Sections:

- Interior and exterior photographs

- Building records

- Historical information (past owners, past uses, important events at the building site, etc.)

- Especially check the Historic American Building Survey or the Historic American Engineering Record (U.S. Department of the Interior, Heritage Conservation and Recreation Service, Pension Building, Washington, D.C.) 

APPENDIX D

Methods for the Detalled Evaluation of Systems

APPENDIX D. 1

Concrete Systems

D-1 


\begin{tabular}{|c|c|c|c|c|c|}
\hline & 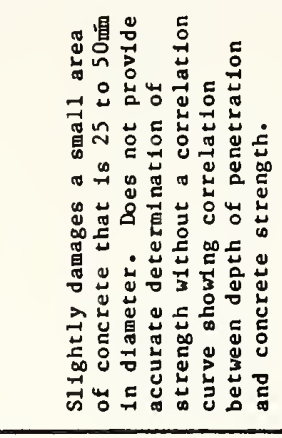 & 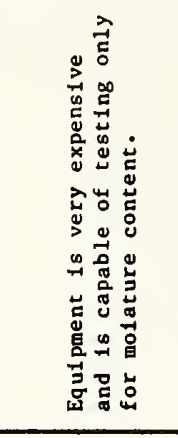 & 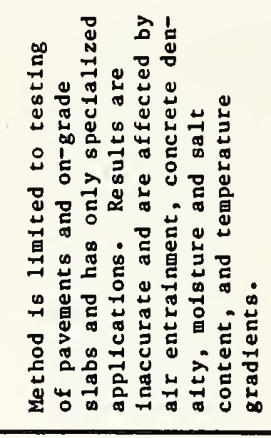 & 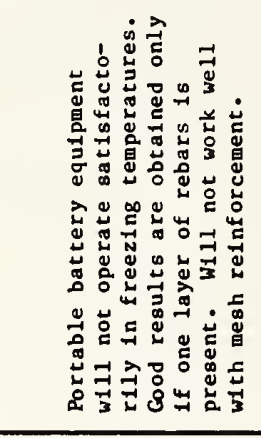 & 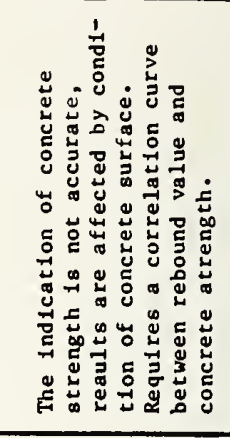 \\
\hline$\frac{3}{3}$ & 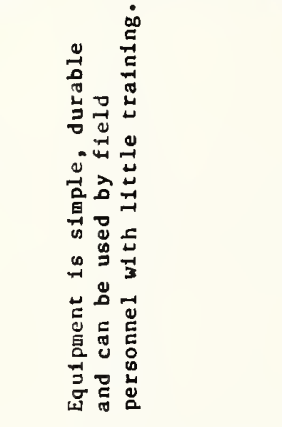 & 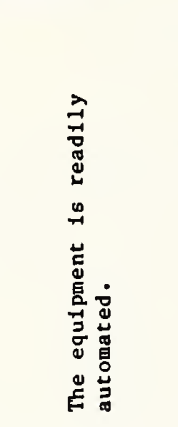 & 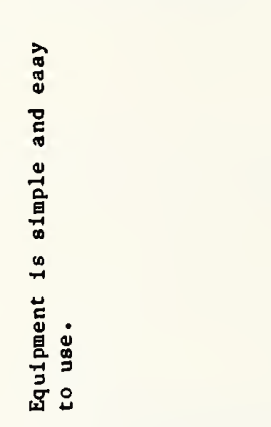 & 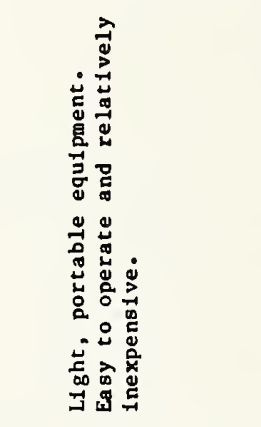 & 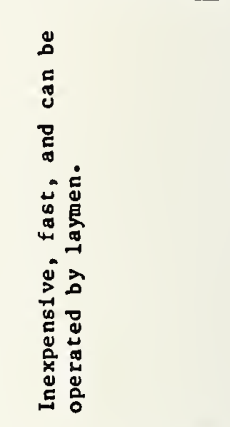 \\
\hline$\frac{a}{x}$ & 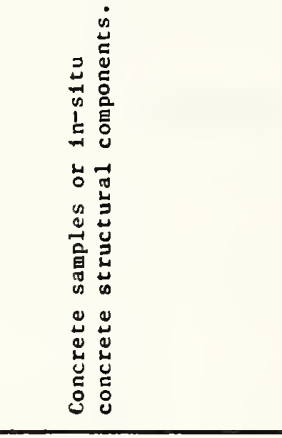 & 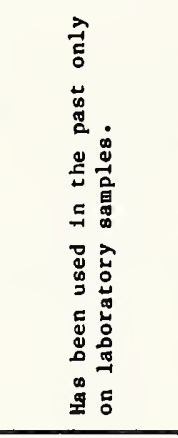 & 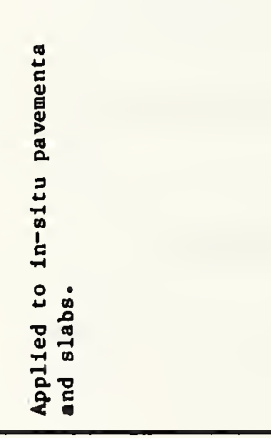 & 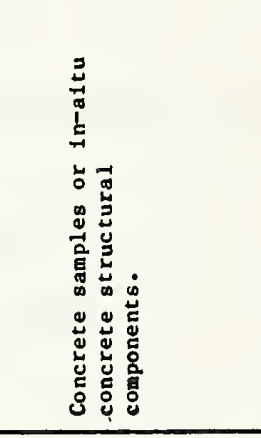 & 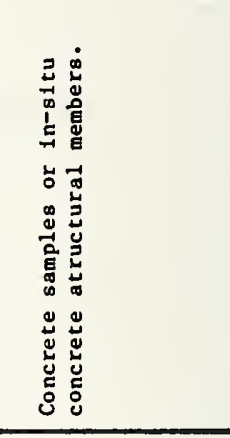 \\
\hline 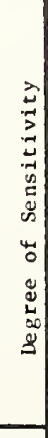 & 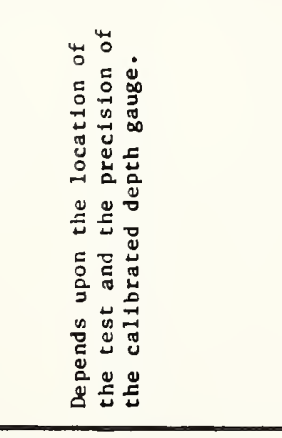 & 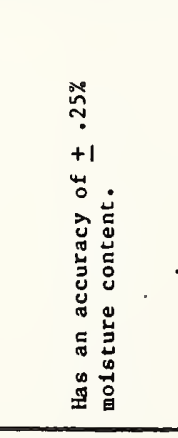 & & 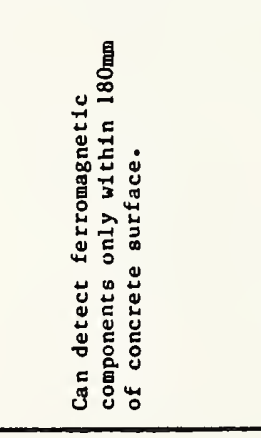 & 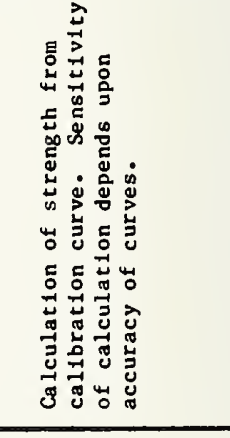 \\
\hline & 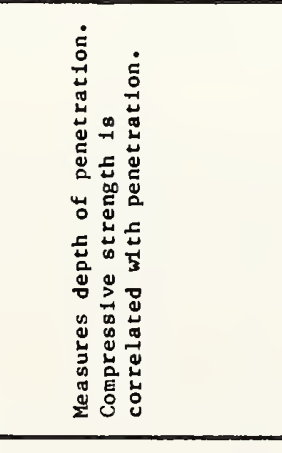 & 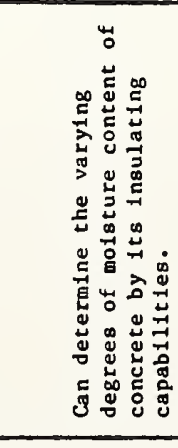 & 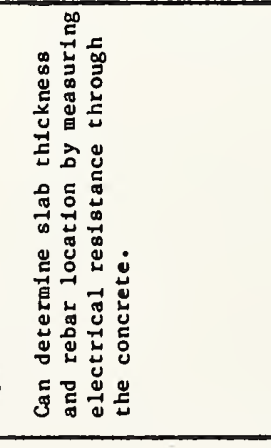 & 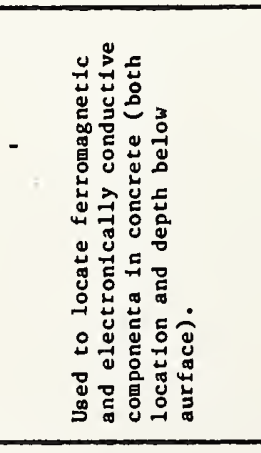 & 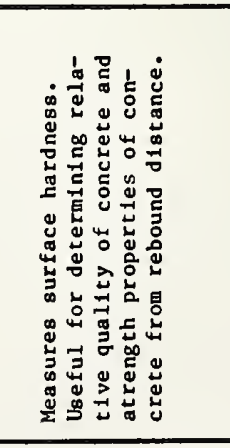 \\
\hline & 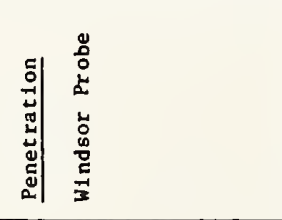 & 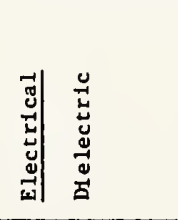 & 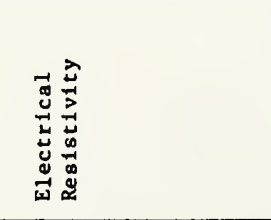 & 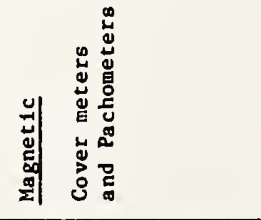 & 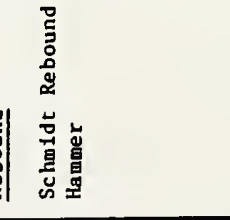 \\
\hline
\end{tabular}




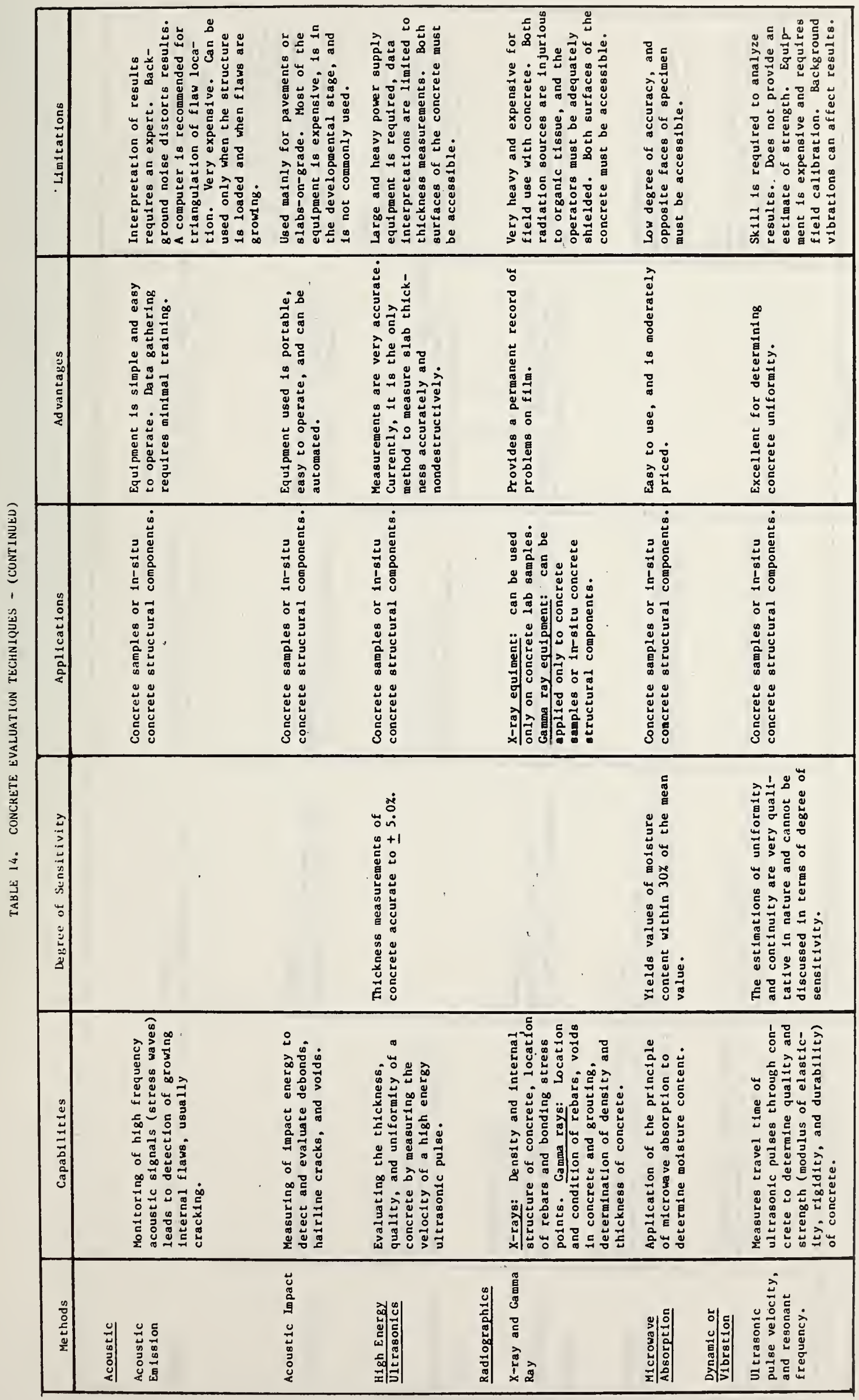




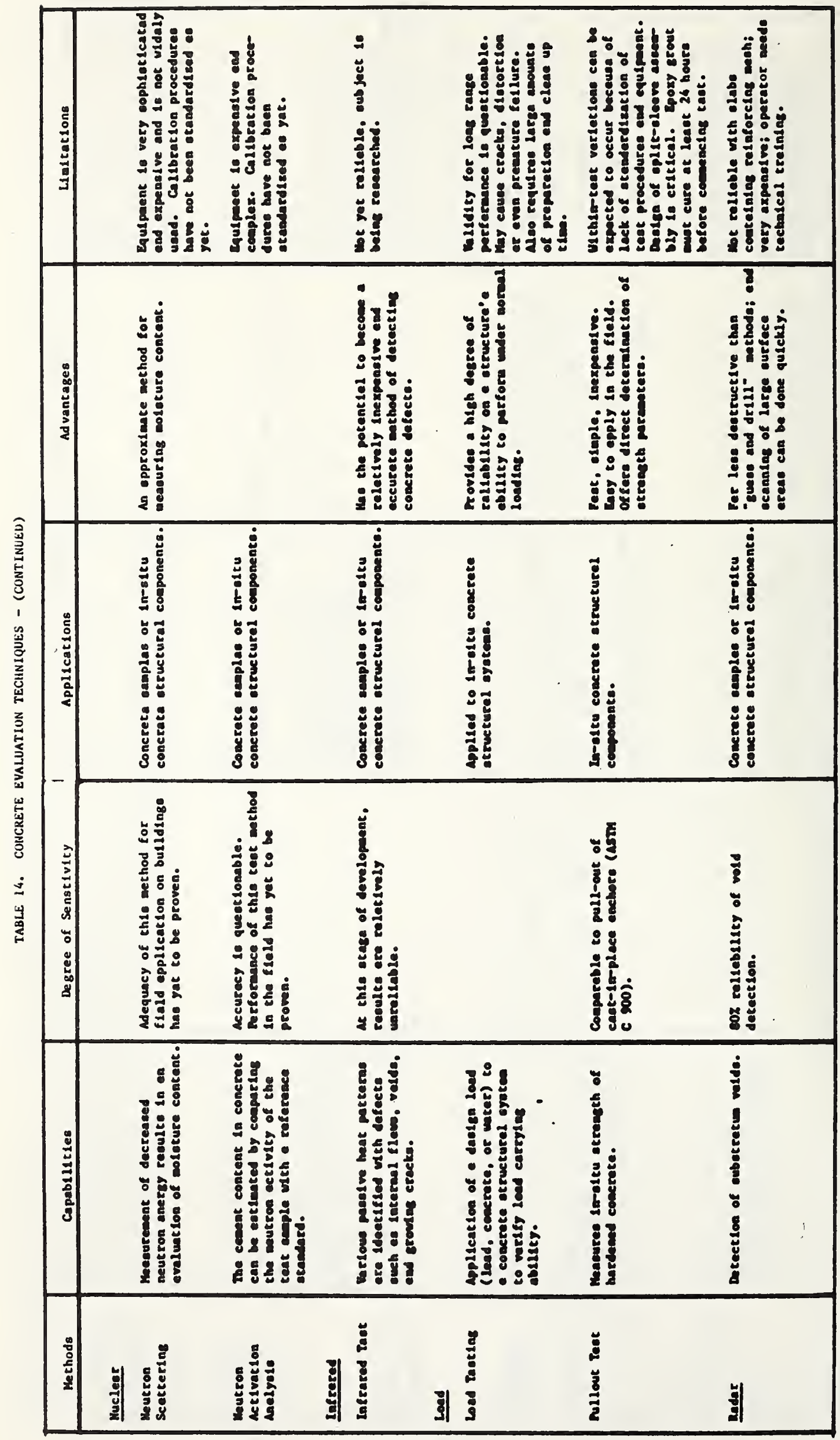


APPENDIX D. 2

\section{Wood Systems}

D-5 


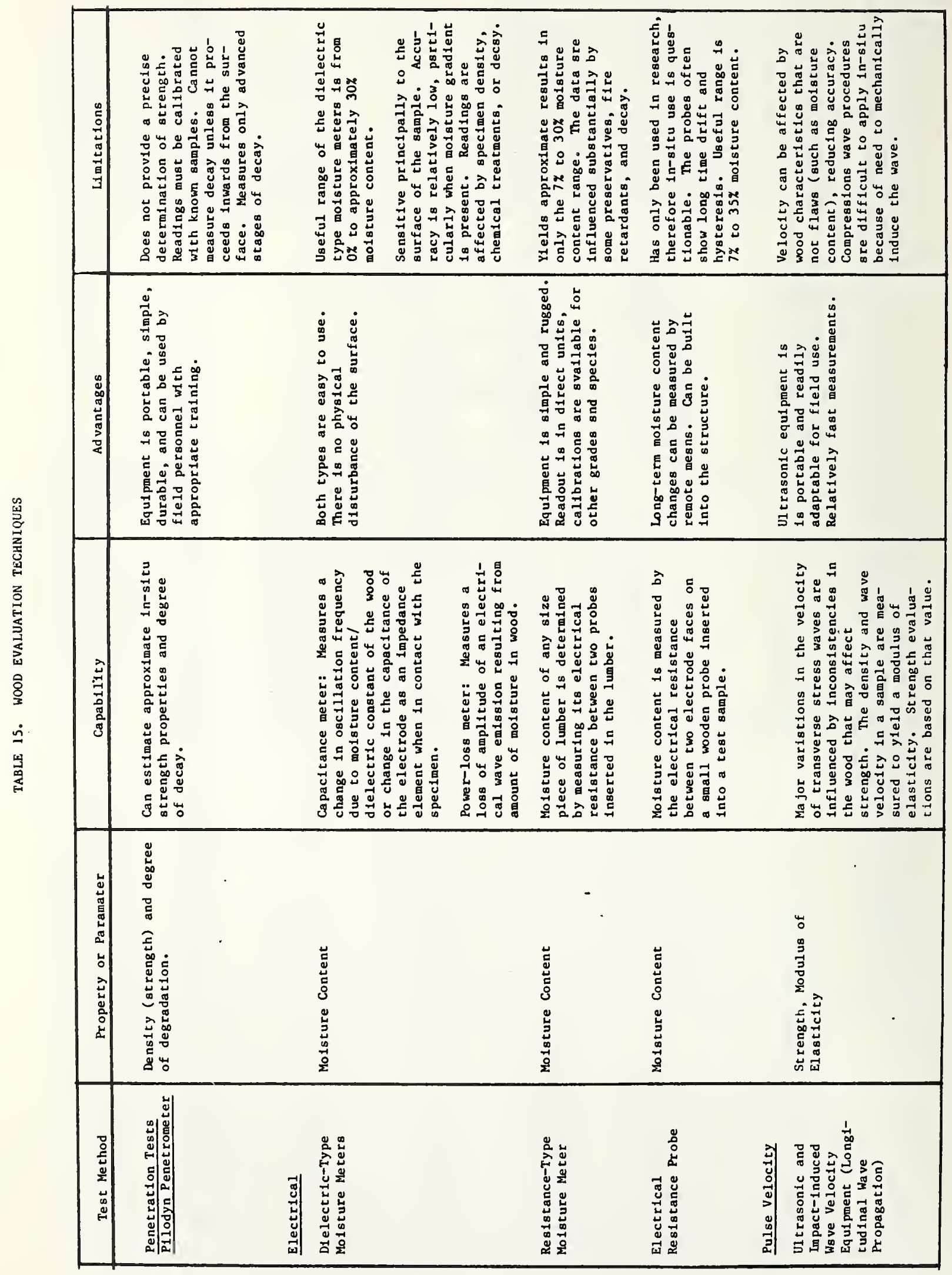




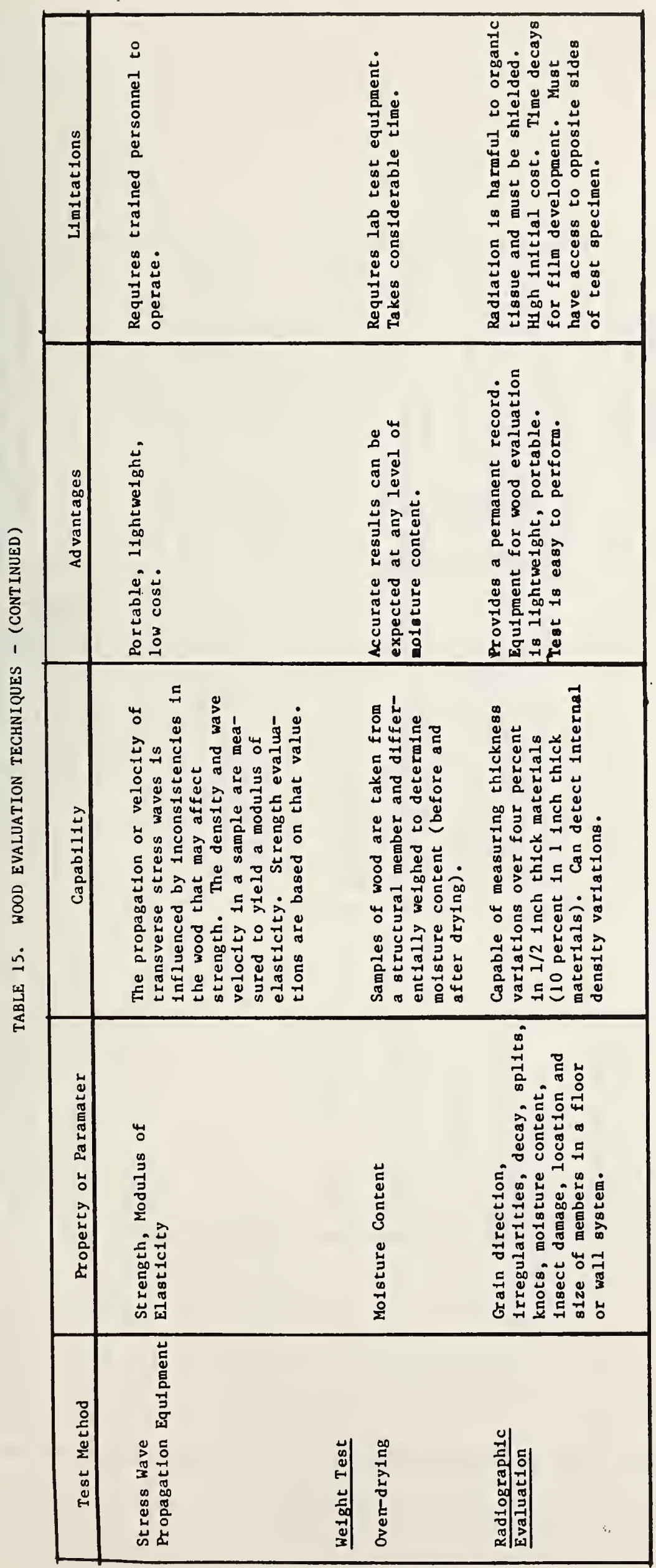

D-7 
APPENDIX D. 3

Masonry Systems

$$
\text { D-8 }
$$




\begin{tabular}{|c|c|c|c|c|c|c|c|c|}
\hline 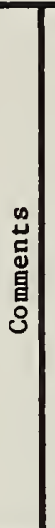 & 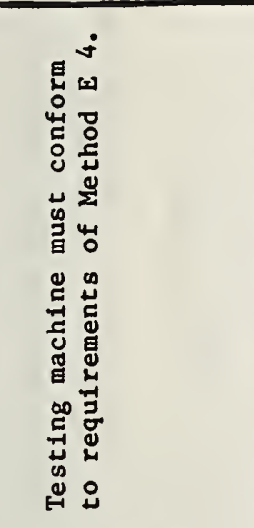 & 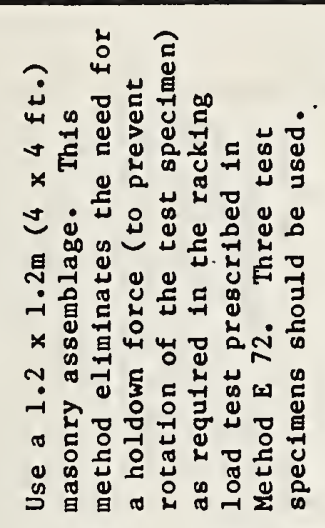 & 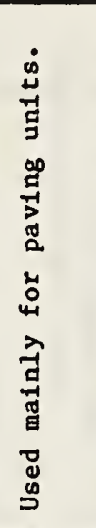 & 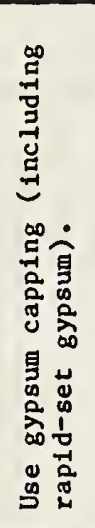 & 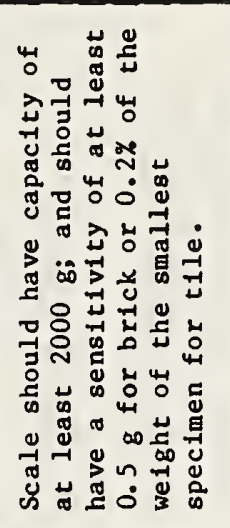 & 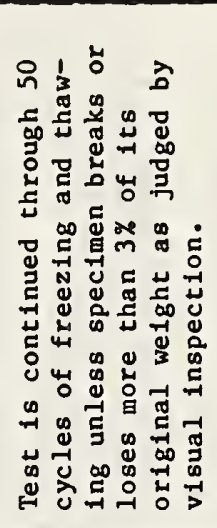 & 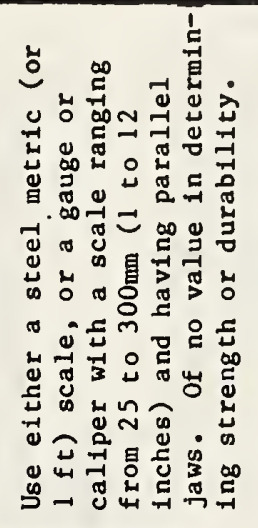 & 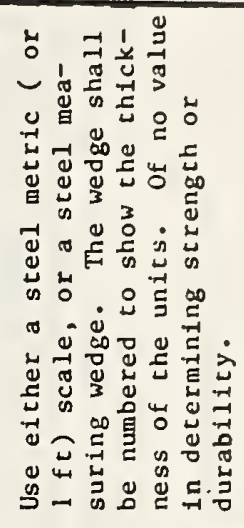 \\
\hline 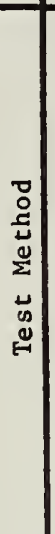 & 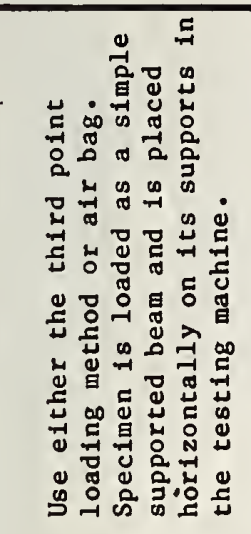 & 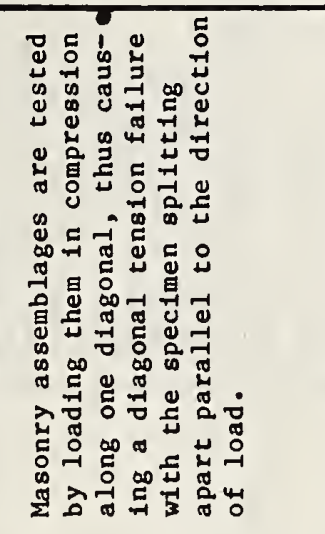 & 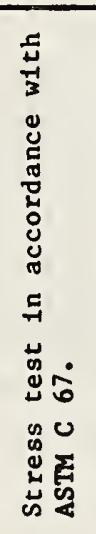 & 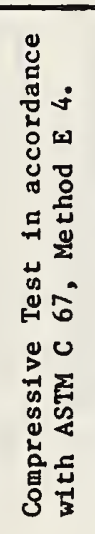 & 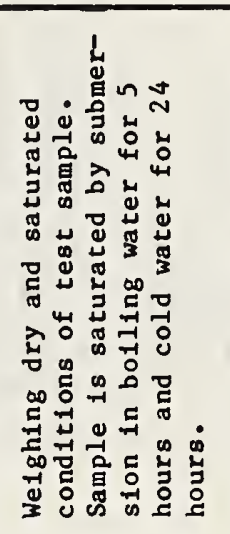 & 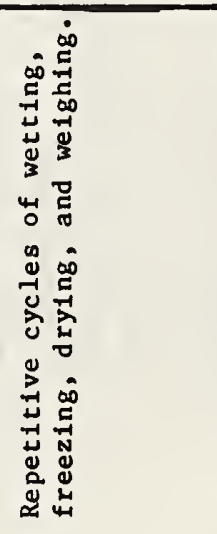 & 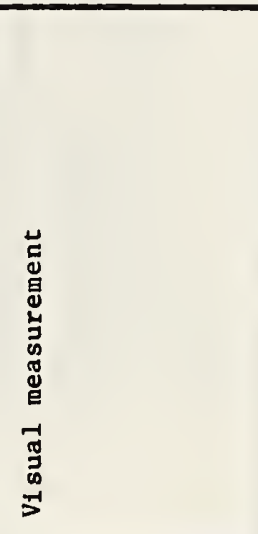 & 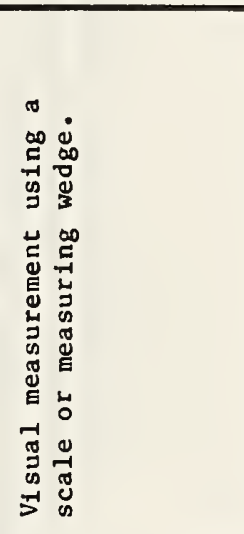 \\
\hline 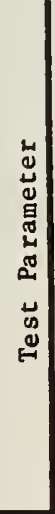 & 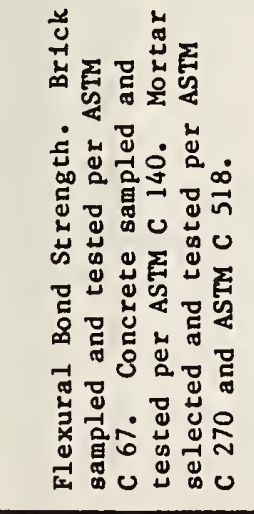 & 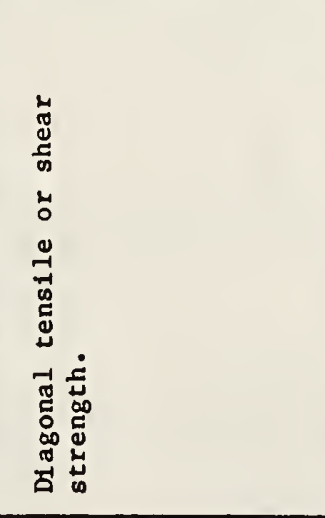 & 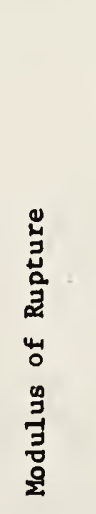 & 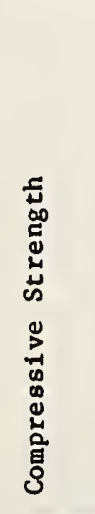 & $\begin{array}{l} \\
\\
\end{array}$ & 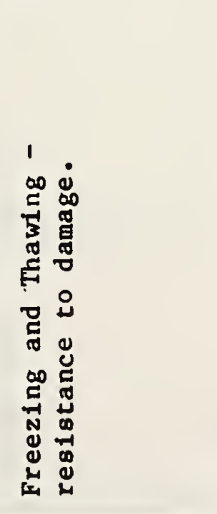 & $\stackrel{N}{N}$ & 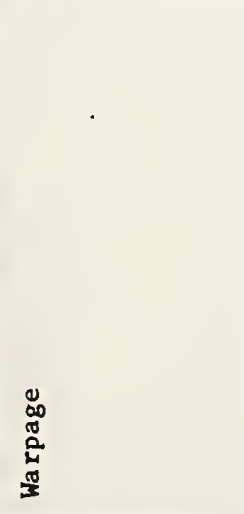 \\
\hline 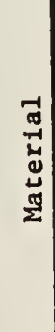 & 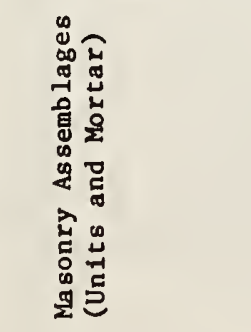 & & & & - & & & \\
\hline
\end{tabular}




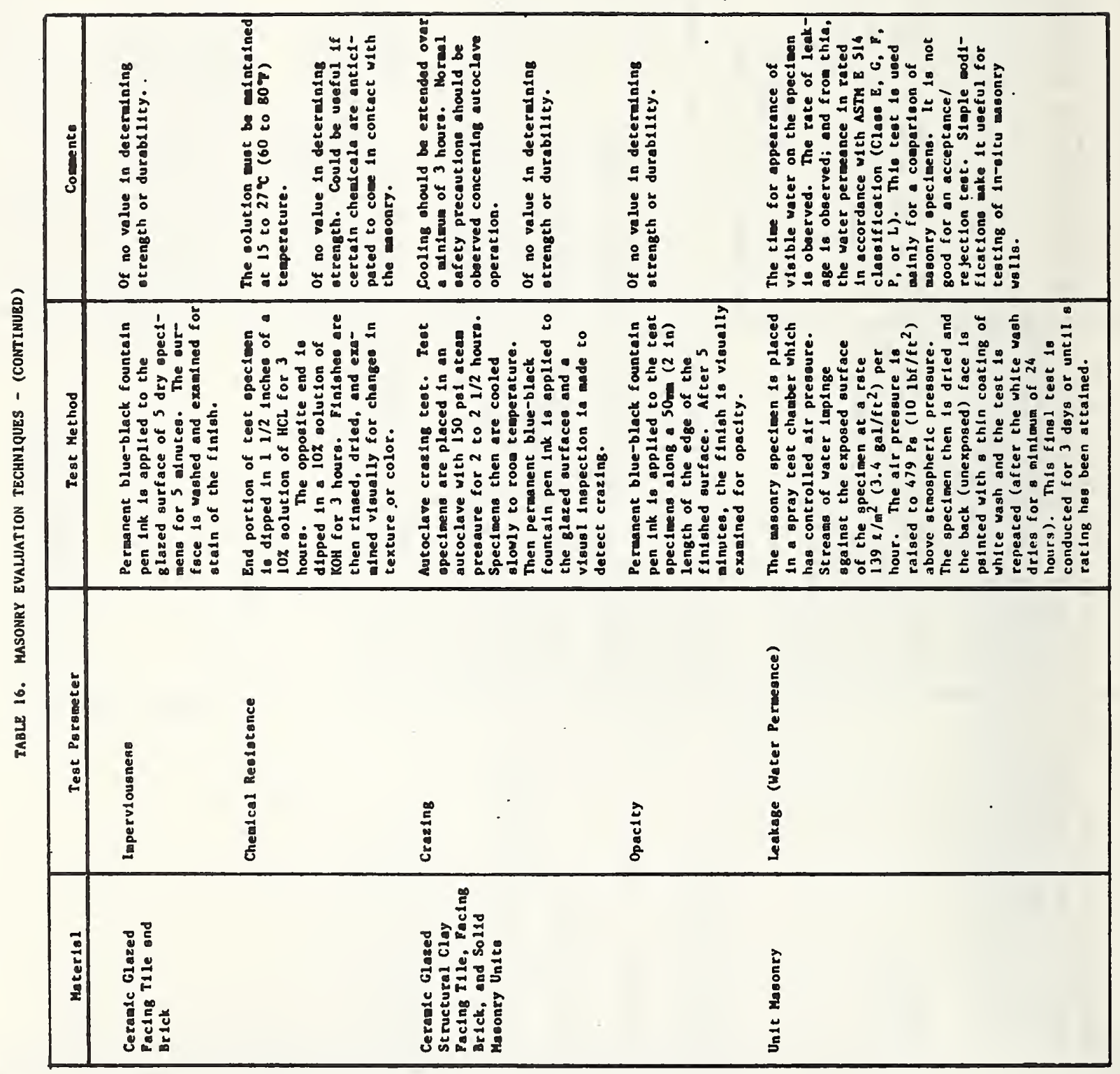




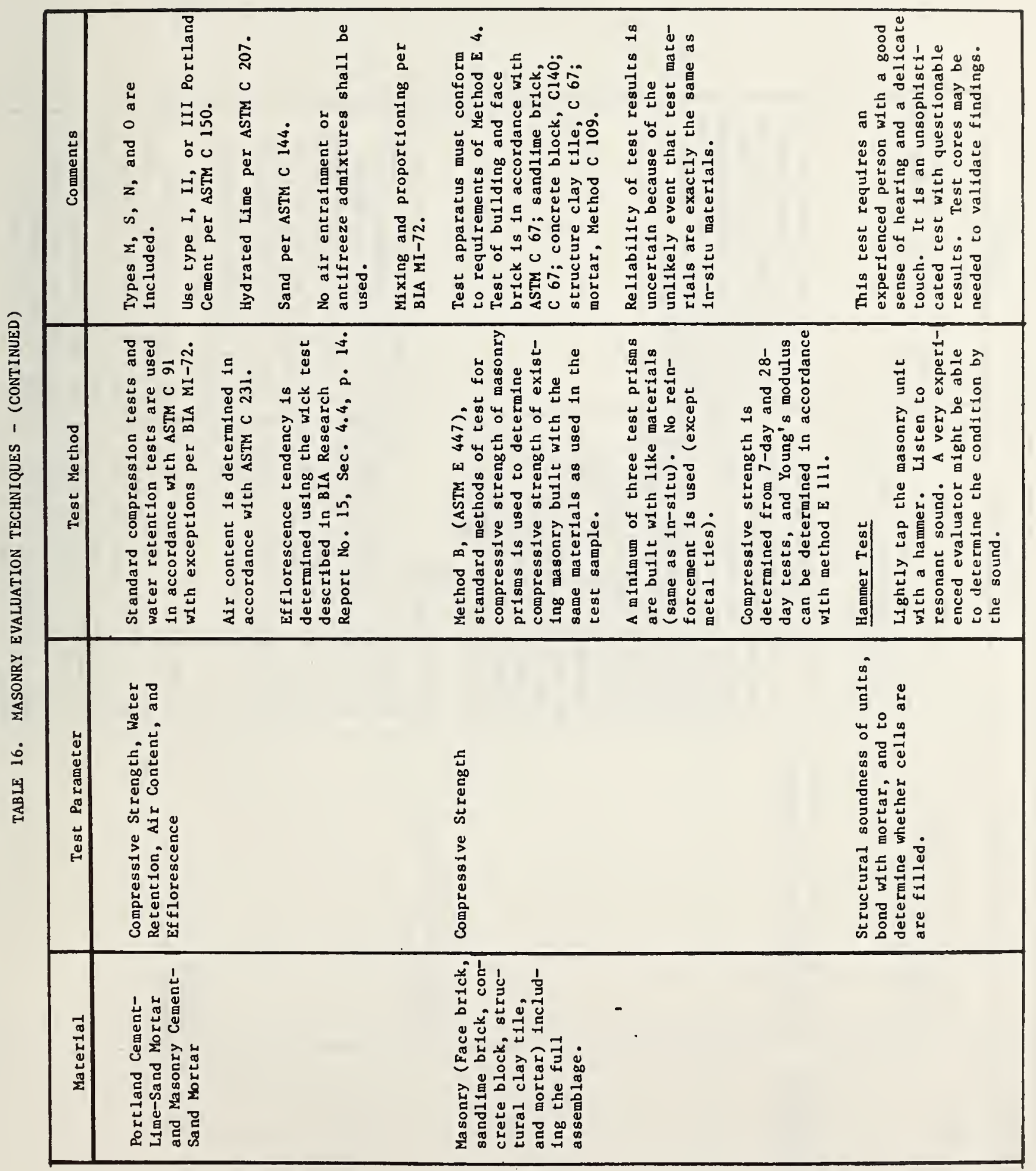




\begin{tabular}{|c|c|c|c|c|}
\hline 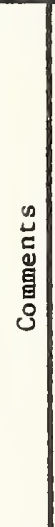 & 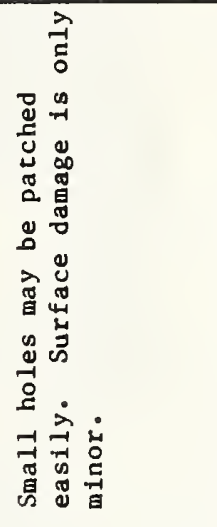 & 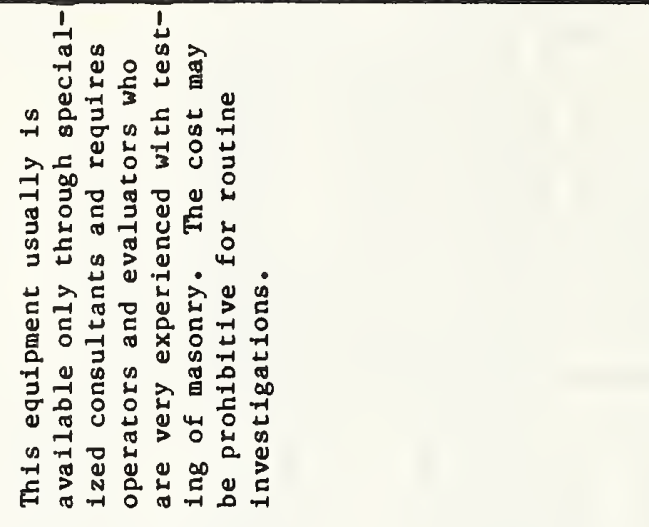 & 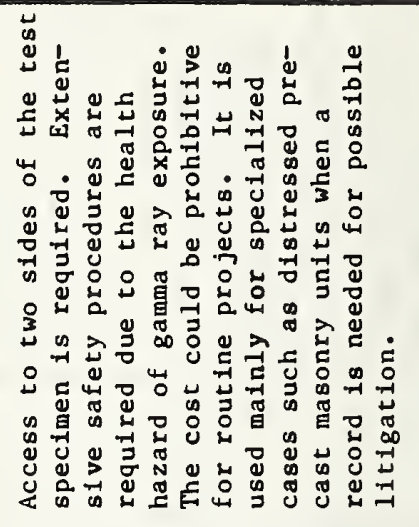 & 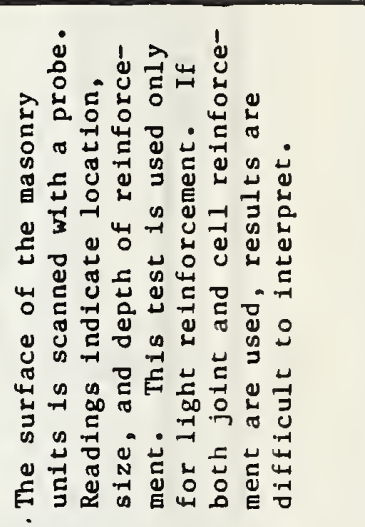 \\
\hline 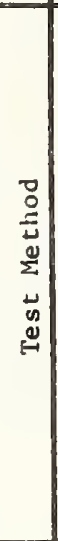 & 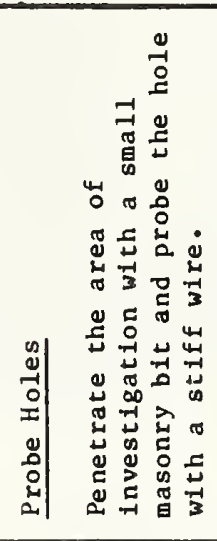 & 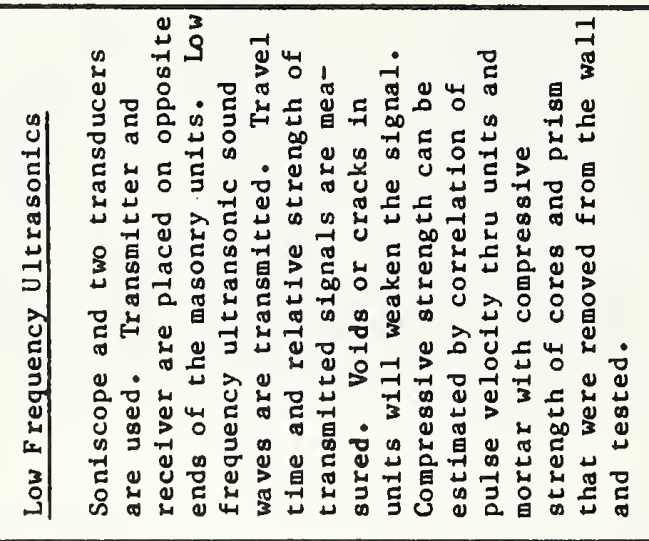 & 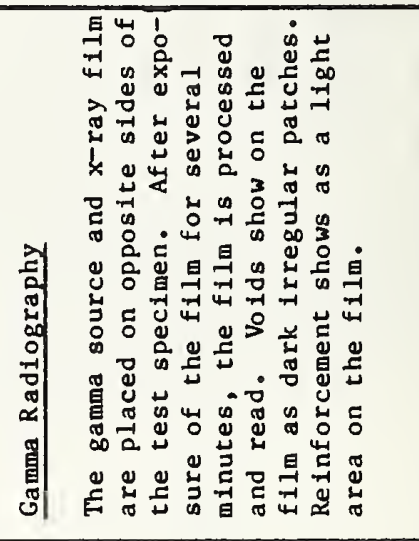 & 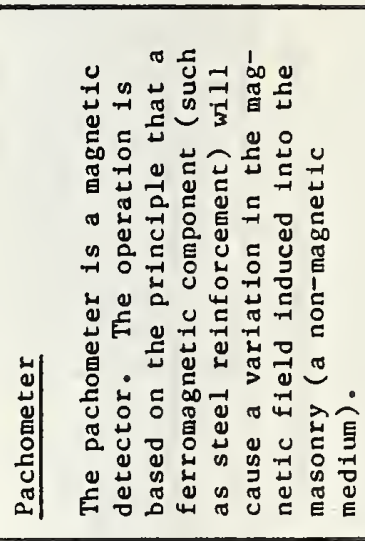 \\
\hline 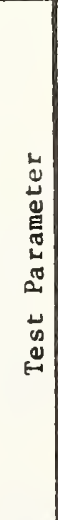 & 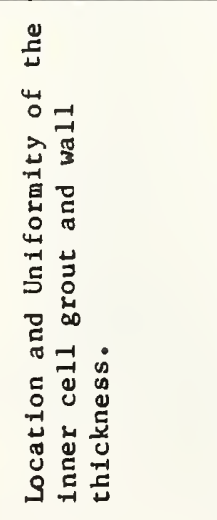 & 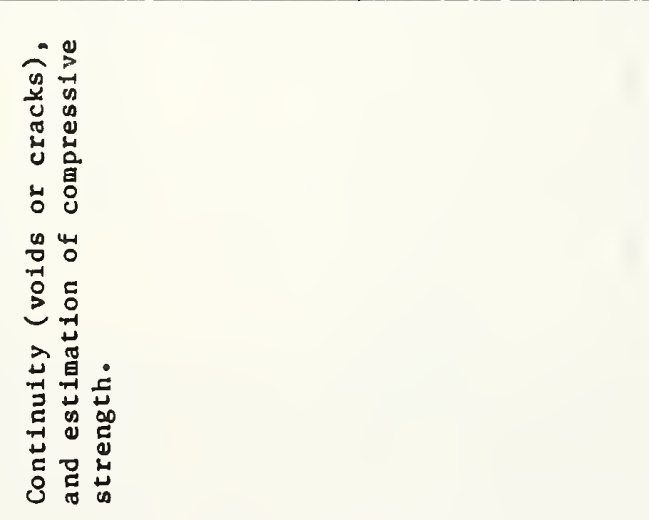 & 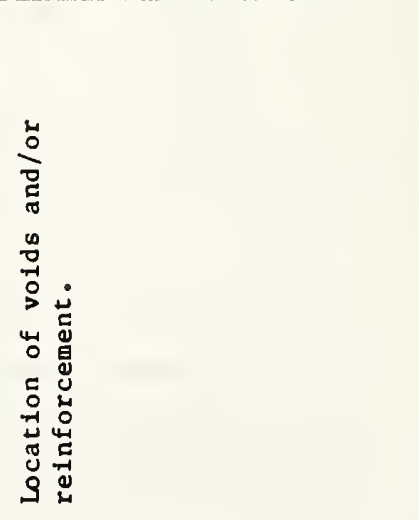 & 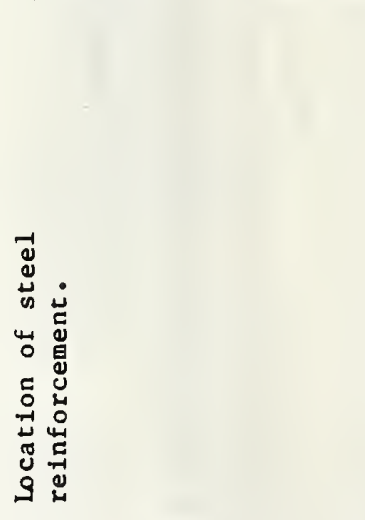 \\
\hline 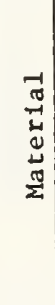 & 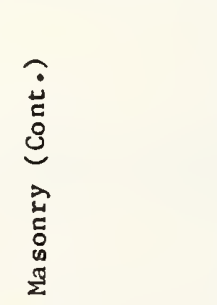 & 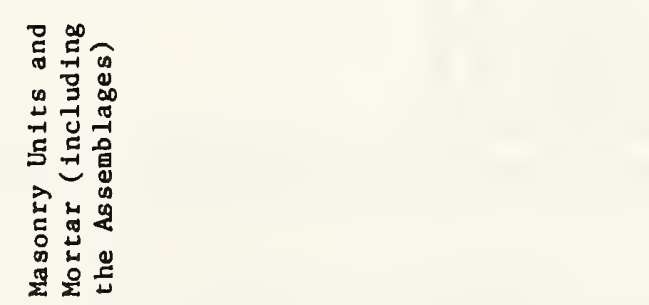 & & \\
\hline
\end{tabular}


APPENDIX D. 4

Metal Systems

D-13 


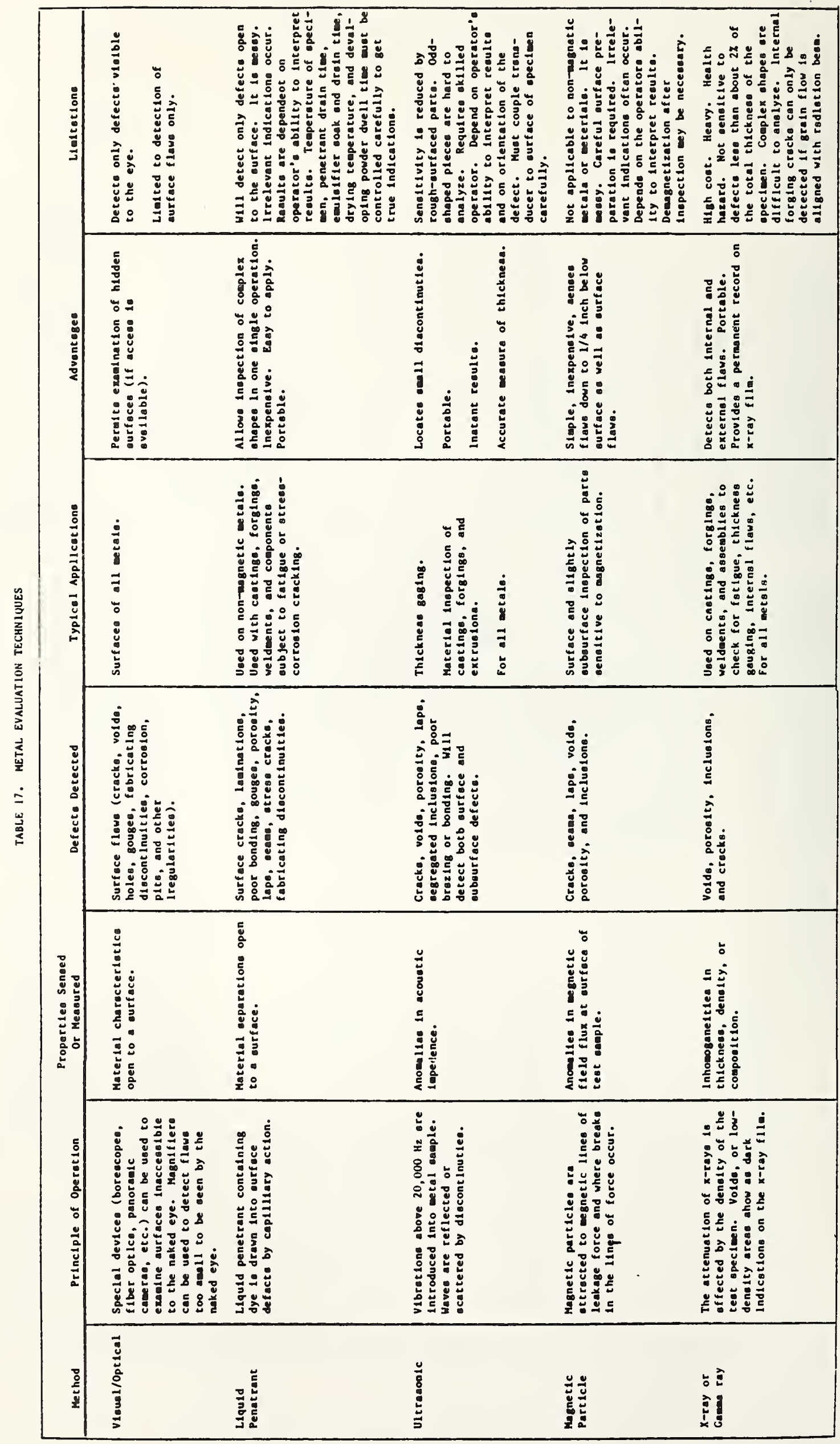




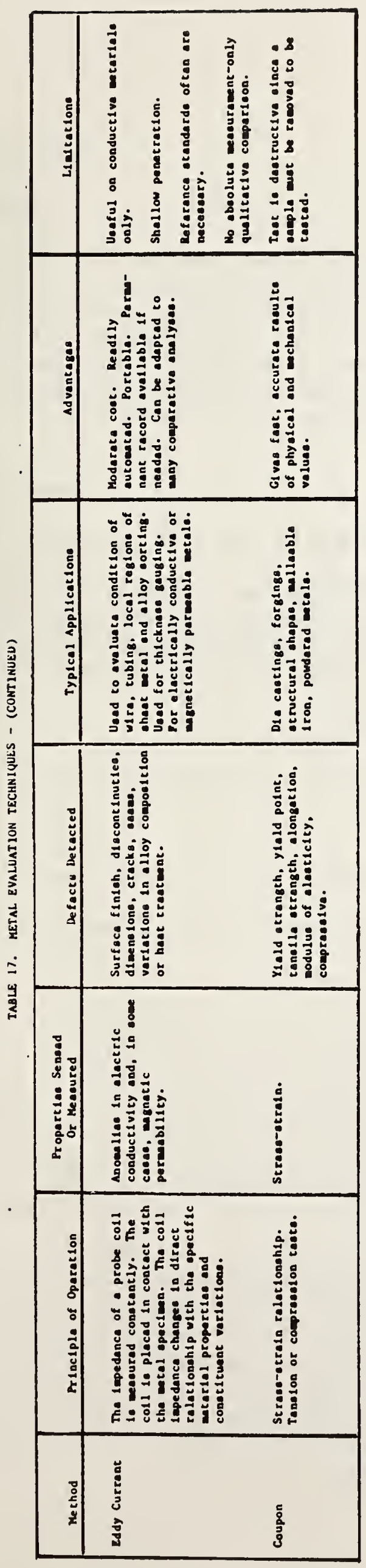


APPENDIX D. 5

HVAC Systems

$$
\text { D-16 }
$$




\section{5 HVAC SYSTEMS}

\section{5.1 GENERAL}

This section covers methods which supplement the information derived from the preliminary evaluation discussed in section 4. Methods outlined in this section include those procedures which are more detailed or sophisticated than those given under section 4. Accordingly, they will require a greater degree of expertise, understanding, judgment, and time. They should be conducted after the preliminary procedures of section 4, have been completed and the HVAC systems are still considered to be sound candidates for solar retrofit.

\section{5.2 GUIDELINES}

D.5.2.1 Determining Infiltration Rate Using Tracer Gas [42, 46]

The actual infiltration air exchange rate within a structure can be determined through the use of a tracer gas which is released into the space to be measured. The concentration of the gas then is monitored over a period of time, and the exchange rate can be expressed through the following relationship:

$$
I=-1 / t \ln (c / c o)
$$

where: I = infiltration rate as air volume changes per hour

$$
\begin{aligned}
t= & t i m e \\
c o= & \text { concentration of tracer gas at time zero (beginning of test) } \\
c= & \text { concentration of tracer gas at a specific time within the test } \\
& \text { period. }
\end{aligned}
$$

When the natural logarithm ( $1 n$ ) of the relative concentration (c/co) is plotted as a function of time, the rate of infiltration ( $I$ ) is the negative slope of the best fit line through the data points. Several tracer gases, such as carbon dioxide, helium, nitrous oxide, ethane, methane, and others, have been used as indicators of concentration of decay due to infiltration. Currently one of the most popular is sulfur-hexafluoride ( $\mathrm{SF}_{6}$ ). Samples of the air within the structure are taken and analyzed on the spot or stored in sample bags during the test and later analyzed.

The tracer gas technique is probably the best measure of natural infiltration because it does not introduce any unnatural constraints for making the determinations (other than some form of forced air circulation within the space to maintain mixing of tracer gas and air). The use of sulfur-hexafluoride requires very small amounts of harmless gas (generally on the order of 10-50 parts per billion) thus altering to a negligible extent the composition of the air. At infiltration rates of greater than three air changes per hour, the tracer gas technique may give unreliable results because of the introduction of larger

$$
\text { D-17 }
$$


amounts of unmixed air causing significant scatter in the data. Although higher rates of exchange seldom are encountered, where they do occur, greater care in mixing and more frequent sampling may be required.

\section{D.5.2.2 Determining Humidity with Color Changing Agents [56]}

The color change humidity indicator is a simple, inexpensive device for monitoring relative humidity within a structure. One such indicator uses cobaltous chloride as the basic ingredient for indicating the relative humidity. Cobaltous chloride is exposed to the atmosphere on blotting paper, and when equilibrium is reached, the color of the ingredient changes. P1ugtype indicators may be used to indicate the relative humidity in wall cavities and in enclosed roof ceiling cavities. Color change indicators may be used also to monitor the relative humidity in occupied spaces.

The available relative humidity range for various chemicals is from 10 to 80 percent. It is possible to measure relative humidity within five percent of the published equilibrium point. A $10^{\circ} \mathrm{F}$ change in temperature will affect indicator accuracy by only $2-1 / 2$ percent. Because the equilibrium point varies with the specific chemical used, a particular chemical is accurate only at a specific humidity (not a range). The accuracy of the indicator may be affected by temperature changes and long-term exposure to high humidity, high temperature, or direct sunlight. Direct contact with water also will cause the chemicals to leach out of the paper and thus lose their calibration.

\section{D.5.1.3 Determining Humidity with an Electric Hygrometer [57]}

With a change in humidity, many substances absorb or give up moisture and exhibit changes in electrical impedance. Sensors are available which have dual electrodes or windings that are electrically separated by a thin film of binder material containing a salt solution (such as lithium chloride). Means are provided for measuring the AC electrical impedance between the electrodes through the salt film. Since the impedance through the salt responds to changes in relative humidity and temperature, accurate indications of relative humidity can be obtained.

These electrical impedance hygrometers are relatively sensitive to humidity changes and are adaptable for remote read-out. Accuracy is in the order of \pm 1.5 percent $\mathrm{RH}$ and elements are available to cover the range from 10 to 90 percent RH. Because the electrical impedance hygrometer is susceptible to damage by air contaminants and water, frequent calibration checks are required. Nevertheless, elements may be placed in remote places for monitoring changes in relative humidity under high humidity conditions.

\section{D.5.1.4 Determining Heating System Efficiency by Using Electric Co-Heating [58]}

Electric co-heating is a technique used to determine the net efficiency of a heating system (a furnace, for example) within a house. Several portable, thermostatically controlled, and metered electric heaters are distributed throughout the house. The furnace is turned off, and only the electric 
heaters are used to measure the total heat consumed in the house. Next, the furnace is turned on and cycled manually at an arbitrary rate (for example, four minutes on and sixteen minutes off) for about three hours. Throughout the procedure, the indoor temperature is kept constant by appropriate control of the heat provided by the electric heaters. Finally, the furnace is turned off and the electric heaters again carry the full load to obtain a check on the total load.

The indoor temperature is recorded and periodic measurements of the outdoor temperature are taken. Also, the air infiltration rate (through cracks in walls, etc.) is monitored using tracer gas techniques. The following steps are then used to calculate the net system efficiency:

1) The heat load, including air infiltration, is determined through the power consumed by the electrical heaters operating alone.

2) The portion of the heat load supplied by the furnace is determined from the difference between the measured total load and the measured electrical power consumed by the heaters while operating in conjunction with the furnace.

3) The efficiency is calculated by dividing this difference by the average energy consumed by the furnace.

The electric co-heating technique also may be used to evaluate fireplace efficiency, and to determine the fraction of the heating load needed for the individual rooms in the dwelling. Unlike some methods of efficiency evaluation, electric co-heating cancels out distribution heat losses (through ducts, etc.). In other words, the efficiency calculation includes only the heat that benefits the living space. As a result, this method distinguishes between heating system efficiency and the house's envelope performance. Electric co-heating, however, is still in the development stage. For example, it is not practical for use with structures having a large number of rooms because of the present difficulty in monitoring the infiltration losses and the power consumed by the individual rooms.

\section{D.5.2.5 Determining Wall Thickness of Containment Vessels [59]}

It is possible to use ultrasonic techniques to determine the thickness of materials to obtain an indication of wear and deterioration. The pulse-echo ultrasonic thickness technique is recognized as an accurate method of measuring thickness of materials when the velocity of the pulse wave is known. Ul trasonic transducers have been developed that will allow the determination of piping and tubing wall thicknesses (as well as other forms) without physically penetrating the material. Ultrasonic pulses are generated and the time required for the pulse to be reflected back from the opposite surface is very accurately recorded. By knowing the transmission velocity of the material, and with the appropriate electronic circuitry, a digital readout can be obtained which is a direct measure of the thickness of the material. The technique has been used to evaluate large boiler installations for heat exchanger deterioration caused by corrosion.

$$
\text { D-19 }
$$


Small transducers are available to determine thickness of closed materials without physically penetrating the surface. By scanning the surface variations, wall thickness can be determined, thus gaining an indication of deterioration.

Some distortion results from rough surfaces as the ultrasonic pulse is scattered, with a resulting lack of sharpness in the return echo. As surface curvature increases, the coupling efficiency between transducers and the material to be measured decreases, causing some loss in accuracy. Some materials have special acoustical characteristics and can cause scattering, velocity variation, and attenuation, with a resulting loss of accuracy. For these reasons, it is important that thickness determinations be made by experienced personnel.

D.5.2.6 Determining Blower Revolutions per Minute (RPM) and Horsepower (HP) to Maintain System Air Flow Rate [7]

When solar equipment is added to an existing warm air heating system, it may become necessary to add a hot water heat exchanger to the existing ductwork. This will increase system resistance and will require increased blower RPM to maintain the original air flow rate. The RPM needed to overcome the increased system resistance is determined by:

$$
\frac{\mathrm{N}_{2}}{\mathrm{~N}_{1}}=\frac{\mathrm{P}_{2}}{\mathrm{P}_{1}}
$$

where

$P_{1}$ is the existing system static pressure

$\mathrm{N}_{1}$ is the existing blower RPM

$\mathrm{P}_{2}$ is the new system static pressure

$\mathrm{N}_{2}$ is the new blower RPM required

The increased power requirements then are determined by:

$$
\frac{\mathrm{HP}_{2}}{\mathrm{HP}_{1}}=\left[\frac{\mathrm{N}_{2}}{\mathrm{~N}_{1}}\right]^{3}
$$

where

$\mathrm{HP}_{1}$ represents the existing power requirements as motor horsepower

$\mathrm{HP}_{2}$ represents the new power requirements resulting from the increased RPM

The existing blower power can be determined by using an ammeter and a voltmeter as described in section 6.1 .3$.

Blower manufacturers keep on file the blower performance characteristics of all blowers manufactured by them. A set of characteristic curves for a simulated blower is illustrated in figure 7. With the existing system air flow rate (CFM) and blower RPM known, the estimated existing system static 


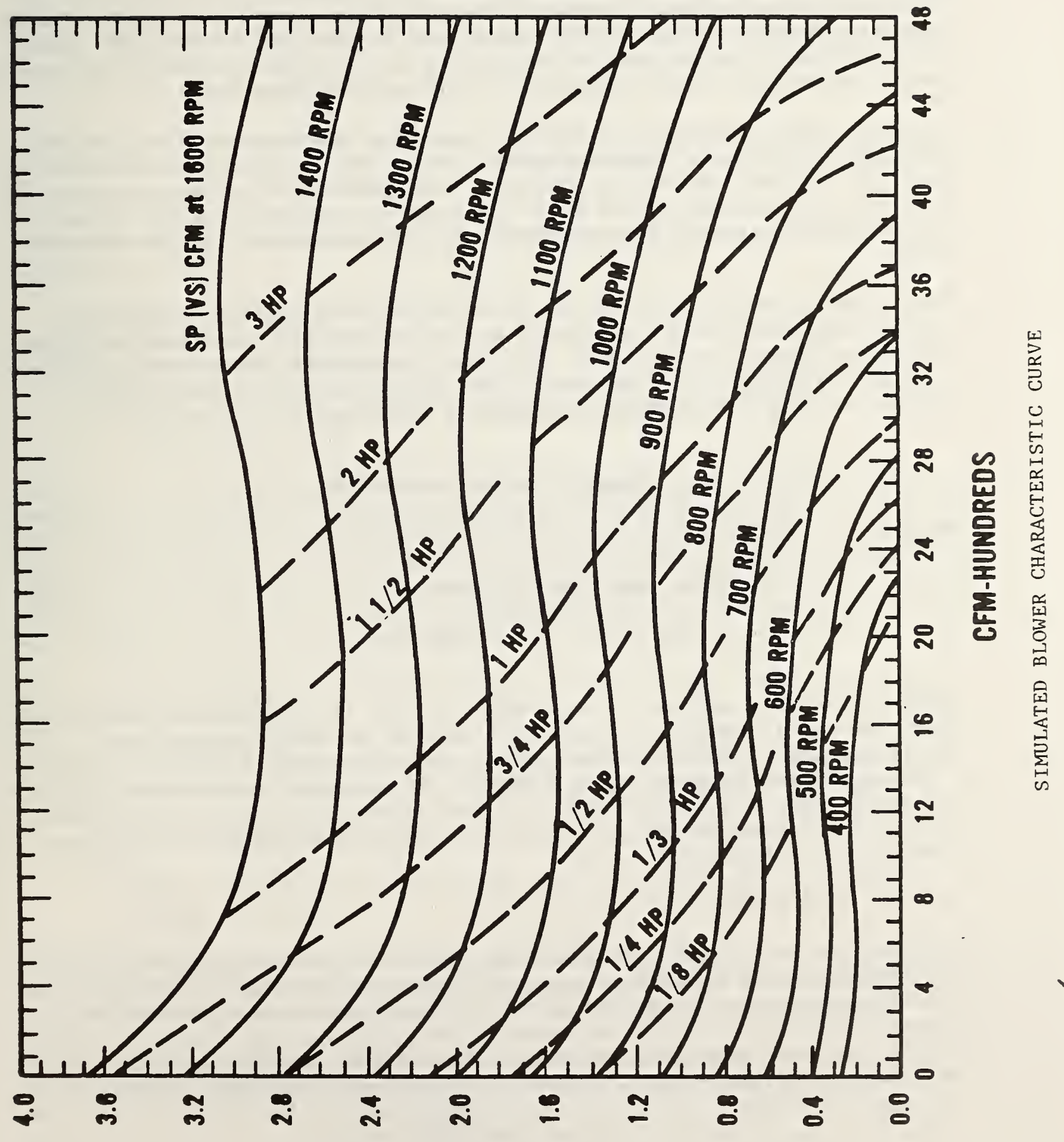

'gM' J JAnSS3yd JIIVIS

FIGURE 7 [7] 
pressure drop may be estimated and the corresponding HP may be determined. For example, according to figure 7, the simulated blower depicted is expected to deliver $2400 \mathrm{CFM}$ against approximately 1.4 inches of water system static pressure, requiring approximately $1 \mathrm{HP}$ of motor power, at a blower speed of 1000 RPM. Note: Figure 7 cannot be used for any other blower. The manufacturer's specific characteristic curves must be used for the specific blower in question. Other methods for estimating the existing system CFM and system static pressure drop are discussed in sections 4.2.9 and 4.2.10.

If a new heat exchanger coil is to be added to the existing blower system, the coil manufacturer will supply data on the static pressure drop across the coil for various standard air volumes. This additional resistance may be added to the existing system static pressure to determine the new system static pressure required to determine the new blower speed and HP discussed above.

For a belt driven blower, the blower speed may be increased by changing the sheaves (pulleys) on the blower and/or the motor in accordance with the following inverse relationship. The same relationship may be used to determine the existing blower RPM except that measuring RPM directly with a tachometer or a strobe light is much more accurate.

$$
\text { Blower } \mathrm{RPM}=\text { Motor } \mathrm{RPM} \times \mathrm{D}_{1} / \mathrm{D}_{2}
$$

where

$\mathrm{D}_{1}$ is the motor pulley pitch diameter

$\mathrm{D}_{2}$ is the blower pulley pitch diameter.

Direct drive fans may have a multi-speed motor. It then will be necessary to check the motor nameplate to determine whether the motor is multi-speed, and at which speeds it will operate. Also check the wiring of the motor against a wiring diagram located on the nameplate or equipment to determine whether the motor speed can be increased. If the blower speed cannot be increased, an additional booster fan can be added in series with the existing fan to restore system flow rate.

\section{D.2.5.7 Determining Duct Velocity [7]}

The air flow requirements of a cooling system are approximately 400 standard CFM (SCFM) per ton of cooling capacity. Since the air flow requirements for a cooling system are greater than the air flow requirements for a heating system, the retrofitting of an existing forced air heating system to include cooling may pose some problems with duct size. Air duct velocities can be determined from the system CFM and duct dimensions by a simple formula:

$$
\begin{gathered}
V=\frac{A C F M}{A} \\
D-22
\end{gathered}
$$


where ACFM is the actual system air flow rate in $\mathrm{ft}^{3} / \mathrm{min}$ and $\mathrm{A}$ is the duct cross-sectional area in $\mathrm{ft}^{2}$. Table 18 shows recommended and maximum air velocities for low pressure residential duct systems. If the duct velocity exceeds the values listed in table 18 , the ducts are undersized and should be enlarged, or the system. duct work redesigned to accommodate the increased air volume required for cooling. Note - the table is for low pressure duct work. Medium and high pressure duct work will tolerate greater velocities.

\section{5.2.8 Determining Performance of Heating Coils [7]}

This section covers the performance of central heating coils, zone heating coils (fan coil units, reheat units), natural convective heating equipment, and radiant heating equipment.

The performance of an existing forced air heating coil is limited by the following factors:

1) Supply water temperature

2) Water flow rate

3) Return air temperature

4) Air flow rate

5) Coil construction - materials, number of passes, etc.

6) Coil surface area.

Return air temperature is governed by space comfort conditions and is not appreciably alterable. Increasing the water flow rate has limited effect on full coil capacity, as shown in figure 8 . For a given heating coil construction and surface area, equivalent heat output can be obtained with decreasing supply water temperature by increasing the air flow rate, as shown in figure 9. Increasing air flow rate, however, introduces a number of potential problems. This method is satisfactory only if:

1) The supply air temperature does not fall below a reasonable level for room comfort;

2) The existing blower and/or the existing air supply terminal can be modified economically to provide for the increased flow rate;

3) The potential increased noise is not objectionable;

4) The increased air velocity does not create objectionable drafts within the space.

If these criteria cannot be met, it will be necessary to increase the heat exchange area or consider installing a higher temperature solar heating system (such as an evacuated tube or solar assisted heat pump system).

Additional heat transfer surface can be provided in a number of ways, depending upon the equipment. It is easiest to either replace the coil in an existing unit or add an additional coil to the unit. This will depend upon the replacement coils available for the unit, and whether or not space is available for the inclusion of an additional coil or a larger coil. 
TABLE 18. RESIDENTIAL DUCT AIR VELOCITY [7]

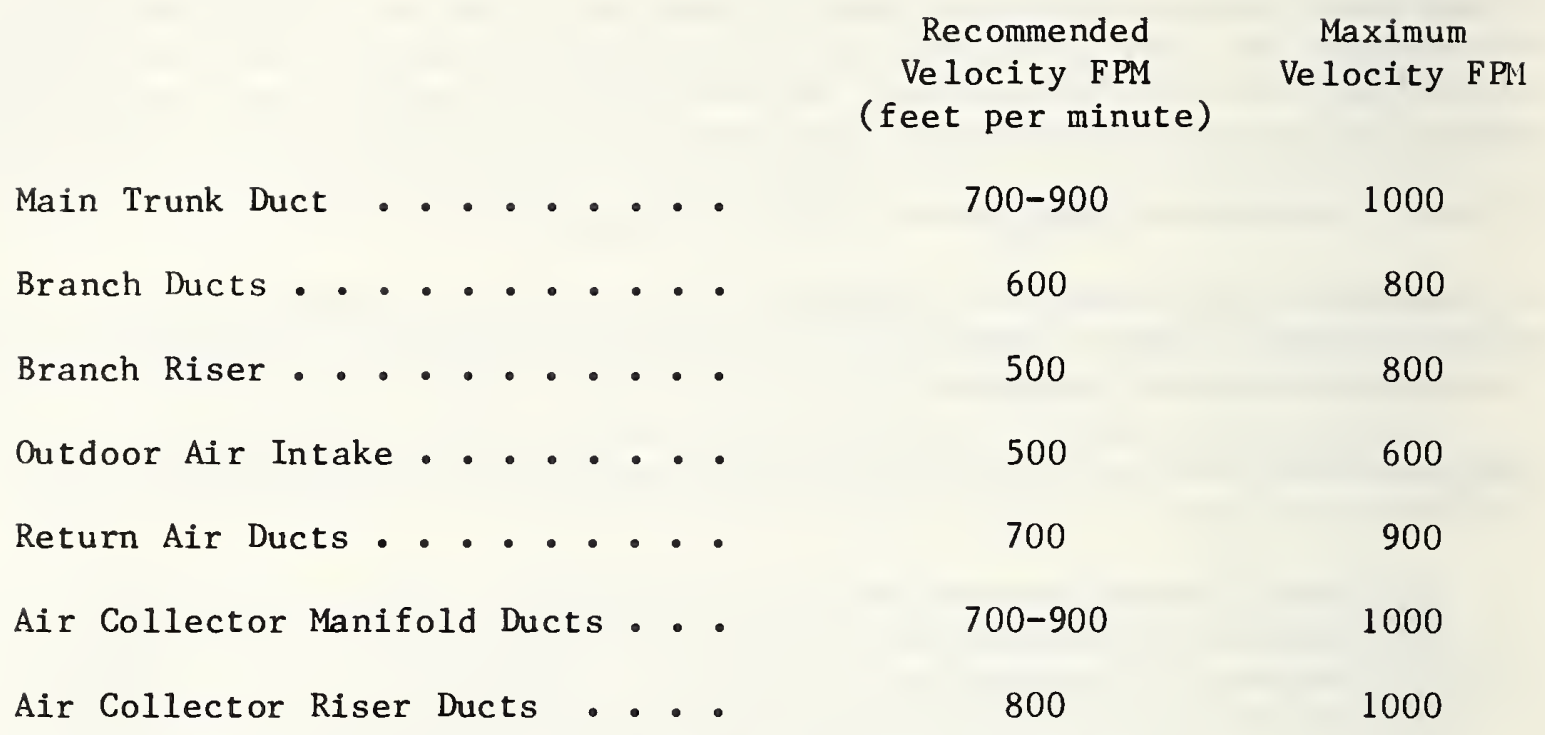

COMMERCIAL DUCT CLASSIFICATIONS

\begin{tabular}{lll} 
& \multicolumn{1}{l}{ Velocity } & Static Pressure \\
Low Pressure & $<2000 \mathrm{fpm}$ & $\mathrm{SP}<2$ in W.G. \\
Medium Pressure & $>2000 \mathrm{fpm}$ & 2 in $<\mathrm{SP}<6$ in \\
High Pressure & $>2000 \mathrm{fpm}$ & 6 in $<\mathrm{SP}<10$ in
\end{tabular}




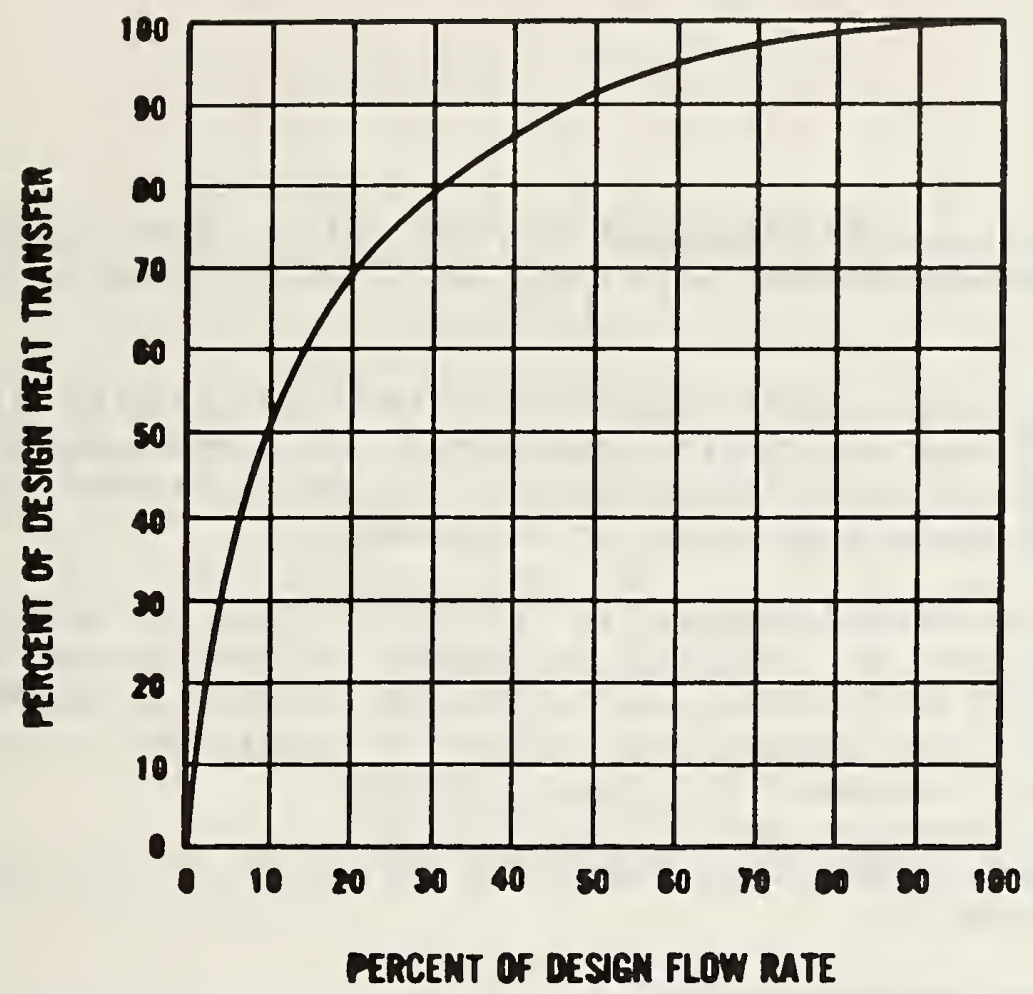

FIGURE 8 [7]

EFFECTS OF WATER FLOW RATE ON COIL HEAT TRANSFER FOR $20^{\circ} \mathrm{F}$ WATER TEMPERATURE DROP AT $200^{\circ} \mathrm{F}$ WATER SUPPLY TEMPERATURE

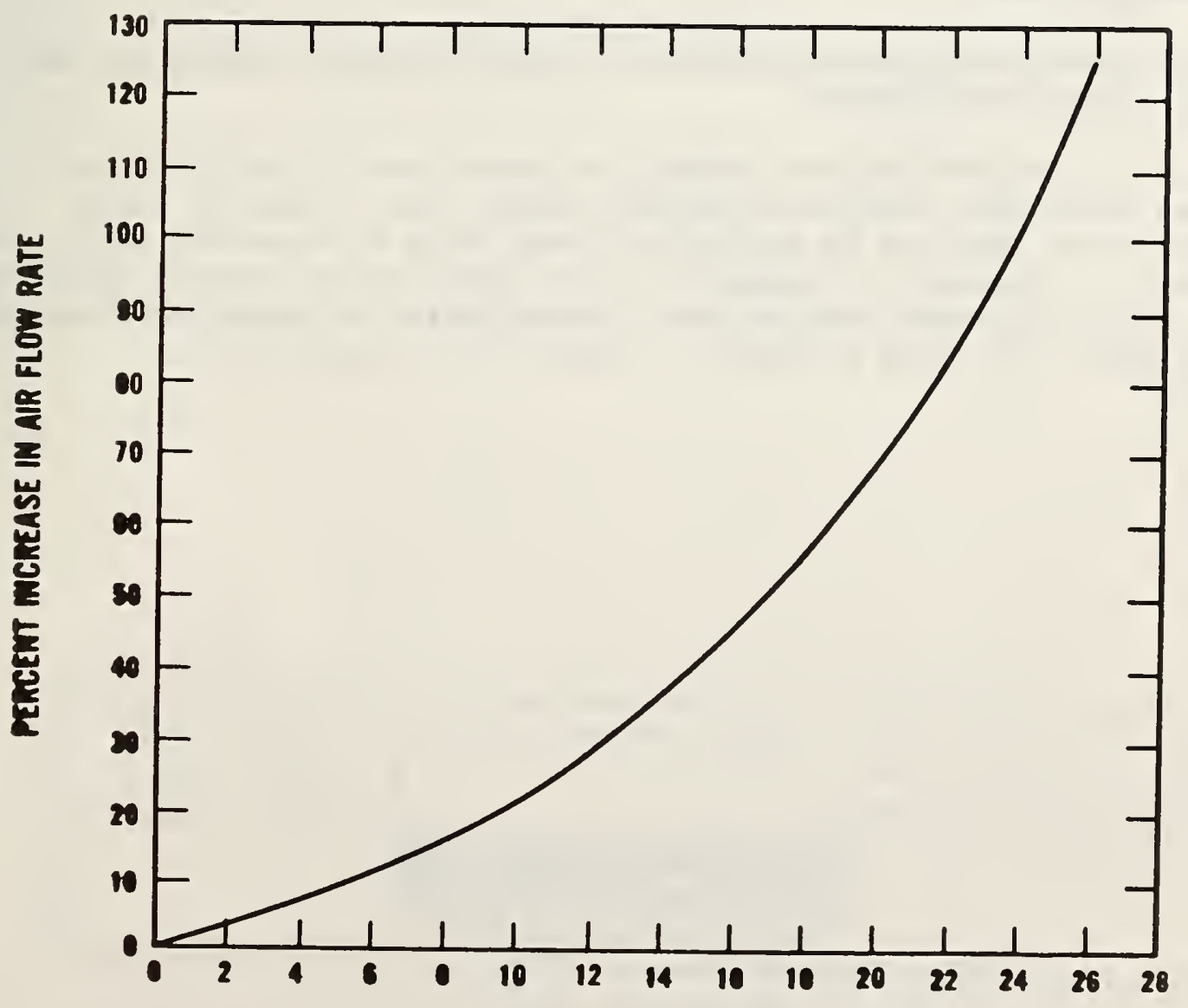

FERCENT OECREASE IN SUPPLY WATER TEMPERATURE

INCREASE IN AIR FLOW REQUIRED TO MAINTAIN CONSTANT HEATING COIL OUTPUT WITH DECREASE IN SUPPLY WATER TEMPERATURE 
Another alternative is to add additional fan/coll units. Each zone should be analyzed, to determine whether additional units can be placed in the zone.

Table 19 shows the characteristic change in heating coll capacity with changing supply water and return alr temperatures, all other factors remaining constant. The table again illustrates how coll heat transfer capacity is greatly reduced with decreasing supply water temperature.

This 1llustration is intended to show the limitations inherent with coll performance characteristics. Detalled performance information must be obtained from catalogs or from the manufacturer of the coil or heating unit, so that a qualified system designer may analyze the possibility of utilizing existing heat transfer equipment in a solar retrofit.

The performance of existing natural convective and radiant heat transfer equipment is influenced by:

1) Supply water temperature

2) Water flow rate

3) Room air or radiant surface temperature

4) Unit construction

5) Surface area

Radiant units additionally are influenced by their surface emissivity, but this effect is not significant.

The major factor influencing the capacity of these units is supply water temperature, with water flow rate playing a minor role. Table 20 shows correction factors that can be applied to these units to determine their offdesign capacity. However, it probably will be necessary to replace existing units with ones of greater surface area. Substitution of single row baseboard units with double row units as shown in figure 10 is one convenient alternative. 


\begin{tabular}{|c|c|c|c|c|c|c|c|c|c|c|c|c|c|c|}
\hline \multirow{2}{*}{$\begin{array}{c}\text { ENTERING } \\
\text { AIR } \\
\text { TEMP F }\end{array}$} & \multicolumn{14}{|c|}{ ENTERING WATER TEMPERATURES, F } \\
\hline & 95 & 100 & 110 & 120 & 130 & 140 & 150 & 160 & 170 & 180 & 190 & 200 & 210 & 220 \\
\hline 40 & .458 & .500 & .583 & .666 & .75 & .833 & .917 & 1.00 & 1.08 & 1.16 & 1.25 & 1.33 & 1.42 & 1.50 \\
\hline 50 & .375 & .417 & .500 & .583 & .666 & .75 & .835 & .917 & 1.00 & 1.08 & 1.16 & 1.25 & 1.33 & 1.42 \\
\hline 60 & .292 & .333 & .417 & .500 & .583 & .666 & .750 & .835 & .917 & 1.00 & 1.08 & 1.16 & 1.25 & 1.33 \\
\hline 70 & .208 & .250 & .333 & .417 & .500 & .583 & .666 & .750 & .835 & .917 & 1.00 & 1.08 & 1.16 & 1.25 \\
\hline 80 & .125 & .167 & .250 & .333 & .417 & .500 & .583 & .666 & .750 & .835 & .917 & 1.00 & 1.08 & 1.16 \\
\hline
\end{tabular}

NOTE: These Factors as based on constant GPM.

CAPACITY CORRECTION FACTORS FOR ENTERING CONDITIONS

OTHER THAN 60 F EAT AND 180 F EWT

TABLE 19 [7]

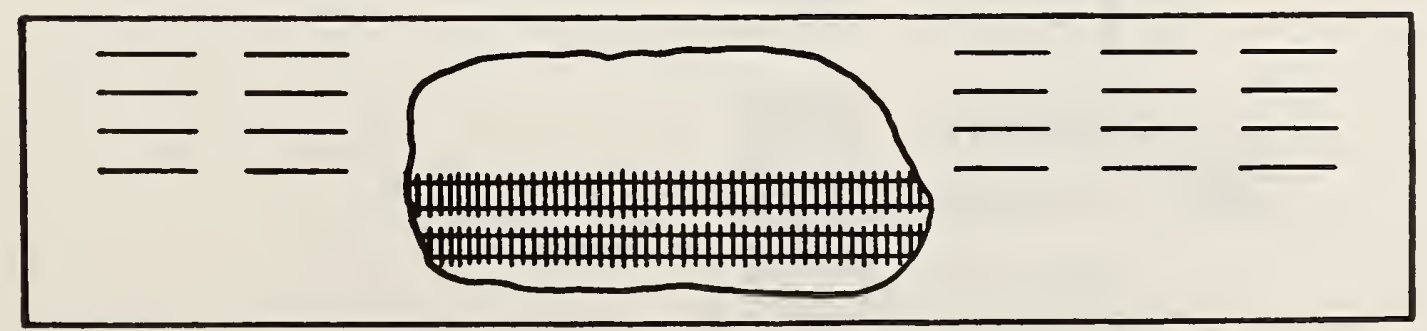

DOUBLE ROW BASEBOARD UNIT

FIGURE 10 [7] 


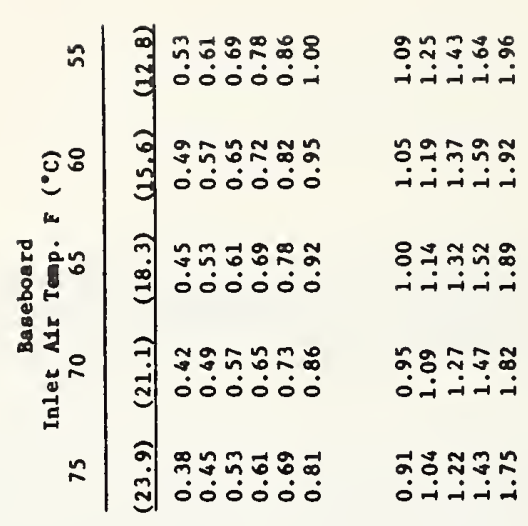

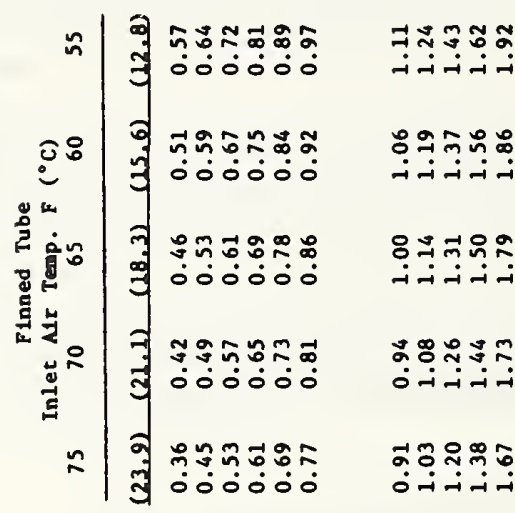

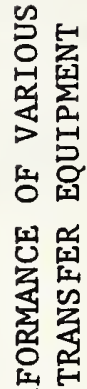

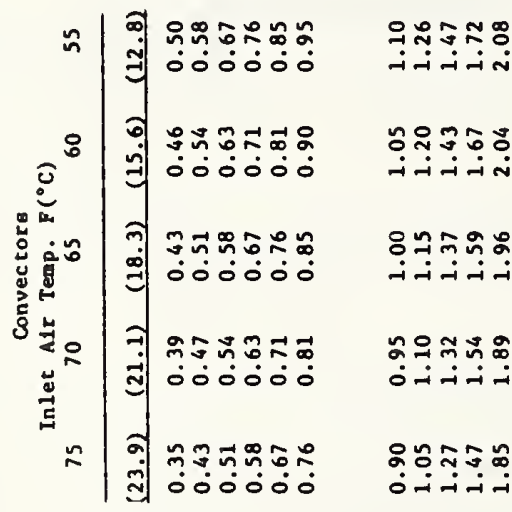

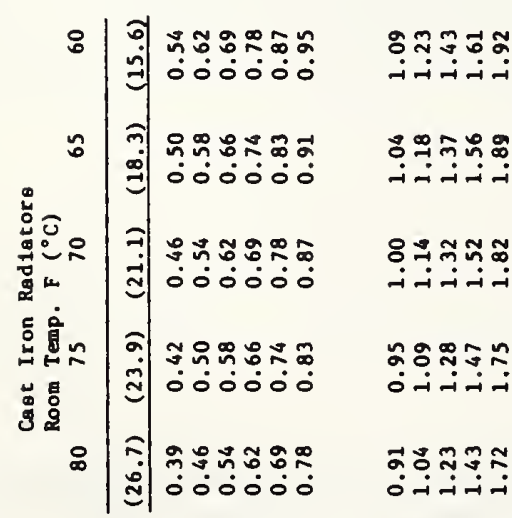
采 秃完 宓王 我 을

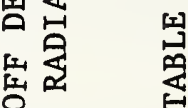
号是 语

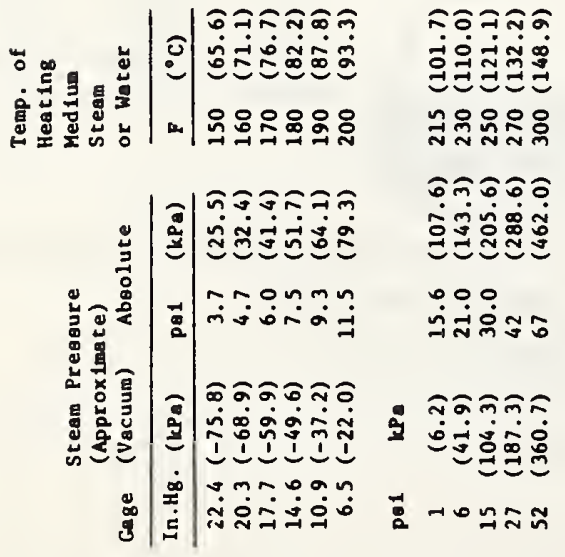




\section{D.5.2.9 Solar Heating and Cooling Schematic Drawings}

One of the most important elements in evaluating the suitability of a building for proposed solar retrofit is available space. In addition to the solar collectors on the roof, considerably space is needed for auxiliary equipment, some of which is both large and heavy. The equipment required will depend upon the type of solar system being considered and its relationship to existing heating and air conditioning equipment. In particular, space will be required for heat storage units, pumps, air handlers, and heat exchangers.

The following figures no. 11-15 identify the kinds of equipment needed for only a few of the possible solar heat configurations which are in general use. Included is a schematic drawing of the operating modes for one type of heat collector system. Before deciding what specific space is needed for solar heating, it is important to consult with a competent solar system designer. The kinds and configuration of equipment chosen will vary between designers, and will be strongly influenced by the existing system and its components, the character of load, location of building, and other factors. 


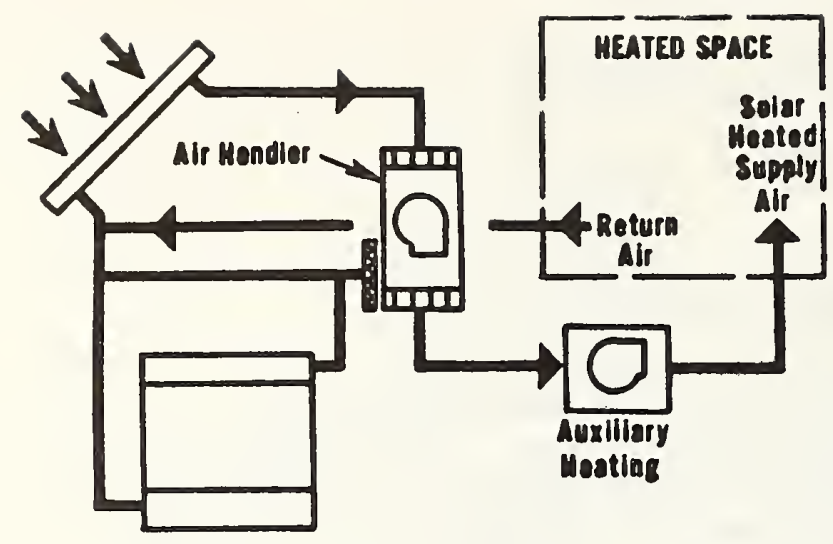

A HEATIMG from Collectors

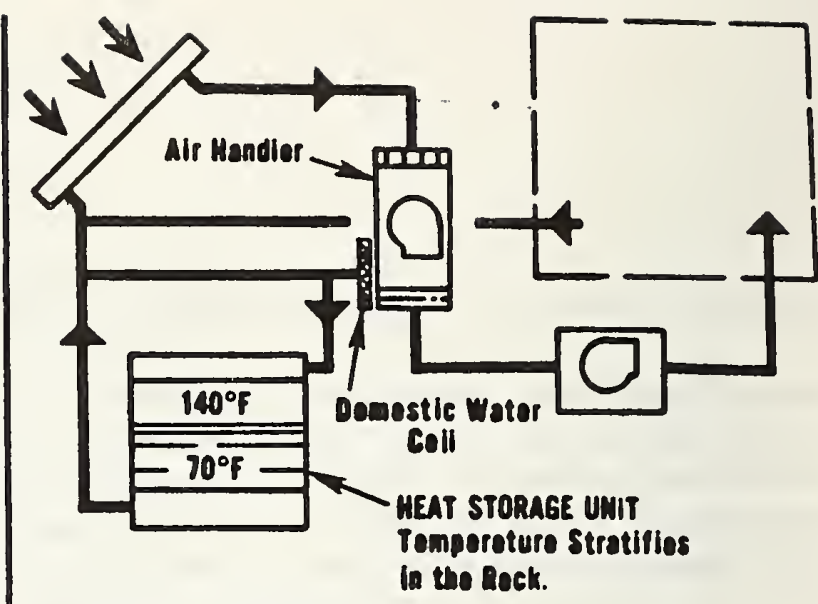

B STORING Heat

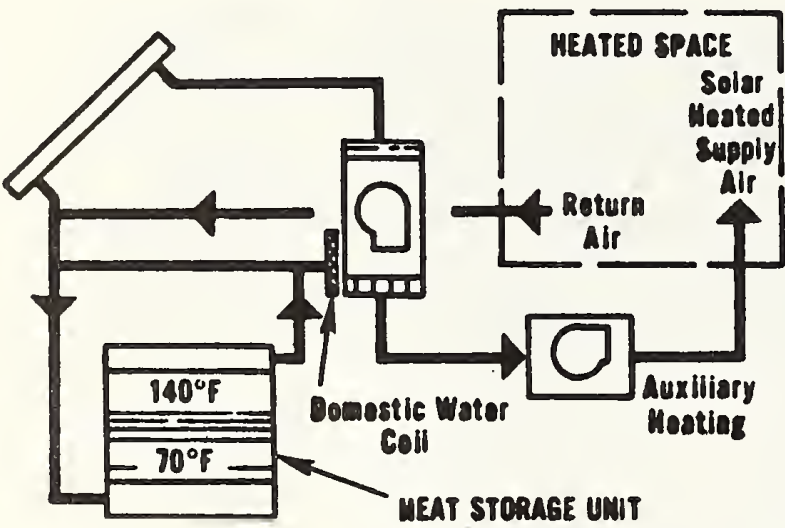

C MEATING from Storage

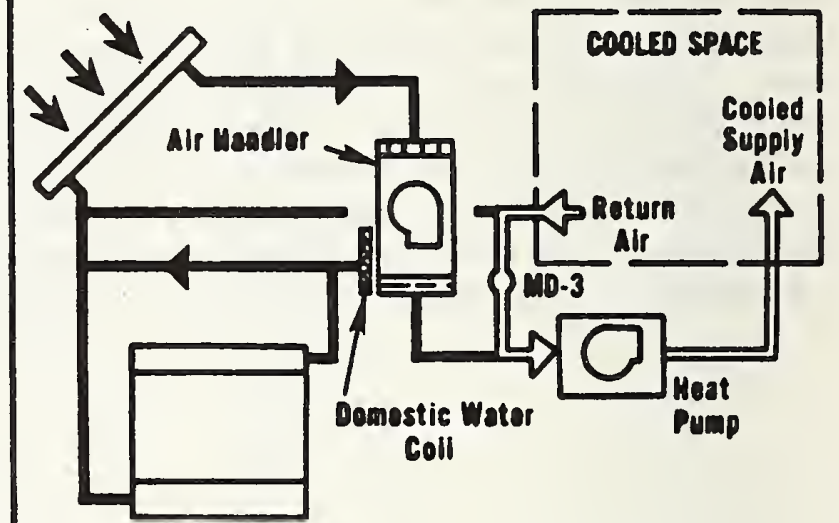

D Summer water heating Optional AIR CONOITIONIMG

OPERATING MODES OF AIR TYPE SOLAR SYSTEM WITH ROCK BED STORAGE FIGURE 11 [7]

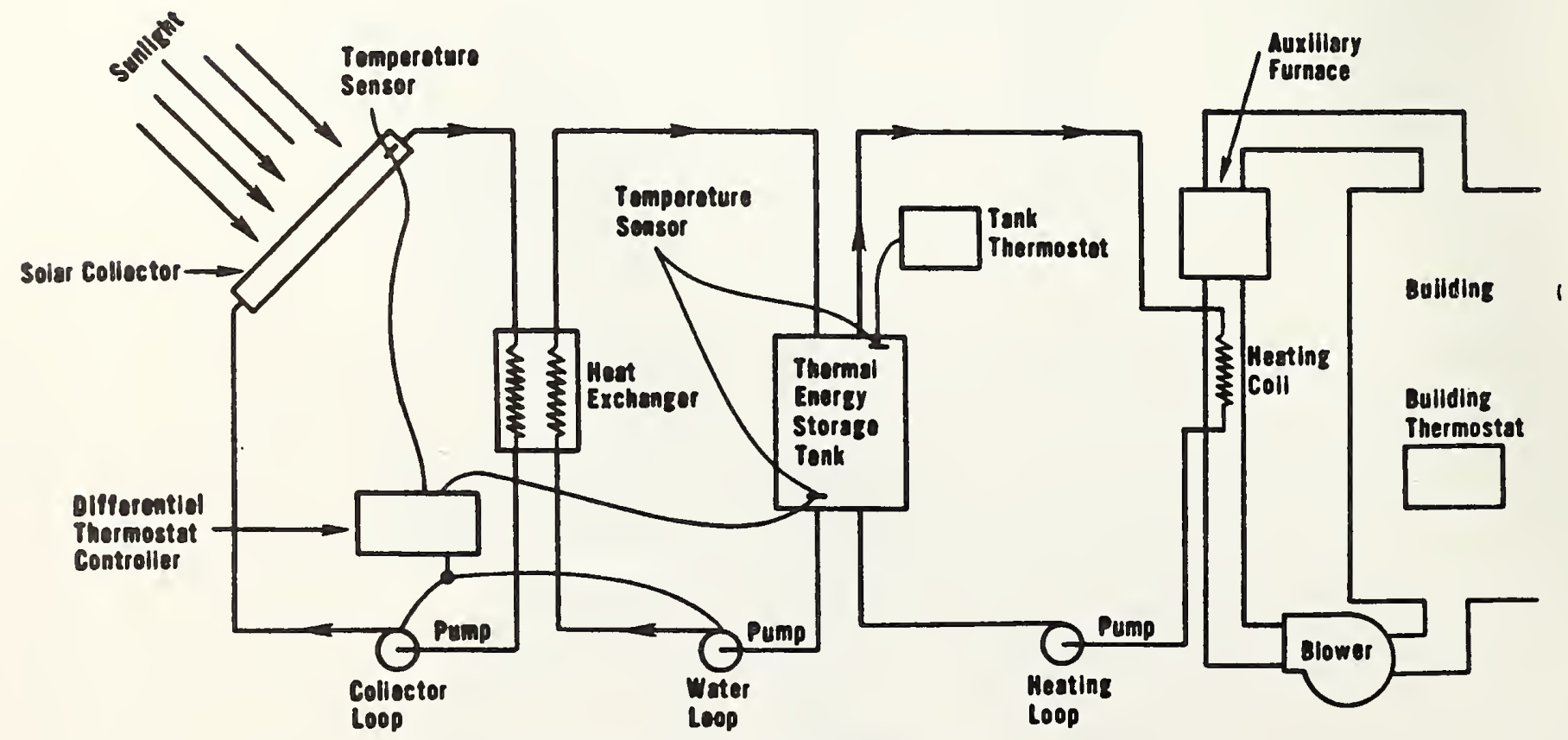

WATER-BASED SYSTEM WITH TANK STORAGE 


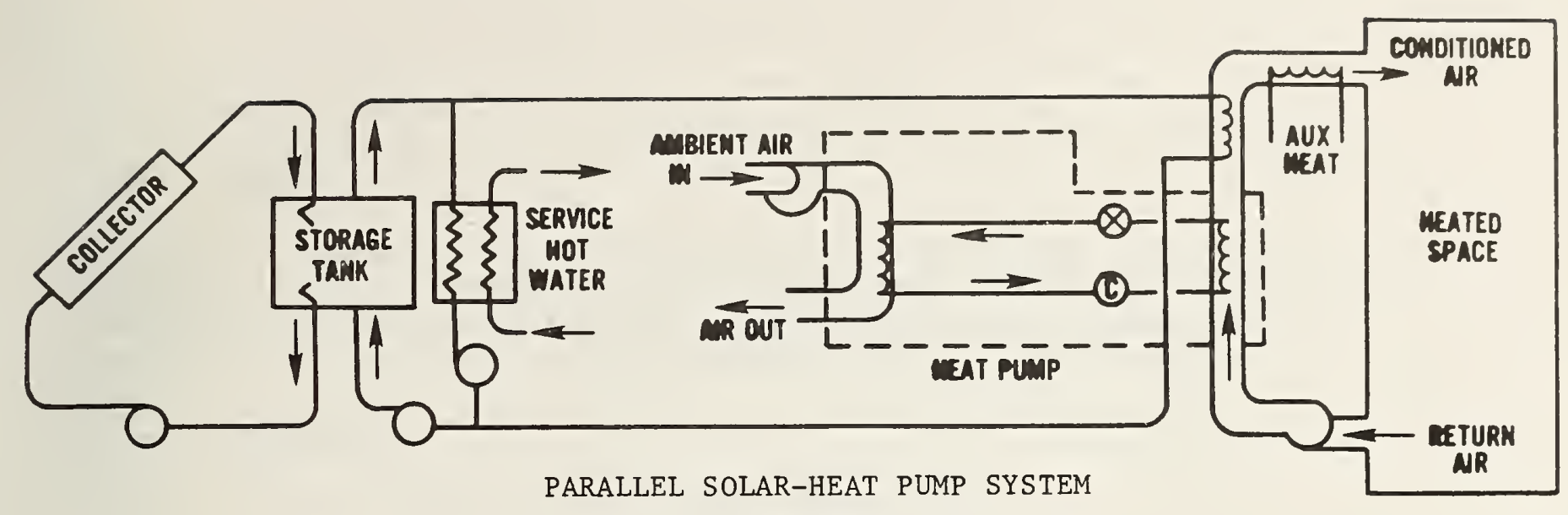

FIGURE 13 [7]
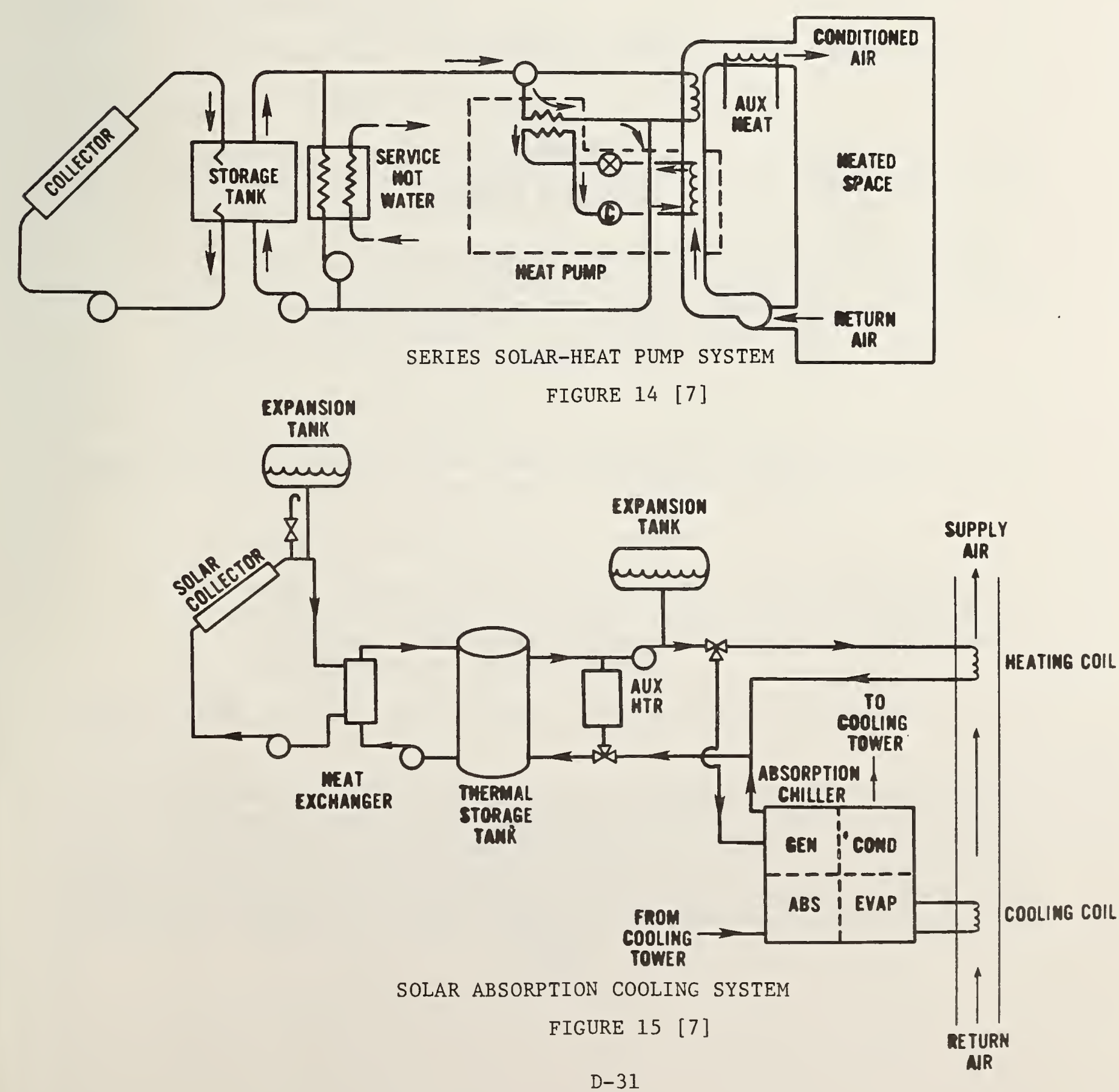
APPENDIX D. 6

Plumbing Systems

D-32 


\section{6 PLUMBING SYSTEMS}

\section{D.6.1 GENERAL}

This section covers specific tests to be used for further evaluation of existing plumbing systems being considered for adaptation to solar retrofit. Instructions for visual inspection of the systems and a check 1ist of potential problems were incorporated in section 5 of this report.

\section{D.6.2 GUIDELINES}

\section{D.6.2.1 Test for Leaks in Water Supply System [38]}

A simple method for checking on the presence of leaks in the water supply lines of the building follows:

1) Close the valves to all plumbing fixtures on the supply line.

2) Be sure the main water supply valve is fully open.

3) Listen for a gurgling or murmuring sound in the supply pipe. Hold a rod against the ear, and make contact with the other end of the rod at various points along the system, to pin point suspected leaks.

4) If no leak can be determined in any of the interior supply lines, and a leak still is suspected, listen for signs of leakage in the supply pipe leading from the water main outside the building. Also invite the water company to investigate their supply lines if gurgling or running water sounds persist.

\section{D.6.2.2 Test of Supply Piping [38]}

Clogged water supply pipes often cause a reduction in water pressure at the faucets. Adequacy of the pressure may be checked as follows:

1) Open top floor lavatory and sink faucets.

2) Open bathtub faucets and flush the toilets. If the flow of water in the top floor fixtures is reduced substantially, the piping may be of inadequate size or badly clogged with scale, assuming there is normal pressure at the water supply.

D.6.2.3 Water Test for Leaks in Drain, Waste and Vent (DWV) System $[60,61,62]$

A standing water test of the DWV system is a simple method for testing for leaks in the drain piping. A suitable plug can be inserted in the clean out at the lowest point of the system, and each water closet and P-trap can be plugged, thereby creating a closed DWV system. With at least a $10 \mathrm{foot}$ head of standing water in the vent piping for 30 minutes or more, the DWV piping system can be checked for leaks to determine whether parts of the piping need 
to be replaced. A partial inspection behind a wall may be made through suitable openings such as electrical wall outlets, or by removing the baseboard.

D.6.2.4 Air Test for Leaks in DWV System $[61,62,63]$

An alternate test for leakage in the DWV piping consists of plugging all terminals, including open vents in the system, and compressing the air in the system to at least $10^{\circ} \mathrm{Hg}$ (or $5 \mathrm{psi}$ ) for 15 minutes to see whether the system will hold the pressure. Leaks may be detected by listening for leaking air, or by using a soap bubble test.

D.6.2.5 Siphonage of Traps $[64,65,66,67,68,69,70,71,72]$

Where several plumbing fixtures are connected to a single horizontal drain, or a drain empties into a vertical stack which also carriers effluent from floors above, there exists the possibility that the movement of waste in the system will induce siphonage in the system (i.e., removal of the water seal from traps). Too little water remaining in a fixture trap may permit vermin or sewer gas entering the building through the trap.

In testing for siphonage, one or more fixtures are filled to overflowing and discharged. The remaining level of water in the trap seal of each fixture is then measured to determine the depth of seal retention. At least 50 percent or $25 \mathrm{~mm}$ ( $1 \mathrm{in}$ ) of the original seal depth should be retained in all fixtures. If excessive siphonage occurs, the drain lines and connections should be cleaned, enlarged, properly vented, or otherwise modified.

If an existing building is being considered for solar retrofit, the entire drainage system should be examined (and tested if necessary) under the supervision of experienced plumbing officials, to assure compliance with the health and safety requirements of the appropriate plumbing code. 
APPENDIX D. 7

Electrical Systems

D-35 


\section{7 ELECTRICAL SYSTEMS}

\section{7.1 GENERAL}

Section 6 of this report covered the preliminary evaluation of existing electrical systems, and consisted primarily of visual inspection of the systems. This section includes actual tests to be performed on the systems, utilizing instruments. Consequently, experience with certain high voltage instruments, and a greater amount of time and judgment will be required.

\section{7.2 GUIDELINES}

D.7.2.1 Megohm Test (Megger Tester) for Electrical Insulation [38, 73]

If the insulation appears to be deteriorated (crumbling or cracking), it is always best to replace the wiring. If there is a question regarding the adequacy of the insulation, the megohm test may be used to check it. In this test, the wires for each circuit are disconnected at the power supply, and a "Megger" tester is used to apply test voltages to the branch circuits. Branch circuits should read at least one megohm to ground. If lights or appliances are included in the branch circuit, readings should exceed 500,000 ohms. (Feeders should be tested in accordance with Article 110-20 of the National Electrical Code.) If there are any low resistance readings or indications of shorts in the circuit, the insulation is considered faulty, and the circuit wiring should be replaced. Because high voltages are used and experienced judgment is needed, only a qualified electrician should perform the test.

\section{D.7.2.2 Voltage Drop Determination [74]}

The measure of voltage drop in a branch circuit under normal load is ${ }^{-}$a good indicator of excessive impedance (e.g., excessive length) of the circuits. Conductors in branch circuits will perform more efficiently if the following conditions are met:

1) The voltage drop at the farthest outlet for power, heating and lighting loads does not exceed 3 percent.

2) The maximum total voltage drop in feeders and branch circuits to the farthest outlet does not exceed 5 percent.

If voltage drops are much in excess of these values, the circuit needs replacement. Generally, ordinary voltmeters may be used for determining voltage drops in the circuits. Because measurements must be made under load (with the current also being measured) only a qualified person should undertake the tests.

\section{D.7.2.3 Circuit Analyzer for Circuit Faults [75]}

A commercially available electrical analyzer is available to determine various faults in existing wiring systems. It was originally developed for testing 
newly wired circuits, but it also may be used for assessing performance of existing systems. The circuit analyzer will check the following circuit conditions :
1) Open ground
2) Open hot
3) Open neutral
4) Hot/ground reversed
5) Hot/neutral reversed

Measurements obtained will indicate only design or operating faults such as improper connections. The analyzer will not determine the condition of the materials which make up the branch circuit. The manufacturer's instructions must be followed in using the analyzer and interpreting the readings, and only a qualified person should conduct the tests. The analyzer can be used on two-wire circuits by utilizing a special adapter.

\section{D.7.2.4 Circuit Breaker and Resistance Tester [76]}

A commercial circuit breaker and resistance tester is available also for evaluating circuit breakers by simulating an overload condition as a proof test of the circuit breaker. A special component comes with the instrument which may be used for evaluating resistance of windings (and other equipment resistances) in the range of 1 megohm to 1000 megohms. The current is limited to five milliamperes for maximum safety. The resistance tester is intended to indicate potential breakdown in electrical resistance of insulating materials.

Circuit breakers are tested with the breaker removed from the panel. If there is no master disconnect, the utility company should be asked to cut off service during removal of the breaker. Only a qualified electrician should be engaged to conduct the tests. 


\begin{tabular}{|c|c|c|}
\hline U.S. DEPT. OF COMM. & $\begin{array}{l}\text { 1. PUBLICATION OR } \\
\text { REPORT NO. }\end{array}$ & 2. Performing Organ. Report Nof 3. Publication Date \\
\hline $\begin{array}{l}\text { BIBLIOGRAPHIC DATA } \\
\text { SHEET (See instructions) }\end{array}$ & NBSIR 81-2289 & July 1931 \\
\hline
\end{tabular}

4. TITLE AND SUBTITLE

Preliminary Guidelines for Condition Assessment of Buildings Being Considered for Solar Retrofit

5. AUTHOR(S)

Frank H. Lerchen, James H. Pielert, Phillip T. Chen

6. PERFORMING ORGANIZATION (If joint or other than NBS, see in structions)

NATIONAL BUREAU OF STANDARDS

DEPARTMENT OF COMMERCE

WASHINGTON, D.C. 20234

9. SPONSORING ORGANIZATION NAME AND COMPLETE ADDRESS (Street. City. State, ZIP)

U.S. Department of Energy

Office of Solar Applications for Bulldings

Office of the Assistant Secretary

Conservation and Renewable Energy

Washington, D.C. 20585

10. SUPPLEMENTARY NOTES

Document describes a computer program; SF-185, FIPS Software Summary, is attached.

11. ABSTRACT (A 200-word or less factual summary of most significant information. If document includes a significant bibliography or literature survey, mention it here)

This report was developed to help Federal agencies determine if buildings in their inventory are suitable for solar energy retrofit. It describes evaluation methods which are available to the facilities engineer to assist in determining whether the building and its systems (structural, HVAC, plumbing, and electrical) can be retrofitted with solar energy equipment under the Solar Federal Buildings Program (SFBP). Techniques for preliminary on-site inspection are emphasized, while more detailed evaluation techniques are described briefly and are referenced further.

The report describes evaluation methods available specifically for use with the structural materials of concrete, steel, masonry, and wood, as well as for use with the heating/ventilating/air conditioning, plumbing, and electrical supportive systems.

Comparative tables are provided for each building material to aid the reader in making a quick selection of the evaluation method most appropriate for the parameter to be tested. In addition, checklists are provided which identify common problems associated with each building material, possible causes of the problem, and the potential impact of the problem on the existing building systems and the solar retrofit system.

12. KEY WORDS (Six to twelve entries: alphabetical order: capitalize only proper names; and separate key words by semicolons) Building rehabilitation; concrete; electrical; evaluation; HVAC; masonry; plumbing; steel; solar; structural systems; test methods; wood 20402.

14. NO. OF PRINTED PAGES 138

15. Price

Q Order From National Technical Information Service (NTIS), Springfield, VA. 22161 
